NATIONAL LABORATORY

\title{
Annual Technical Progress Report of Radioisotope Power Systems Materials Production and Technology Program Tasks for October 1, 2007 through September 30, 2008
}

\section{April 2009}

Prepared by

J. F. King

RPS Program Manager

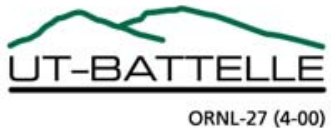




\section{DOCUMENT AVAILABILITY}

Reports produced after January 1, 1996, are generally available free via the U.S. Department of Energy (DOE) Information Bridge.

Web site http://www.osti.gov/bridge

Reports produced before January 1, 1996, may be purchased by members of the public from the following source.

National Technical Information Service

5285 Port Royal Road

Springfield, VA 22161

Telephone 703-605-6000 (1-800-553-6847)

TDD 703-487-4639

Fax 703-605-6900

E-mail info@ntis.gov

Web site http://www.ntis.gov/support/ordernowabout.htm

Reports are available to DOE employees, DOE contractors, Energy Technology Data Exchange (ETDE) representatives, and International Nuclear Information System (INIS) representatives from the following source.

Office of Scientific and Technical Information

P.O. Box 62

Oak Ridge, TN 37831

Telephone 865-576-8401

Fax 865-576-5728

E-mail reports@osti.gov

Web site http://www.osti.gov/contact.html

This report was prepared as an account of work sponsored by an agency of the United States Government. Neither the United States Government nor any agency thereof, nor any of their employees, makes any warranty, express or implied, or assumes any legal liability or responsibility for the accuracy, completeness, or usefulness of any information, apparatus, product, or process disclosed, or represents that its use would not infringe privately owned rights. Reference herein to any specific commercial product, process, or service by trade name, trademark, manufacturer, or otherwise, does not necessarily constitute or imply its endorsement, recommendation, or favoring by the United States Government or any agency thereof. The views and opinions of authors expressed herein do not necessarily state or reflect those of the United States Government or any agency thereof. 
Radioisotope Power Systems Materials Production and Technology Program Materials Science and Technology Division

\section{ANNUAL TECHNICAL PROGRESS REPORT OF RADIOISOTOPE POWER SYSTEMS MATERIALS PRODUCTION AND TECHNOLOGY PROGRAM TASKS FOR OCTOBER 1, 2007 THROUGH SEPTEMBER 30, 2008 \\ J. F. King}

April 2009

Prepared for

Department of Energy Office of Radioisotope Power Systems

AF 0110100

Prepared by

OAK RIDGE NATIONAL LABORATORY

Oak Ridge, Tennessee 37831-6079

managed by

UT-BATTELLE, LLC

for the

U.S. DEPARTMENT OF ENERGY

under contract DE-AC05-00OR22725 


\section{CONTENTS}

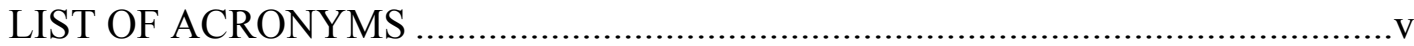

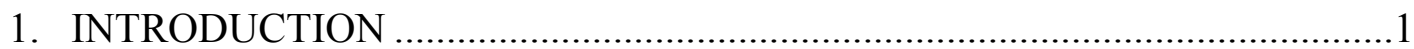

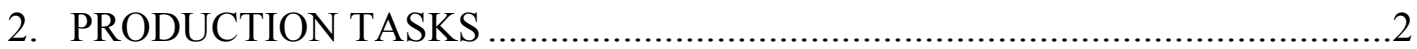

2.1 CARBON-BONDED CARBON FIBER ...............................................2

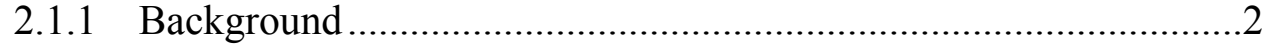

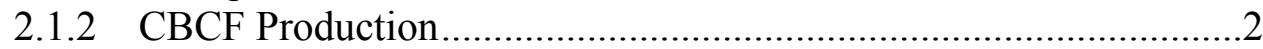

2.1.3 CBCF Shipments ......................................................................2

2.1.4 CBCF Production and Qualification Procedures ...........................2

2.1.5 CBCF Production Capability ....................................................... 3

2.1.6 CBCF Component Archives .......................................................

2.1.7 Trend Analysis of CBCF Compression Strength.............................3

2.2 IRIDIUM ALLOY BLANK AND FOIL PRODUCTION .......................4

2.2.1 Blank and Foil Production .........................................................4

2.2.1.1 Blank Production from K3 Ingot ...................................4

2.2.1.2 Storage of Foil............................................................5

2.2.1.3 Nonconformance Reports and Deviation Requests ..........5

2.2.2 Equipment Qualification ........................................................5

2.2.2.1 Qualification of New Button Arc Melting Furnaces.........5

2.2.2.2 Qualification of New Beam Deflection System for Electron Beam Melting Furnace ........................................7

2.2.3 Training .......................................................................... 14

2.2.4 Trend Analysis of Glow Discharge Mass Spectrographic

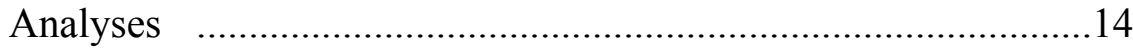

2.2.4.1 Description of GDMS ............................................14

2.2.4.2 Methods and Results of GDMS Trend Analysis.............14

2.2.4.3 Conclusions from GDMS Trend Analysis.....................21

2.2.4.4 Recommendations for GDMS Analysis........................21

2.2.5 Equipment Major Maintenance and Purchases............................22

2.2.6 Presentations and Publications..................................................22

2.2.6.1 Peer Review Publications .............................................222

2.2.6.2 Presentations ...........................................................22

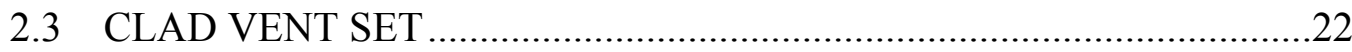

2.3.1 Maintenance Production Summary ...........................................22

2.3.2 Nonconformance Reports and Deviation Requests ....................23

2.3.3 Evaluation/Qualification of New Coordinate Measuring Machine in Dimensional Inspection Area (Milestone 2.C.4) .......23

2.3.4 Evaluation of a Cylindrical Standard ..........................................24

2.3.5 Evaluation of CVS Reinspection Surveillance Cups for Diameters and Radii.............................................................26

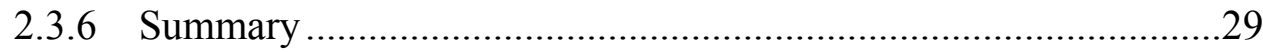

2.3.7 Decontamination Cover Tooling.............................................29

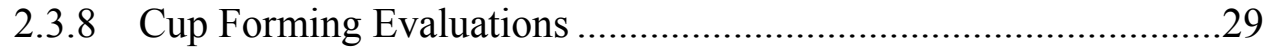

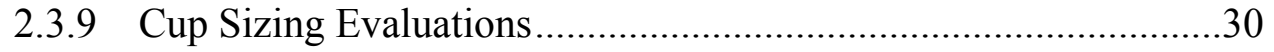


2.3.10 Frit Vent Tooling Evaluation ..........................................................31

2.3.11 Equipment Maintenance and Housekeeping....................................34

2.3.12 Electron Beam Welder Re-Qualification Support After

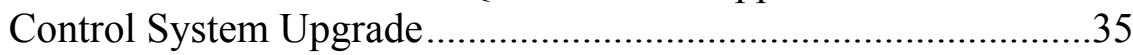

2.4 IRIDIUM POWDER AND INVENTORY MANAGEMENT ....................36

2.4.1 Iridium Demand and Supply Schedule …………...........................36

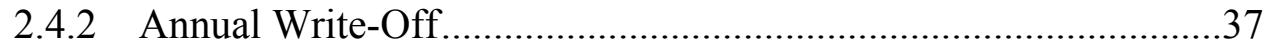

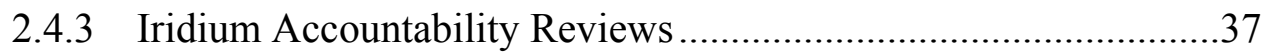

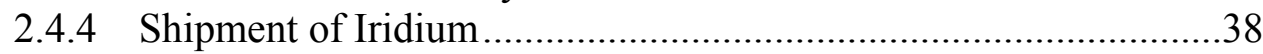

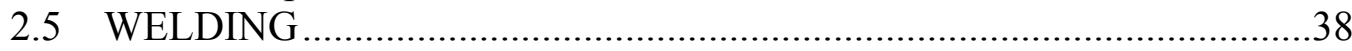

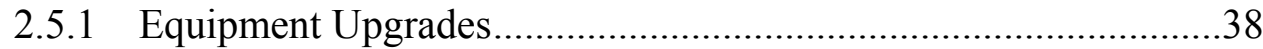

2.5.2 Equipment Requalification ........................................................39

2.5.3 Russian Fuel Procurement ............................................................42

2.5.4 Radioactive Material Transport ....................................................42

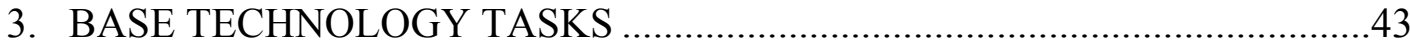

3.1 ALLOY CHARACTERIZATION .......................................................

3.1.1 Effects of Temperature, Grain Size, and Strain Rate on the Ductility and Strength of DOP-26 Iridium ....................................43

3.1.2 Grain-Boundary Chemistries of DOP-26 Iridium Alloyed with Copper.................................................................................43

3.1.3 Effects of Environment and Temperature on the Tensile Properties of Ta-base Alloys........................................................44

3.1.4 Diffusion of Silicon into DOP-26 Iridium.....................................44

3.2 ORNL CHARACTERIZATION OF MIN-K TE-1400 …........................45

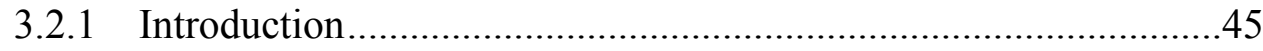

3.2.2 Experimental Procedures …………………………..................46

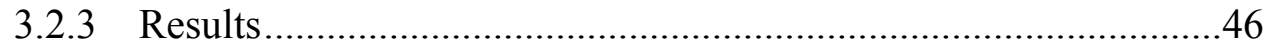

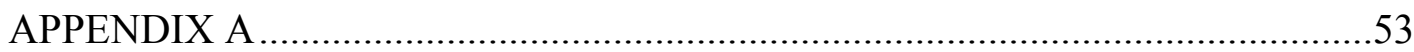

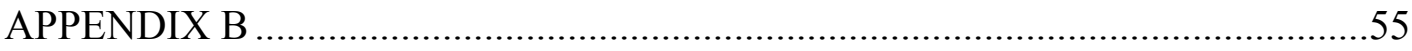




\section{LIST OF ACRONYMS}

$\begin{array}{ll}\text { ASTM } & \text { American Society for Testing and Materials } \\ \text { CBCF } & \begin{array}{l}\text { carbon-bonded carbon fiber } \\ \text { CCB }\end{array} \\ \text { Configuration Control Board } \\ \text { CMM } & \text { Coordinate Measuring Machine } \\ \text { CVS } & \text { Computer Numerical Control } \\ \text { DC } & \text { clad vent set } \\ \text { DOE } & \text { decontamination cover } \\ \text { EDM } & \text { Department of Energy } \\ \text { FVA } & \text { frit vent assemblies } \\ \text { FY } & \text { fiscal year } \\ \text { GDMS } & \text { glow discharge mass spectroscopy } \\ \text { INL } & \text { Idaho National Laboratory } \\ \text { LANL } & \text { Los Alamos National Laboratory } \\ \text { MMRTG } & \text { multi-mission radioisotope thermoelectric generator } \\ \text { NASA } & \text { National Aeronautics and Space Administration } \\ \text { NDE } & \text { nondestructive examination } \\ \text { ORNL } & \text { Oak Ridge National Laboratory } \\ \text { RPS } & \text { Radioisotope Power Systems } \\ \text { TSE } & \text { transient strain event }\end{array}$




\subsection{INTRODUCTION}

The Office of Radioisotope Power Systems (RPS) of the Department of Energy (DOE) provides RPS for applications where conventional power systems are not feasible. For example, radioisotope thermoelectric generators were supplied by the DOE to the National Aeronautics and Space Administration (NASA) for deep space missions including the Cassini Mission launched in October of 1997 to study the planet Saturn. For the Cassini Mission, ORNL

produced carbon-bonded carbon fiber (CBCF) insulator sets, iridium alloy blanks and foil, and clad vent sets (CVS) used in the generators. The Oak Ridge National Laboratory (ORNL) has been involved in developing materials and technology and producing components for the DOE for more than three decades.

This report reflects program guidance from the Office of RPS for fiscal year (FY) 2008. Production activities for prime quality (prime) CBCF insulator sets, iridium alloy blanks and foil, and CVS are summarized in this report. Technology activities are also reported that were conducted to improve the manufacturing processes, characterize materials, or to develop information for new RPS. 


\subsection{PRODUCTION TASKS}

\subsection{CARBON-BONDED CARBON FIBER}

\subsubsection{Background}

The CBCF production facilities have been operated in a production maintenance mode since the Cassini campaign to produce prime insulators. Dedicated facilities for CBCF production remain in the Carbon Materials Technology Laboratory at ORNL. During much of the 1990s CBCF production was directed at making experimental variations of $\mathrm{CBCF}$ that explored the potential for improved insulating attributes at very high temperatures. The effect of brief excursions to reentry temperatures was also explored. Sleeves produced in FY 2000 were the first to be fully characterized in nearly a decade. Resolution of issues related to elevated impurities in CBCF allowed for continued production of prime insulators in FY 2003 through FY 2008. Prime insulation sets were shipped to Idaho National Laboratory (INL) in FY 2006 through FY 2008 to support the Mars Science Laboratory Mission.

\subsubsection{CBCF Production}

More than forty additional prime candidate CBCF insulation sets were produced in FY 2008 to support future RPS Program missions. Production yields were greater than $90 \%$. Numerous Quality Assurance Surveillances were conducted at ORNL including: Instrument Calibration, Dimensional Inspection of Insulators and Personnel Training.

\subsubsection{CBCF Shipments}

Twelve prime CBCF Sleeves and fifty-seven prime CBCF Discs were certified and shipped to INL to support the Mars Science Lab Mission. The shipment of six prime CBCF Sleeves to INL in January was monitored with a data logging accelerometer to log dynamic events. The usual shipping box was over-packed in a secondary cardboard box with additional protective packing materials. The data collected by the accelerometer indicated the benefit of the additional protective packing.

\subsubsection{CBCF Production and Qualification Procedures}

The procedure, "Radiographic Inspection of CBCF Insulators", was revised to include references to updated Fabrication, Hoisting, \& Rigging Division procedures controlling all aspects of work in ORNL radiographic facilities. Since the long-term availability of Kodak Type M industrial Xray film is uncertain, the procedure was further modified to allow an equivalent film to be used. A plan was developed to qualify one of three AGFA brand X-ray films. Qualification of an alternative film should be completed in the first quarter of FY 2009.

The CBCF Procedure, "Drying, Curing and Carbonization" MET-CER-SOP-32, was revised to allow the use of a digital control and data acquisition system on the carbonization furnace. A 
carbonization run was lost in each of the past several years due to a failure of the strip chart recorder to accurately $\log$ the temperature profile.

\subsubsection{CBCF Production Capability}

Key personnel including the task manager, two principal technicians and two machinists remain committed to the near-term ( $\sim 5$ years) production of CBCF insulators. A second machinist was trained and executed all machining operations in FY 2008. A back-up inspector was also trained in the dimensional and visual inspection of $\mathrm{CBCF}$ insulators and qualification specimens. Additionally, personnel involved in qualification testing will be available to support near-term production.

Facilities and equipment used for the production of $\mathrm{CBCF}$ are kept in good working order through annual production activities and continuous maintenance and calibrations. A state-ofthe-art control and data logging system was installed on the carbonization furnace.

\subsubsection{CBCF Component Archives}

A program quality audit highlighted the need to execute final disposition on an extensive archive of non-prime CBCF insulators. Many pre-Cassini insulators dated back to 1984. All archived $\mathrm{CBCF}$ hardware was inventoried and discarded if it had no further value to the program.

\subsubsection{Trend Analysis of CBCF Compression Strength}

The Cassini production campaign was followed by a brief recess from producing prime CBCF insulators. When attempts to produce prime insulators resumed around FY 2000, difficulties were encountered with respect to surface appearance. Freckled areas representing mm-sized areas of poorly bonded fiber lead to the realization that the Durez 22352 Resin (Lot 07B2A) purchased in 1990 for the Cassini campaign was no longer performing well with respect to flow and bonding characteristics.

A new lot of Durez 22352 Resin (Lot 0422) was procured and qualified in FY 2003. The surface appearance/bonding issue was resolved with the new resin. Production of prime CBCF insulators using resin Lot 0422 continued in FY 2004 through FY 2008. Particular attention was given to monitoring the aging and performance of the resin. Compression strength appears to be a reasonable indicator of the condition of the resin. The average compression strength of the $\mathrm{CBCF}$ sleeves and discs is plotted in Figure 1 for the past five years. 


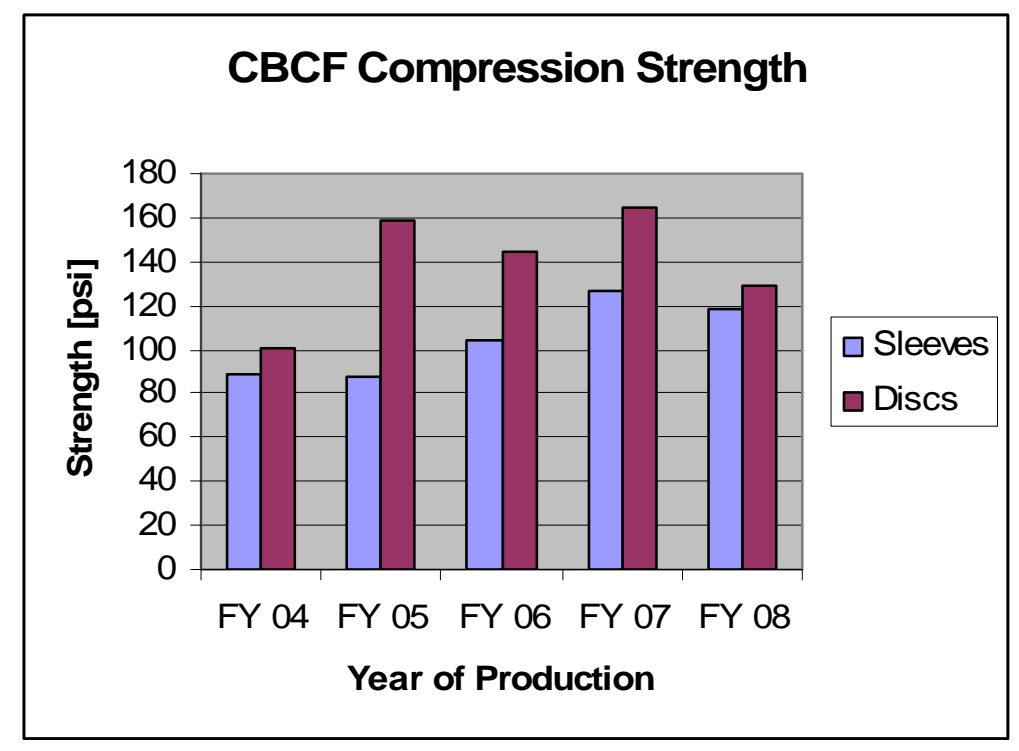

Figure 1. Compression strength of $\mathrm{CBCF}$ produced using Durez 22352 Resin Lot 0422.

In FY 2004 and FY 2005 the compression strength of the sleeves exceeded the specification minimum strength requirement of $75 \mathrm{psi}$ with some margin. In successive production years, the strength increased substantially showing that aging of the resin exhibited a beneficial effect. The same trend can be seen in the compression strength of disc lots. In view of the experience with Durez Resin Lot 07B2A, it was recognized that there is likely a limit to the beneficial effects of resin aging. Consequently, a new lot of Durez 22352 resin was purchased in FY 2008. Qualification of this new lot of resin continues.

\subsection{IRIDIUM ALLOY BLANK AND FOIL PRODUCTION}

The goals for this activity are to produce prime blanks and foil under full configuration control, maintain production capability and to supply materials needed for CVS demonstration and maintenance activities. During FY 2008 a total of 30 blanks from K3 ingot were produced and stored with an approved data package. Two new button arc melting furnaces were qualified for iridium alloy production. An upgraded control system for the electron beam (EB) melting furnace was also qualified for production.

\subsubsection{Blank and Foil Production}

\subsubsection{Blank Production from K3 Ingot}

Melting and extrusion of the K3 ingot was performed during FY 2005. Rolling of the material to sheet was performed in FY 2006. Five of the 17 sheets were processed in the past year to produce blanks. A total of 30 blanks were electrodischarge machined (EDM) from sheets K3-1 through K3-5 and the blanks were surface ground. A second machinist was trained in each of 
these operations. All of the blanks passed the dimensional and dye penetrant inspections. The blanks were sampled and cleaned. Ultrasonic inspection was completed with all blanks passing this test. Metallographic analysis and chemical analysis of sample materials was also successfully completed. Initial visual examination showed indications of inclusions for 14 blanks. These blanks were reworked by sanding and re-cleaned. Visual examination showed indications of inclusions on 3 of the reworked blanks. A second rework by sanding and recleaning of these blank was performed using an approved procedure. Subsequent visual examination was successfully completed for the three blanks. All of the reworked blanks passed dimensional and dye penetrant inspection. A revision of the rework procedure was approved by the ORNL Configuration Control Board in order to decrease the need for a second rework by sanding in the future. A data package was prepared for the 30 blanks. The blanks were placed in storage with the approved data package in September 2008.

\subsubsection{Storage of Foil}

Iridium alloy foil was packaged and stored for future use. The foil was packaged in three wood boxes in accordance with the applicable shipping procedure. Approved data packages were stored previously. The quantities of foil in each of the three boxes are shown in Table 1.

Table 1. Summary of Foil Stored with Approved Data Packages

\begin{tabular}{ccc} 
Ingot numbers & Foil Pieces & area, square meters \\
\hline EFR 301, 3 & 30 & 0.24 \\
EFR 304, 5 & 32 & 0.22 \\
EFR 306, 7, 8 & 37 & 0.31 \\
TOTAL & 99 & 0.77
\end{tabular}

\subsubsection{Nonconformance Reports and Deviation Requests}

Nonconformance Reports and Deviation Requests for the Iridium Alloy Blank and Foil Tasks are listed in Appendix A.

\subsubsection{Equipment Qualification}

\subsubsection{Qualification of New Button Arc Melting Furnaces}

Installation of two new button arc melting furnaces was completed. The furnaces, shown in Figure 2, are equipped with two new 1500 ADC power supplies and controllers and use the same hearth plates, drop-molds, electrodes, and electrode holders dedicated for production of iridium alloy blanks and foil. The new furnaces replaced two furnaces that were about 40 years old and that were becoming increasingly difficult to maintain. The furnaces achieved an acceptable pressure level of $1 \times 10^{-5}$ torr, as compared to a procedural requirement of not more than $5 \times 10^{-5}$ torr. An equipment operating procedure for the furnaces was approved. More than 12 button melts and drop-castings of non-iridium materials were made in the two new button arc melting furnaces. As a result of these tests a minor modification was made to the furnace used for button 
melting to provide additional water-cooling of the top flange of the furnace dome. The furnaces were shown to operate reliably.

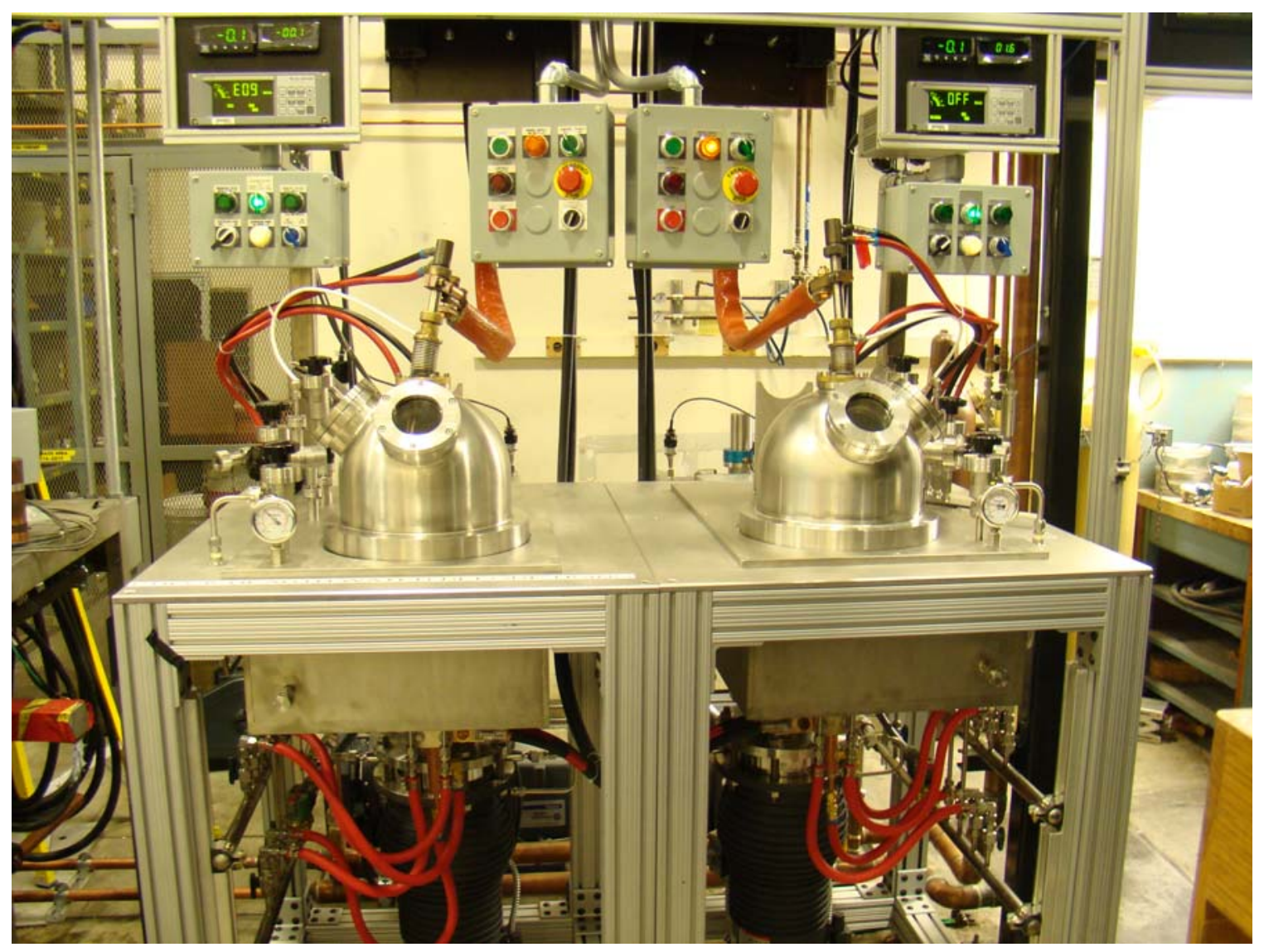

Figure 2. Newly Installed Button-Arc Melting Furnaces (side panels are removed).

The qualification of the furnaces consisted of melting and characterizing two buttons using prime DOP-26 iridium alloy recycle material. The furnace internals were cleaned in accordance with procedure MET-MatP-SOP-82 rev. 9. The melt stock identified as M19898 and M19899 had been previously melted using K-batch recycle melt stock. Both melt stocks were analyzed by GDMS prior to melting in the new furnaces. Two buttons were arc melted in furnace MP-68 and drop-cast in furnace MP-69 following methods described in procedure MET-MatP-SOP-82 rev. 9. The first melt, identified as M20077, contained melt stock entirely from remelt material M19899. The second melt, identified as M20078, contained melt stock mostly from remelt material M19898, but with about 30\% from M19899. The resulting drop-cast material was cleaned and sampled for chemical analysis. The results of chemical analyses for both the starting stock and the melted and drop-cast materials are listed in Table 2. The chemistry specification limits for blanks are also listed as a range for the alloying elements $\mathrm{Al}, \mathrm{W}$, and $\mathrm{Th}$ and as a maximum value for the listed impurity elements. Other impurity elements analyzed at less the 1 ppm by weight are omitted from the Table. Both melted materials meet specified composition 
requirements. There is no evidence of any significant increase in impurity contents from melting and the variations in analyses of alloying elements are considered to be within the normal range. The furnaces meet all technical requirements for use in melting of iridium production materials.

Table 2. Chemical Analysis of Recycle Materials Melted in New Button Arc Melting Furnaces

\begin{tabular}{|c|c|c|c|c|c|}
\hline \multirow[b]{2}{*}{ Element } & \multicolumn{5}{|c|}{ Chemical composition, ppm by weight } \\
\hline & Spec limits & $\begin{array}{l}\text { M } 19899 \\
\text { (before melt) }\end{array}$ & $\begin{array}{l}\text { M } 20077 \\
\text { (after melt) }\end{array}$ & $\begin{array}{l}\text { M } 19898 \\
\text { (before melt) }\end{array}$ & $\begin{array}{l}\text { M } 20078 \\
\text { (after melt) }\end{array}$ \\
\hline$\overline{\mathrm{Al}}$ & $20-80$ & 46 & $\overline{77}$ & 43 & 61 \\
\hline $\mathrm{Si}$ & 50 & 1.4 & 0.57 & 1.3 & 0.47 \\
\hline $\mathrm{Ti}$ & 50 & 2.7 & 3.8 & 1.8 & 2 \\
\hline $\mathrm{Fe}$ & 50 & 2 & 2.7 & 1.3 & 2.3 \\
\hline $\mathrm{Ni}$ & 50 & 0.7 & 1.2 & 0.25 & 0.48 \\
\hline $\mathrm{Cu}$ & 50 & 0.97 & 0.64 & 1.2 & 0.48 \\
\hline Mo & 50 & 1.2 & 2.3 & 1.1 & 1.7 \\
\hline $\mathrm{Ru}$ & 50 & 7.8 & 10 & 7.7 & 7.9 \\
\hline $\mathrm{Rh}$ & 50 & 2.5 & 2.9 & 2.2 & 2.2 \\
\hline W & $2000-4000$ & 2780 & 3700 & 2400 & 2800 \\
\hline Th & $30-90$ & 68 & 77 & 65 & 47 \\
\hline $\mathrm{C}$ & 35 & & $<5$ & & $<5$ \\
\hline $\mathrm{O}$ & 50 & & 3.1 & & 1.8 \\
\hline
\end{tabular}

\subsubsection{Qualification of New Beam Deflection System for Electron Beam Melting Furnace}

An upgraded beam-deflection control system for the EB melting furnace was installed and acceptance tested in FY 2007. Acceptance testing included melting of iridium alloy scrap materials. In preparation for the qualification of the system for production use the main gate valve on the hearth system was rebuilt, instrumentation was calibrated and a revised equipment operating procedure was approved. The methods and criteria used to qualify the new control system for iridium alloy production are described below.

EB melting is performed as the initial melting step in the consolidation of the material and as a purification step. Powder blends of Ir- $0.3 \% \mathrm{~W}$ are blended, compacted, sintered, and outgassed in vacuum, followed by the EB melting. Seven compacts of about 80 grams each are melted in each cavity of a water cooled hearth to produce a button of about 520 grams. Typically melting is conducted in five of the six cavities in the hearth. One cavity is not used. Each button is remelted for a total of eight melts. The buttons are turned over after each melt to achieve greater homogeneity of the melt. Mass losses during melting are recorded. The losses consist of both vaporized material and splattered material. The splattered material that remains on the hearth plate after each melt is recovered and remelted with one or more of the buttons. 
Purification occurs by vaporization of impurities in the iridium and is treated in detail in a recent journal article (Ohriner, E.K., Purification of iridium by EB melting, Journal of Alloys and Compounds, Vol. 461, No. 1-2, Aug 11, 2008, p 633-640). The vaporization of the impurities is directly related to the quantity of iridium vaporized. In order to maintain the same purification behavior as obtained using the old control system, the furnace conditions were selected to achieve similar amounts of vaporization as measured for previous production melts.

The effects of various melt parameters on vaporization mass losses were studied by repeated melting of iridium alloy scrap material. The scrap material typically is within the specification limits for blanks but may have $\mathrm{Nb}$ and Mo levels somewhat greater than the limits. However the $\mathrm{Al}$ content of nominally $50 \mathrm{ppm}$ is quickly reduced during EB melting. The following melting parameters were fixed:

Ramp time to one half maximum power: $60 \mathrm{~s}$

Hold time at one half power: $30 \mathrm{~s}$

Ramp time from one half power to maximum power: $90 \mathrm{~s}$

Hold time at maximum power: $60 \mathrm{~s}$

Raster frequency: $2 \mathrm{~Hz}$

Scan diameter: $2 \mathrm{~cm}$

The geometry of the cavities in the hearth and the orifice of the EB gun are shown in Figure 2. As the distance from the cavity to the gun and the deflection angle of the EB increases, increased beam power is needed to compensate for energy losses due to increased beam reflection. Due to symmetry considerations, cavities having the same distance from the gun have the same power and focus conditions and are treated as equivalent in the analysis of mass loss due to vaporization described below. The arrangement of compacts in the hearth is shown in a photograph in Figure 3.

Buttons are weighed before and after each melt to determine mass loss. The mass loss due to vaporization is directly associated with purification behavior. The mass due to splatter from each button can only be estimated from the splatter recovered from the hearth plate. Splatter is material that is ejected as liquid drops from the melt due to rapid local evolution of gas during melting. The amount of splatter was found to be significantly higher for the melting of the scrap material than for the subsequent melting of the powder compacts. In addition, replacing the used hearth plate with a newly machined and cleaned hearth plate decreased the amount of splatter by almost one order of magnitude. After several melts were performed in each cavity, the amount of splatter progressively increased with each successive melt. This behavior was not expected and was not seen previously, since the same hearth has been used for about 10 years. It is planned to investigate this phenomenon in future studies because it does offer the potential to decrease iridium losses during melting. 


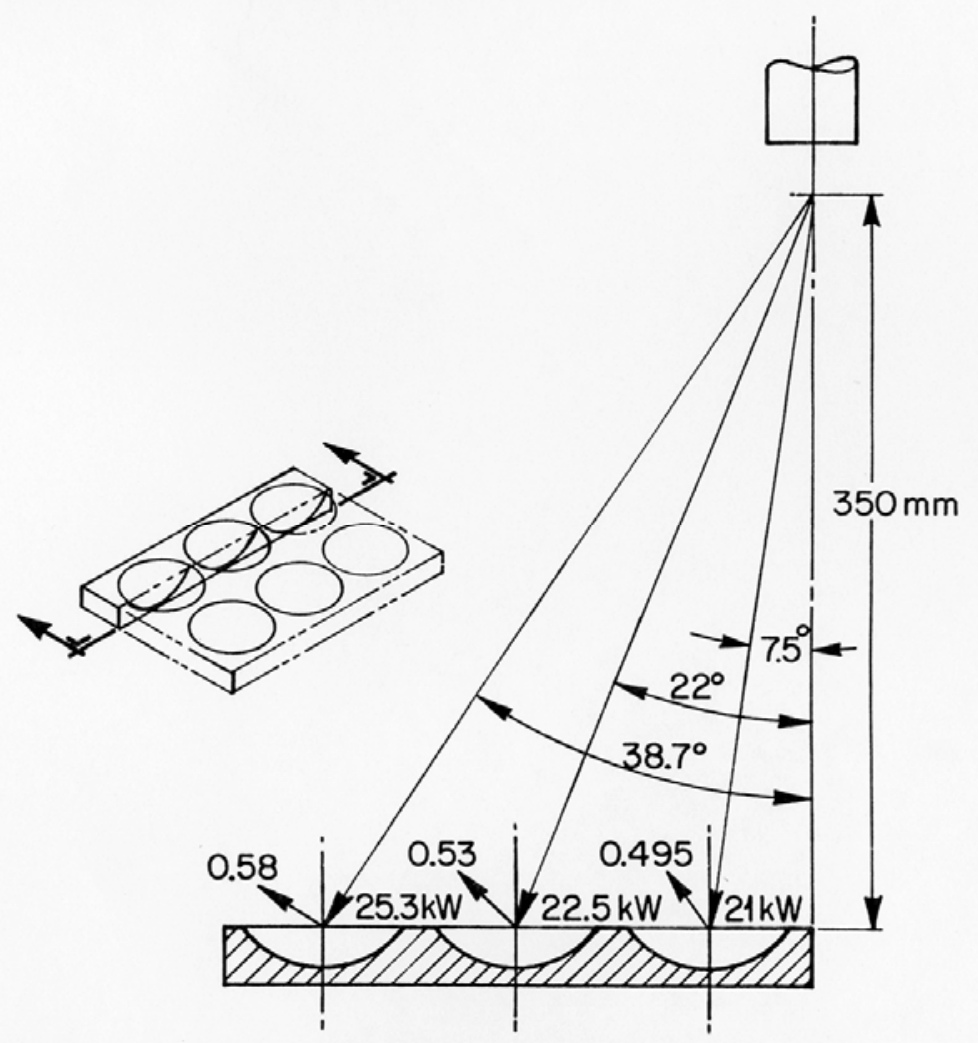

Figure 2. Geometry of hearth plate and melting cavities with respect to electron beam gun.

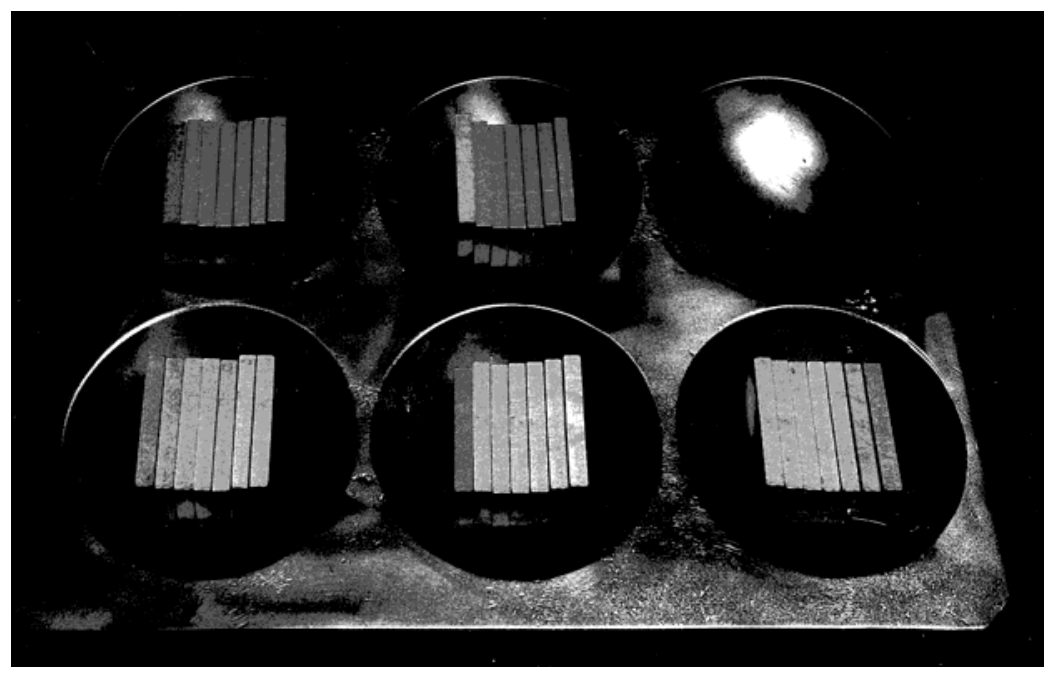

Figure 3. Photograph showing the arrangement of compacts in the cavities of the melting hearth. 
The estimation of total splatter requires an assumption of the relation between the splatter recovered from the hearth plate, which is weighed after each melt, and the total splatter which includes materials that are more violently ejected from the melt pool and collect on the furnace liner or at the bottom of the vacuum chamber and thus can not be readily weighed. During one particularly violent melt event a large amount of splatter was ejected from a melt of iridium scrap. The quantity of splatter recovered from the hearth plate was about one half of the total weight loss for this event. In the analysis of weight loss of scrap melts it was therefore assumed that one half of the splatter was recovered.

The average fractional weight loss due to vaporization for the melting of scrap is tabulated in Table 3 as a function of beam deflection angle to the cavity center point, beam current, and beam focus current. The beam deflection angle is $7.5^{\circ}$ for cavity locations $\# 3$ and $\# 6,22^{\circ}$ for cavity locations $\# 2$ and $\# 5$, and $38.7^{\circ}$ for cavity locations \#1 and \#4. The number of melts for each condition ranged from 1 to 8 . The vaporization rate increases with beam power but also increases rapidly with a more tightly focused beam associated with increased focus current. A highly focused beam in general leads to localized heating and greater iridium vaporization rate in comparison to those for impurities. The removal of impurities is more efficient with a less highly focused beam. Melt stirring was observed to be vigorous for all of the focus conditions evaluated. Defocusing is limited by the need to obtain a well defined beam on the melt and to distribute power near the outer edge of the melt without beam impingement on the copper mold.

Table 3. Percent Mass Loss from Vaporization During Electron Beam Melting of Iridium Scrap

\begin{tabular}{lccccc}
\hline $\begin{array}{c}\text { Beam } \\
\text { Deflection } \\
\text { Angle }\end{array}$ & $\begin{array}{c}\text { Maximum } \\
\text { Beam } \\
\text { Current, ma }\end{array}$ & $\begin{array}{c}\text { Focus Current } \\
\text { at Maximum } \\
\text { Power, A }\end{array}$ & $\begin{array}{c}\text { Focus } \\
\text { Current For } \\
\text { Power Ramp, } \\
\text { A }\end{array}$ & $\begin{array}{c}\text { Mean Estimated } \\
\text { Vaporization, \% }\end{array}$ & $\begin{array}{c}\text { No. of } \\
\text { Melts }\end{array}$ \\
\hline 38.7 & 680 & 1.7 & 1.7 & 0.3 & 1 \\
(cavities 1\&4) & 680 & 1.8 & 1.9 & 0.5 & 1 \\
& 680 & 1.8 & 1.8 & 0.6 & 2 \\
& 570 & 1.9 & 1.9 & 0.4 & 4 \\
& 580 & 1.9 & 1.9 & 0.5 & 2 \\
& 680 & 1.9 & 1.9 & 0.7 & 8 \\
22 & & & & & \\
(cavities 2\&5) & 610 & 1.8 & 1.8 & 0.5 & 2 \\
& 610 & 1.8 & 2 & 1.0 & 1 \\
& 520 & 1.9 & 2 & 0.4 & 2 \\
& 560 & 1.9 & 2 & 1.0 & 2 \\
& 610 & 1.9 & 1.9 & 0.6 & 2 \\
7.5 & 500 & 2 & 2 & 0.8 & 2 \\
(cavities 3\&6) & 540 & 2 & 2 & 1.1 & 1 \\
& 570 & 1.8 & 1.8 & 0.4 & 1 \\
& 570 & 1.8 & 2.1 & 1.0 & 6 \\
& 430 & 1.9 & 2.1 & 0.7 & 2 \\
\hline
\end{tabular}


This is particularly important during the power ramp up when the material is not yet fully molten. Pressure levels during melting were about $2 \times 10^{-4}$ torr during the initial melting and about $5 \times 10^{-5}$ torr during later melts.

The compacts from batch blend L-7 were initially outgassed in a manner similar to that used for previous production melts. This consisted of simultaneous heating of the compacts in five mold cavities for 33 minutes following a ramp to a beam current of $200 \mathrm{~mA}$ in 4 minutes. The dwell time was $7 \mathrm{~s}$ for cavities 3 and $6,8 \mathrm{~s}$ for cavities 2 and 5 , and $10 \mathrm{~s}$ for cavity 1 . The focus current was 1.9 A for outgassing. Melt parameters were selected on the basis of percent weight loss data in Table 3 and previous production melting experience. The maximum beam current was 680 $\mathrm{mA}$ for cavity 1, 520mA for cavities 2 and 5, and $430 \mathrm{~mA}$ for cavities 3 and 6 . The focus at maximum power was 1.9 A for all cases and was 2.0 during ramp up, except for cavity 1 for which the focus current was 1.9 A during ramp up.

In the case of iridium powder compacts there is a large amount of splatter during the first melt, with total weight losses about four times larger than for succeeding melts. This is attributed to residual oxygen on the powder surfaces. Prior heating of the compacts in hydrogen and vacuum furnaces as well as extended heating in the electron-beam furnace at a temperature below the melting point are not completely effective in removing the oxygen. During melting the evolution of iridium oxide vapor and perhaps also carbon monoxide can propel liquid droplets from the melt. The mass loss from vaporization during melting of the outgassed compacts was calculated from the measured mass losses and the mass of recovered splatter by assuming that the splatter from each button was in proportion to the total loss for that button. The amount of recovered splatter averaged about $20 \%$ of the total mass loss for melts 3 through 8 , and was about $50 \%$ for melt 2. The first melt showed about four times the total mass loss and six times the amount of recovered splatter of the subsequent melts. The recovered splatter for the first melt was about $33 \%$ of the measured mass loss. This value is less than for the second melt and is an indication that significant splatter during the first melt is not recovered from the hearth plate. This is consistent with visual observation of the melts. It is for this reason that in averaging and analyzing mass losses due to vaporization that the first melt is not included. The percent mass losses due to vaporization are listed in Table 4. Samples were taken from each of the five buttons and cleaned and analyzed using standard methods. The results of chemical analysis are listed in Table 5. Also listed are the average impurity levels for the starting L-batch powder and analysis for button L-5, previously melted with the original deflection control system. 
Table 4. Mass Loss From Vaporization During

Electron Beam Melting of Iridium Compacts

\begin{tabular}{crrrrrr}
\hline \multicolumn{7}{c}{ Mass Loss, \% } \\
\hline Melt No. & Cavity 1 & Cavity 2 & Cavity 3 & Cavity 5 & Cavity 6 & Average \\
1 & 3.60 & 2.63 & 2.26 & 2.79 & 2.70 & 2.80 \\
2 & 0.80 & 1.37 & 0.90 & 0.79 & 0.34 & 0.84 \\
3 & 0.83 & 0.82 & 0.25 & 0.53 & 0.54 & 0.59 \\
4 & 0.68 & 0.70 & 0.56 & 1.08 & 0.49 & 0.70 \\
5 & 0.70 & 0.83 & 0.63 & 0.80 & 0.54 & 0.70 \\
6 & 1.37 & 0.65 & 0.43 & 0.88 & 0.54 & 0.77 \\
7 & 0.92 & 0.66 & 0.60 & 0.77 & 0.52 & 0.69 \\
8 & 0.94 & 0.61 & 0.70 & 0.91 & 0.67 & 0.77 \\
Melts 2 to 8 & & & & & & \\
mean & 0.89 & 0.81 & 0.58 & 0.82 & 0.52 & 0.72 \\
std dev & 0.23 & 0.26 & 0.20 & 0.17 & 0.10 & 0.19 \\
rel. std dev. & 0.26 & 0.33 & 0.35 & 0.20 & 0.19 & 0.27 \\
\hline
\end{tabular}

All of the EB melted buttons have impurity contents well within the specified limits for both blanks and foil. However for the large majority of elements this is also the case for the starting powder. The measured impurity contents of the five L-7 buttons melted with the new beam deflection system are similar to those for the L- 6 button melted with the previous control system. There are four elements for which the L-7 buttons are consistently higher, B, Si, Rh, and Ta. The values for Ta may be artificially high for the L-7 material since the reference pins used with this analysis also showed unusually high values for these analyses. Although the Si values listed in Table 5 for L-7 are higher than for L-6, this is likely within the uncertainty of the measurements. As an example, the G1-10 reference pin which averages $2.9 \mathrm{ppm}$ Si had a reading of $5.4 \mathrm{ppm}$ when run with the L-6 sample. The uncertainty in the Rh measurements can be expected to have similar uncertainty and the B levels are all less than $0.1 \mathrm{ppm}$. It is concluded that the impurity levels associated with material melted with the new beam deflection system are not measurably different from those melted with the original system.

The effect of variations in melting conditions between the five cavity locations on the impurity levels of the melted buttons was also evaluated. The average impurity contents for buttons from cavities 1,2 , and 5, with mass losses per melt in the range of $0.8 \%$ to $0.9 \%$, were compared to those for cavities 3 and 6 , with mass losses per melt in the range of 0.5 to $0.6 \%$. The average impurity levels were in agreement within the estimated accuracy of $\pm 30 \%$ of the value for the elements $\mathrm{Si}, \mathrm{V}, \mathrm{Ru}$, and $\mathrm{Pt}$. In the cases of $\mathrm{B}, \mathrm{Na}, \mathrm{Ti}, \mathrm{Cr}$, and $\mathrm{Fe}$ the average values were less than $1 \mathrm{ppm}$ and lower for the buttons with the lowest mass losses, those of cavities 3 and 6 . In principle, lower mass loss should be associated with higher residual impurity contents. It was therefore concluded that within the range of measured mass loss per melt cycle, of about $0.5 \%$ to $0.9 \%$, there was no measurable change in purification behavior. 
Table 5. Chemical Analyses of L-batch Powder and Electron Beam Melted Buttons

\begin{tabular}{|c|c|c|c|c|c|c|c|}
\hline Element & L powder & $\begin{array}{c}\text { L-6 } \\
\text { button }\end{array}$ & $\begin{array}{c}\text { L-7 } \\
\text { cavity } 1\end{array}$ & $\begin{array}{c}\text { L-7 } \\
\text { cavity } 2 \\
\end{array}$ & $\begin{array}{c}\text { L-7 } \\
\text { cavity } 3\end{array}$ & $\begin{array}{c}\text { L-7 } \\
\text { cavity } 5\end{array}$ & $\begin{array}{c}\text { L-7 } \\
\text { cavity } 6\end{array}$ \\
\hline B & 1.4 & $<0.01$ & 0.08 & 0.01 & 0.02 & 0.23 & 0.06 \\
\hline $\mathrm{C}$ & 18 & $\mathrm{NM}^{\mathrm{a}}$ & $<5$ & 7 & $<5$ & 8 & 8 \\
\hline $\mathrm{O}$ & $\mathrm{NM}^{\mathrm{a}}$ & $\mathrm{NM}^{\mathrm{a}}$ & 5 & 7 & 5 & 4 & 7 \\
\hline $\mathrm{Na}$ & 26.9 & 0.14 & 1.3 & 0.19 & 0.45 & 0.69 & 0.1 \\
\hline $\mathrm{Mg}$ & 0.7 & $<0.01$ & 0.05 & $<0.01$ & 0.01 & 0.07 & $<0.01$ \\
\hline $\mathrm{Al}$ & 1.3 & 0.02 & 0.43 & 0.018 & 0.027 & 0.56 & 0.036 \\
\hline $\mathrm{Si}$ & 4.6 & 1 & 2.9 & 1.7 & 1.5 & 2.5 & 3.5 \\
\hline $\mathrm{P}$ & 0.75 & $<0.01$ & 0.01 & $<0.01$ & $<0.01$ & $<0.01$ & $<0.01$ \\
\hline $\mathrm{S}$ & 4.8 & $<0.01$ & 0.07 & $<0.01$ & 0.02 & 0.09 & 0.02 \\
\hline $\mathrm{Cl}$ & 47.7 & $<0.05$ & $<0.05$ & $<0.05$ & $<0.05$ & $<0.05$ & $<0.05$ \\
\hline $\mathrm{K}$ & 8.4 & 0.07 & 0.1 & $<0.05$ & 0.06 & 0.14 & $<0.05$ \\
\hline $\mathrm{Ca}$ & 1.5 & $<0.05$ & 0.09 & $<0.05$ & 0.17 & 0.3 & 0.09 \\
\hline $\mathrm{Ti}$ & 0.27 & 0.34 & 0.71 & 0.42 & 0.29 & 0.81 & 0.53 \\
\hline $\mathrm{V}$ & $<0.01$ & 0.03 & 0.03 & 0.03 & 0.03 & 0.04 & 0.05 \\
\hline $\mathrm{Cr}$ & 0.21 & 0.013 & 0.017 & 0.0068 & 0.0034 & 0.048 & 0.01 \\
\hline $\mathrm{Mn}$ & 0.13 & $<0.01$ & 0.01 & $<0.01$ & $<0.01$ & $<0.01$ & 0.02 \\
\hline $\mathrm{Fe}$ & 7.2 & 0.032 & 0.16 & 0.0071 & 0.028 & 0.12 & 0.021 \\
\hline $\mathrm{Co}$ & 0.02 & $<0.005$ & 0.006 & 0.006 & $<0.005$ & 0.02 & $<0.005$ \\
\hline $\mathrm{Ni}$ & 0.24 & $<0.01$ & $<0.01$ & 0.085 & 0.065 & 0.033 & 0.013 \\
\hline $\mathrm{Cu}$ & 0.17 & $<0.05$ & 0.098 & $<0.05$ & 0.21 & 0.21 & 0.031 \\
\hline $\mathrm{Zn}$ & 3.7 & $<0.01$ & $<0.01$ & 0.03 & 0.05 & 0.53 & $<0.01$ \\
\hline As & 0.93 & $<0.01$ & $<0.01$ & $<0.01$ & $<0.01$ & $<0.01$ & $<0.01$ \\
\hline $\mathrm{Br}$ & 0.03 & $<0.05$ & $<0.05$ & $<0.05$ & $<0.05$ & $<0.05$ & $<0.05$ \\
\hline $\mathrm{Zr}$ & 0.24 & 0.17 & $<0.01$ & 0.25 & 0.23 & 0.26 & 0.28 \\
\hline $\mathrm{Nb}$ & 0.13 & 0.076 & $<0.01$ & 0.12 & 0.12 & 0.12 & 0.16 \\
\hline Mo & 0.04 & 1.3 & 2.1 & 2.3 & 0.16 & 2.4 & 2.8 \\
\hline $\mathrm{Ru}$ & 27.9 & 26 & 24 & 24 & 24 & 26 & 31 \\
\hline $\mathrm{Rh}$ & 29 & 1.1 & 2.4 & 1.3 & 3.6 & 2.2 & 3.3 \\
\hline $\mathrm{Pd}$ & 0.91 & $<0.01$ & $<0.01$ & $<0.01$ & $<0.01$ & $<0.01$ & $<0.01$ \\
\hline $\mathrm{Ag}$ & 0.15 & $<0.05$ & $<0.05$ & $<0.05$ & $<0.05$ & $<0.05$ & $<0.05$ \\
\hline $\mathrm{Cd}$ & 0.06 & $<0.05$ & $<0.05$ & $<0.05$ & $<0.05$ & $<0.05$ & $<0.05$ \\
\hline $\mathrm{Sn}$ & 1 & $<0.05$ & $<0.05$ & $<0.05$ & $<0.05$ & $<0.05$ & 0.18 \\
\hline $\mathrm{Sb}$ & 1.1 & $<0.05$ & $<0.05$ & $<0.05$ & $<0.05$ & $<0.05$ & $<0.05$ \\
\hline $\mathrm{Te}$ & 0.011 & $<0.01$ & $<0.01$ & $<0.01$ & $<0.01$ & $<0.01$ & $<0.01$ \\
\hline $\mathrm{Ba}$ & 0.12 & $<0.01$ & $<0.01$ & $<0.01$ & $<0.01$ & $<0.01$ & $<0.01$ \\
\hline $\mathrm{Re}$ & $<0.05$ & $<0.05$ & 0.044 & 0.044 & $<0.05$ & $<0.05$ & $<0.05$ \\
\hline $\mathrm{Pt}$ & 11 & 2.2 & 1.2 & 2.1 & 0.81 & 2.6 & 2.3 \\
\hline $\mathrm{Au}$ & $<0.5$ & $<0.5$ & $<0.5$ & $<0.5$ & $<0.5$ & 2.2 & 1 \\
\hline $\mathrm{Tl}$ & 1.9 & $<0.01$ & $<0.01$ & 0.18 & 0.05 & 0.25 & 0.02 \\
\hline $\mathrm{Pb}$ & 0.57 & $<0.01$ & $<0.01$ & 0.03 & $<0.01$ & $<0.01$ & 0.03 \\
\hline $\mathrm{Bi}$ & 1.6 & 0.05 & $<0.01$ & 0.04 & 0.05 & $<0.01$ & 0.05 \\
\hline $\mathrm{Ta}$ & 3.2 & 1.2 & 13 & 21 & 3.5 & 16 & 2.8 \\
\hline
\end{tabular}




\subsubsection{Training}

Two technicians were trained in the procedure for EB melting of iridium alloy. One machinist was trained in the procedure for machining of iridium alloy blanks.

\subsubsection{Trend Analysis of Glow Discharge Mass Spectrographic Analyses}

\subsubsection{Description of GDMS}

Chemical analysis for alloying elements and impurities, other than carbon and oxygen are performed by GDMS. Currently the analyses are performed by Evans Analytical Group, Shiva Technologies, (Syracuse NY) in accordance with procedure MET-MatP-SOP-79 as approved on June 3, 2002. This procedure makes use of two reference materials that are supplied by ORNL and run with each group of up to ten test samples. As a result of an earlier trend analysis in 2005 , it was found that variations in specimen pin length had a significant effect on thorium results, but not those of other elements. Since October 2005, a specified a pin length of $20.0 \pm$ $0.3 \mathrm{~mm}$ has been maintained for GDMS analysis.

Two types of reference pins are run with each group of samples. They are used to correct the raw results for the alloying elements and important impurity elements. Corrected values for the alloying elements, aluminum, tungsten, and thorium are calculated by normalizing the results for the G1-10 reference pin to the nominal values of 50,3000, and $60 \mathrm{ppm}$, respectively, in accordance with the standard procedure MET-MatP-SOP-79. Another type of reference pin, RS10-9, is used to correct the values of certain important impurity elements. The values for the reference pins are uncorrected values. A corrected value for elements $\mathrm{Al}, \mathrm{W}$, and $\mathrm{Th}$ in the RS10-9 reference pins is calculated for the purpose of this study, although it is not currently calculated during routine analysis.

\subsubsection{Methods and Results of GDMS Trend Analysis}

This study deals with analyses of iridium alloy reference pins over the period of October 2005 through September 2007. The averages, standard deviations, and relative standard deviations (standard deviation/average value) of the uncorrected values are shown in Tables 6 and 7 for G110 type pins and RS10-9 type pins, respectively. The relative standard deviations for both the G1-10 and RS10-9 reference materials are all rather large. The relative standard deviations for Th are 0.26 and 0.24 , respectively for G1-10 and RS10-9. The relative standard deviations for Al are 0.20 and 0.23 , respectively for $\mathrm{G} 1-10$ and RS10-9. The relative standard deviations for $\mathrm{W}$ are 0.16 and 0.13 , respectively for G1-10 and RS10-9. In Table 6 the last two analyses of Th (S07P5150 and S07P6395) in particular are very low for pins G1-10-26 and G1-10-29. These values differ appreciably from the other values for Th in the G1-10 reference pins in Table 6 , although a Grubbs' test does not show them to be outliers at a 95\% level of confidence. If these two low values are not included, the relative standard deviation for Th in G1-10 is 0.17 . 
The reported uncorrected values for silicon, an important impurity element in iridium, are also shown in Tables 6 and 7 for the two reference materials. The relative standard deviations for this impurity are also rather high at values of 0.32 and 0.23 .

Table 6. GDMS Analysis of G1-10 Reference Pins Used for Correction of Results for Alloying Elements

\begin{tabular}{|c|c|c|c|c|c|}
\hline & & Anal & tent, $\mathrm{pl}$ & incorr & \\
\hline Job No. & Pin No. & $\mathrm{Al}$ & $\mathrm{W}$ & $\mathrm{Th}$ & $\mathrm{Si}$ \\
\hline UN3161 & G1-10-21 & 83 & 4200 & 32 & 5.7 \\
\hline UN3553 & G1-10-21 & 76 & 4100 & 29 & 5.5 \\
\hline UN3923 & G1-10-21 & 84 & 2500 & 25 & 8.8 \\
\hline UN4022 & G1-10-22 & 68 & 3500 & 24 & 4.7 \\
\hline UN4140 & G1-10-22 & 82 & 3700 & 30 & 5.8 \\
\hline UO0132 & G1-10-23 & 65 & 4400 & 35 & 4.3 \\
\hline UO0446 & G1-10-24 & 80 & 4500 & 36 & 5.6 \\
\hline UO0915 & G1-10-24 & 75 & 4000 & 34 & 5.3 \\
\hline UO2422 & G1-10-25 & 70 & 4200 & 33 & 5.2 \\
\hline UO2995 & G1-10-25 & 64 & 4400 & 36 & 2.1 \\
\hline UO5916 & G1-10-28 & 48 & 2900 & 24 & 4.2 \\
\hline UP0418 & G1-10-26 & 94 & 4500 & 36 & 4.8 \\
\hline UP1407 & G1-10-26 & 100 & 4700 & 30 & 6.3 \\
\hline UP3170 & G1-10-27 & 69 & 4600 & 34 & 5.2 \\
\hline UP4041 & G1-10-27 & 67 & 4400 & 20 & 4.7 \\
\hline UP8309 & G1-10-27 & 77 & 4000 & 24 & 9.1 \\
\hline S07P3238 & G1-10-26 & 59 & 3500 & 27 & 6.3 \\
\hline S07P5150 & G1-10-26 & 63 & 3200 & 12 & 5.4 \\
\hline S07P6395 & G1-10-29 & 110 & 3200 & 14 & 10 \\
\hline Average & & 75 & 3921 & 28 & 6 \\
\hline Std. Deviat & & 14.8 & 629.4 & 7.2 & 1.8 \\
\hline Relative St & eviation & 0.20 & 0.16 & 0.26 & 0.32 \\
\hline
\end{tabular}


Table 7. GDMS Analysis of RS10-9 Reference Pins Used for Correction of Results for Impurity Elements

\begin{tabular}{llllll} 
& \multicolumn{5}{l}{ Analyzed content, ppm by wt, (uncorrected) } \\
Job No. & Pin No. & Al & W & Th & Si \\
UN3161 & RS10-9-21 & 67 & 4600 & 27 & 9.1 \\
UN3553 & RS10-9-21 & 60 & 3500 & 15 & 7.5 \\
UN3923 & RS10-9-21 & 88 & 4300 & 37 & 10 \\
UN4022 & RS10-9-22 & 60 & 4000 & 27 & 8.4 \\
UN4140 & RS10-9-22 & 81 & 4000 & 28 & 9.8 \\
UO0132 & RS10-9-23 & 51 & 4800 & 31 & 7 \\
UO0446 & RS10-9-24 & 72 & 4900 & 30 & 8.7 \\
UO0915 & RS10-9-24 & 37 & 4800 & 24 & 4.3 \\
UO2422 & RS10-9-25 & 58 & 4500 & 27 & 7.1 \\
UO2995 & RS10-9-25 & 55 & 4600 & 27 & 6.8 \\
UO5916 & RS10-9-26 & 39 & 3400 & 20 & 5.6 \\
UP0418 & RS10-9-26 & 47 & 4700 & 22 & 5.7 \\
UP1407 & RS10-9-26 & 61 & 5000 & 25 & 7.1 \\
UP3170 & RS10-9-27 & 57 & 4500 & 29 & 7.2 \\
UP4041 & RS10-9-27 & 46 & 4400 & 19 & 5.5 \\
UP8309 & RS10-9-27 & 51 & 3900 & 18 & 5.7 \\
S07P3238 & RS10-9-26 & 52 & 3600 & 22 & 5.5 \\
S07P5150 & RS10-9-26 & 45 & 3700 & 21 & 5.2 \\
S07P6395 & RS10-9-29 & 62 & 3300 & 14 & 8.2 \\
& & & & & \\
Average & & 57 & 4237 & 24 & 7 \\
Std. Deviation & & 13.1 & 544.9 & 5.8 & 1.6 \\
Relative Std. Deviation & 0.23 & 0.13 & 0.24 & 0.23
\end{tabular}

In many cases the same reference pin is reused one or more times for subsequent analyses. Due to loss of material from each pin and a consequent change in pin shape over the course of the analysis, there is a potential for a change in the analyzed value for any element over the course of multiple runs. The same data shown in Table 6 is analyzed in Table 8 to trend multiple runs for the same G1-10 reference pin. Similarly the data shown in Table 7 is analyzed in Table 9 to trend multiple runs for the same RS10-9 reference pin. The difference in analyzed value from one run of a reference pin to the next is defined as $\Delta$. Values of $\Delta$ (in ppm) are shown in Tables 8 and 9 for those pins that were run more than once. The average value of $\Delta$ represents a trend for change in analyzed value with each additional run of the same pin. The standard deviation in $\Delta$ represents the scatter in that trend. The average analyzed value for each element is also shown in Tables 8 and 9. The standard deviation in $\Delta$ divided by the average analyzed value is defined as the relative standard deviation for $\Delta$, which is also shown in Tables 8 and 9 . 
Table 8. Analysis of Trends from Multiple Runs of the Same G1-10 Reference Pin

\begin{tabular}{|c|c|c|c|c|c|}
\hline \multirow[b]{2}{*}{ Pin No. } & \multicolumn{5}{|c|}{$\Delta$ or Change in Value from Previous Run of Same Pin } \\
\hline & Run Seq. & $\mathrm{Al}$ & W & Th & $\mathrm{Si}$ \\
\hline G1-10-21 & 2 & -7 & -100 & -3 & -0.2 \\
\hline G1-10-21 & 3 & 8 & -1600 & -4 & 3.3 \\
\hline G1-10-22 & 2 & 14 & 200 & 6 & 1.1 \\
\hline G1-10-24 & 2 & -5 & -500 & -2 & -0.3 \\
\hline G1-10-25 & 2 & -6 & 200 & 3 & -3.1 \\
\hline G1-10-26 & 2 & 6 & 200 & -6 & 1.5 \\
\hline G1-10-27 & 2 & -2 & -200 & -14 & -0.5 \\
\hline G1-10-27 & 3 & 10 & -400 & 4 & 4.4 \\
\hline G1-10-26 & 3 & -41 & -1200 & -3 & 0 \\
\hline G1-10-26 & 4 & 4 & -300 & -15 & -0.9 \\
\hline \multicolumn{2}{|c|}{ Average $\Delta$} & -2 & -370 & -3 & 1 \\
\hline \multicolumn{2}{|c|}{ Std. Dev in $\Delta$} & 16 & 606 & 7 & 2 \\
\hline \multicolumn{2}{|c|}{ Mean concentration } & 75 & 3921 & 28 & 6 \\
\hline \multicolumn{2}{|c|}{ Relative Average $\Delta$} & -0.03 & -0.09 & -0.12 & 0.09 \\
\hline \multicolumn{2}{|c|}{ Relative Std. Dev in $\Delta$} & 0.21 & 0.15 & 0.25 & 0.38 \\
\hline
\end{tabular}

Table 9. Analysis of Trends from Multiple Runs of the Same RS10-9 Reference Pin

\begin{tabular}{|c|c|c|c|c|c|}
\hline \multirow[b]{2}{*}{ Pin No. } & \multicolumn{5}{|c|}{$\Delta$ or Change in Value from Previous Run of Same Pin } \\
\hline & Run Seq. & Al & W & Th & $\mathrm{Si}$ \\
\hline RS10-9-21 & 2 & -7 & -1100 & -12 & -1.6 \\
\hline RS10-9-21 & 3 & 28 & 800 & 22 & 2.5 \\
\hline RS10-9-22 & 2 & 21 & 0 & 1 & 1.4 \\
\hline RS10-9-24 & 2 & -35 & -100 & -6 & -4.4 \\
\hline RS10-9-25 & 2 & -3 & 100 & 0 & -0.3 \\
\hline RS10-9-26 & 2 & 8 & 1300 & 2 & 0.1 \\
\hline RS10-9-26 & 3 & 14 & 300 & 3 & 1.4 \\
\hline RS10-9-27 & 2 & -11 & -100 & -10 & -1.7 \\
\hline RS10-9-27 & 3 & 5 & -500 & -1 & 0.2 \\
\hline RS10-9-26 & 4 & -9 & -1400 & -3 & -1.6 \\
\hline Average $\Delta$ & & 1.1 & -70 & -0.4 & -0.4 \\
\hline Std. Dev in $\Delta$ & & 18 & 804 & 9 & 2 \\
\hline Mean concen & & 57 & 4237 & 24 & 7 \\
\hline Relative Ave & & 0.02 & -0.02 & -0.02 & -0.06 \\
\hline Relative Std. & in $\Delta$ & 0.32 & 0.19 & 0.38 & 0.28 \\
\hline
\end{tabular}


In the case that reuse of the same pin resulted in a consistent trend in the analyzed value of any element, the relative value of $\Delta$ would be large and the standard deviation in $\Delta$ would be small. It is seen in Table 8 for the G1-10 pins that the average values of $\Delta$ are substantially smaller than the corresponding standard deviations in $\Delta$. The relative average value of $\Delta$ for Th, -0.12 , indicates somewhat of a trend of decreasing Th values with repeated pin use, although the variability characterized by the relative standard deviation in $\Delta$ is far larger.

In the case of the RS10-9 pins in Table 9 the relative average values of $\Delta$ are all very small, indicating an average change for repeated use on the same pin of $3 \%$ or less. It can be concluded that erosion of the pin from multiple glow discharge analyses is not a substantial source of error in analysis. The relative standard deviations in $\Delta$ are all large and comparable to those for the G1-10 pins in Table 8.

The extent to which the variation in the GDMS analysis of the reference pins is associated with pin to pin differences as opposed to repeat analyses of the same pin can be treated by an analysis of variance. The variance in the measured values for $\mathrm{Al}, \mathrm{W}, \mathrm{Th}$, and $\mathrm{Si}$ are listed in Table 10 for all analyses in which a reference pin was analyzed more than once. The average value for repeat analyses of the same pin is calculated and the variance associated with this average of multiple pins is calculated. (Note: The variance is weighted to account for different number of repeat measurements of the reference pins.) Variances (weighted) associated with the values for single pins are also calculated. These variances for multiple pins and single pins are listed in Table 10 for both G1-10 and RS10-9 reference pins. The ratios of the variances for single pins are also listed. In all cases the variance for the single pin constitutes a majority of the total variance for each element. If the ratios are averaged for the two pin types, the ratio of the variance for a single pin constitutes 0.67 or more of the total variance. This is a strong indication that the source of variation in the analyzed values is not the result of differences in composition between the reference pins of the same type.

Table 10. Analysis of Variance in Measured Composition of Reference Pins Indicates that the Majority of the Variance is Associated with Repeat Measurements of the Same Pin

$\begin{array}{llccr}\text { Variance type } & \text { Pin type } & \text { Variance for Analyzed Element }\left(\mathrm{ppm}^{2}\right) \\ & & \mathrm{Al} & \mathrm{W} & \text { Th } \\ \text { between pins } & \text { G1-10 } & 22 & 91007 & 12 \\ \text { between pins } & \text { RS10-9 } & 85 & 71167 & 6 \\ \text { same pin } & \text { G1-10 } & 97 & 237448 & 29 \\ \text { same pin } & \text { RS10-9 } & 94 & 172431 & 21 \\ \text { total } & \text { G1-10 } & 119 & 328455 & 41 \\ \text { total } & \text { RS10-9 } & 179 & 243599 & 27\end{array}$

$\begin{array}{lrrr} & \text { Ratio Single Pin Variance to Total Variance } \\ & \text { Al } & \text { W } & \text { Th } \\ \text { G1-10 } & 0.81 & 0.72 & 0.71 \\ \text { RS10-9 } & 0.52 & 0.71 & 0.77 \\ \text { All } & 0.67 & 0.72 & 0.74\end{array}$


The corrected values for the three alloying elements Al, W, and Th in the RS10-9 reference pins are shown in Table 11. These values are not reported in the course of routine analysis but were calculated by treating the RS10-9 pin as if it were a sample material and corrected using the corresponding data obtained for the G1-10 pin from the same run. The relative standard deviations are $0.20,0.16$, and 0.31 for $\mathrm{Al}, \mathrm{W}$, and $\mathrm{Th}$, respectively. In each case these values are similar to or greater than the relative standard deviations for the uncorrected values for both G1-10 and RS10-9 reference materials. This clearly indicates that long-term drift in the analytical measurements is not the primary cause of the variability in the analysis, since any effect of long term drift would be cancelled when the corrected values are used. Long term would be defined as a period of more than two days since the two reference materials for each pair are run within no more than two days of each other. A Grubbs test of the corrected values for the RS10-9 reference pins indicates that one of the $\mathrm{W}$ values and two of the Th values, indicated by ${ }^{*}$ ) in Table 11 are outliers. Removal of these values from the analysis substantially reduces the relative standard deviations for the $\mathrm{W}$ and $\mathrm{Th}$ to 0.077 and 0.17 , respectively, as indicated at the bottom of Table 11. It can also be noted that after the removal of the outliers all of the corrected values for the alloying elements in RS10-9 pins are within the specification limits for blanks. On the basis of this analysis it can be recommended that analysis of sample pins not be considered valid if a Grubbs tests on the corrected value of the RS10-9 reference pin associated with the samples shows an outlier value.

Table 11. Corrected Concentrations of Alloying Elements in RS10-9 Reference Pins

\begin{tabular}{ccccc} 
& & \multicolumn{3}{c}{ Calculated content, ppm by wt, (corrected) } \\
Job No. & Pin No. & Al & W & Th \\
UN3161 & RS10-9-21 & 40 & 3286 & 51 \\
UN3553 & RS10-9-21 & 39 & 2561 & 31 \\
UN3923 & RS10-9-21 & 52 & $5160^{*}$ & $89^{*}$ \\
UN4022 & RS10-9-22 & 44 & 3429 & 68 \\
UN4140 & RS10-9-22 & 49 & 3243 & 56 \\
UO0132 & RS10-9-23 & 39 & 3273 & 53 \\
UO0446 & RS10-9-24 & 45 & 3267 & 50 \\
UO0915 & RS10-9-24 & 25 & 3600 & 42 \\
UO2422 & RS10-9-25 & 41 & 3214 & 49 \\
UO2995 & RS10-9-25 & 43 & 3136 & 45 \\
UO5916 & RS10-9-26 & 41 & 3517 & 50 \\
UP0418 & RS10-9-26 & 25 & 3133 & 37 \\
UP1407 & RS10-9-26 & 31 & 3191 & 50 \\
UP3170 & RS10-9-27 & 41 & 2935 & 51 \\
UP4041 & RS10-9-27 & 34 & 3000 & 57 \\
UP8309 & RS10-9-27 & 33 & 2925 & 45 \\
S07P3238 & RS10-9-26 & 44 & 3086 & 49 \\
S07P5150 & RS10-9-26 & 36 & 3469 & $105^{*}$ \\
S07P6395 & RS10-9-29 & 28 & 3094 & 60
\end{tabular}




$\begin{array}{cccc}\text { All Values } & & & \\ \text { Average } & 39 & 3290 & 55 \\ \text { Std. Deviation } & 7.7 & 511.9 & 17.1 \\ \text { Relative Std. Deviation } & 0.20 & 0.16 & 0.31\end{array}$

Outliers (indicated by *) Removed

$\begin{array}{lccc}\text { Average } & 39 & 3187 & 50 \\ \text { Std. Deviation } & 7.7 & 246 & 8.5 \\ \text { Relative Std. Deviation } & 0.20 & 0.077 & 0.17\end{array}$

Corrected values for $\mathrm{Si}$ in the G1-10 reference pins can be calculated using the corresponding uncorrected values from the RS10-9 pin. This analysis of the same 19 pins listed in Table 11 shows an average corrected value of $2.9 \mathrm{ppm}$ with a standard deviation of $1.0 \mathrm{ppm}$, for a relative standard deviation of 0.36 . The corrected values ranged from $1.9 \mathrm{ppm}$ to $5.4 \mathrm{ppm}$. A Grubbs' test showed no outlier values.

The degree of repeatability in the analyzed values for the GDMS reference pins at Shiva is not expected. An earlier study of reference pin material, which is summarized within the procedure MET-MatP-SOP-79, showed relative standard deviations for Al, W, and Th of $3 \%$ to $4 \%$. The lack of repeatability is currently at a level that it is a practical issue. There has been one occurrence in which lack of repeatability has resulted in material determined to be nonconforming. The corrected aluminum analysis for G8-2 on job UO0132 was reported at $85 \mathrm{ppm}$ as compared to a specification limit of $80 \mathrm{ppm}$ maximum. The material was eventually approved by a Nonconformance Report for use as-is on the basis of additional runs on samples G8-2A, G8-2B, and G8-3 under job UO0446 all of which had reported corrected values of 57 ppm (NCR-IrBF-2157 of February 2005). In this case the reference pins showed normal behavior and the use of a Grubbs test proposed above would not have had any effect.

The technical manager of Shiva verified that procedural steps were followed. The analysts who performed the analyses were interviewed to confirm that the procedure (MET-MatP-SOP-79) was fully followed and also to gather any useful information, ideas, observations, and/or suggestions. A technical review of the analyses was conducted and all data including reports, calculations, and the original spectra of both G1-10 and RS10-9 pins for all nineteen jobs were examined. The original spectra showed that the signal current varied in the range of $10^{-8}$ to $10^{-9}$ A for iridium and $10^{-11}$ to $10^{-12} \mathrm{~A}$ for $\mathrm{W}$. These signals are measured using the Faraday detector. The $\mathrm{Al}$ and $\mathrm{Th}$ analytical signals were in the range of $10^{-12}$ to $10^{-13} \mathrm{~A}$. In some cases the signal was measured with the Faraday detector and in some cases with Daly detector, a counter for low currents in the range below about $10^{-12} \mathrm{~A}$. Due to the design of theVG9000 instrument signals in the range of $10^{-12}$ to $10^{-13} \mathrm{~A}$ is an overlap region in which signals may be measured with the Faraday or Daly detectors. The cross calibration of detectors is tested and recorded regularly as a part of Shiva's quality assurance system so the cross calibration (called an ion counting efficiency on VG9000 systems) should not be a source for any excessive variation. The recommendation of Shiva is not to measure an element in a reference pin using the Faraday detector and the same element in the sample using 
the Daly detector. The glow conditions are selected so that the signal acquisition procedure (selection of detectors) and GDMS instrument (signal intensity) will be tuned in such a way that $\mathrm{Al}$ and Th will be measured on the Daly detector for both reference pins and sample pins. This may result in decreased overall signal and some associated increase in the signal to noise ratio but this effect is expected to be smaller than improvements in $\mathrm{Al}$ and $\mathrm{Th}$ analyses achieved by making all signal measurements with the same detector. Selection of glow conditions and signal acquisition are not presently described in the analytical procedure and thus these minor changes in method can be made without formal revision of the analytical procedure.

\subsubsection{Conclusions from GDMS Trend Analysis}

The following conclusions can be drawn from the analysis of GDMS of iridium alloy reference pins performed since October 2005 with a pin length of $20.0 \pm 0.3 \mathrm{~mm}$.

1. The variability in the GDMS analysis of the iridium alloy reference pins is substantially larger than expected based on previous work.

2. The variability is not related to variations in chemistry between reference pins from the same material.

3. The variability is not related to erosion from repeated use of the same reference pin.

4. The variability is not related to long-term instrument drift.

5. The variability is large enough that there is significant likelihood that production iridium materials with normal chemistry could have reported GDMS values for alloying elements $\mathrm{Al}, \mathrm{W}$, and $\mathrm{Th}$ that are out of specification (false negative).

\subsubsection{Recommendations for GDMS Analysis}

1. The detectors and GDMS instrument signal intensity will be selected such that $\mathrm{Al}$ and Th will be measured on the Daly detector for both reference materials as well as for samples.

2. A corrected value for $\mathrm{Al}, \mathrm{W}$, and $\mathrm{Th}$ in the $\mathrm{RS} 10-9$ reference pin run with each group of samples would be subjected to a Grubbs test for outlier values. If any outlier values were found the analysis would not be considered valid. This would substantially reduce the chance of a false negative value in the analysis of blank and foil samples.

3. Consideration may be given to the addition of Grubb's test to be performed on corrected values for impurity elements in the G1-10 reference pin using the RS109 reference material as the basis for the correction. 
4. The first recommendation above can be implemented without formal revision to the procedure. The additional instructions can be provided in purchase documentation for the analytical services. After sufficient data is gathered, a formal revision of the procedure can be made if warranted. The second and third recommendations can be performed on a trial basis as information only until such time as a formal change to the procedure is implemented.

\subsubsection{Equipment Major Maintenance and Purchases}

Work rolls for the $2 \mathrm{Hi}$ configuration of the Fenn $4 \mathrm{Hi} / 2 \mathrm{Hi}$ mill were received at ORNL. The rolls were a capital purchase with FY 2006 funds. The rolls are primarily for flattening of rolled iridium alloy sheet.

\subsubsection{Presentations and Publications}

\subsubsection{Peer Review Publications}

Ohriner, E.K., Purification of iridium by electron beam melting, Journal of Alloys and Compounds, Vol. 461, No. 1-2, Aug 11, 2008, p 633-640

Ohriner, E.K., Processing of Iridium and Iridium Alloys, Platinum Metals Review, Volume 52, No. 3, July 2008, p 186-197

(This review article was the quarterly journal's 'Most Downloaded Article File' for July 2008.)

\subsubsection{Presentations}

Ohriner, E. K., Analysis of the Purification of Iridium by Electron Beam Melting, TMS 2008 Annual Meeting, Feb. 12, 2008, New Orleans, LA

Ohriner, E. K., Sabau, A., Ulrich, G. B, George. E. P., Deformation Modeling of Iridium DOP-26 Alloy to Determine Potential for Secondary Recrystallization, International Conference on Tungsten, Refractory \& Hardmaterials VII , June 9, 2008, Washington, D.C.

\subsection{CLAD VENT SET}

\subsubsection{Maintenance Production Summary}

Ten prime CVS were shipped in September 2008 to Los Alamos National Laboratory (LANL) as part of the DOE CVS Production Maintenance program. CVS production facility operability was maintained throughout the year. Training of personnel was maintained for all CVS operations during FY08. Trend analyses were maintained for all part types. No adverse trends were noted at the end of the year. All CVS surveillances, per the Surveillance and Process Monitoring Plan for the RPS Program CVS and 
CBCF Production Tasks, GPHS-QA-002, Revision G (Appendix B), were successfully completed during the year. The CVS surveillances are listed below.

\author{
Welding Equipment (Laser and EB) \\ Reinspection \\ Tooling Identification and Control \\ Measuring and Test Equipment \\ Instructions, Procedures, and Drawings \\ Personnel Training
}

\title{
2.3.2 Nonconformance Reports and Deviation Requests
}

The Nonconformance Reports and Deviation Requests for the Clad Vent Set Task are discussed in Appendix B.

\subsubsection{Evaluation/Qualification of New Coordinate Measuring Machine in Dimensional Inspection Area (Milestone 2.C.4)}

Qualification of the new Mitutoyo (Aurora, IL) Crysta Apex 920H CMM to replace the existing Cordax 1820 CMM (Sheffield Measurement, a division of Hexagon Metrology, Inc. Fond du Lac, WI) for CVS cup diameter and radius dimensional inspections was completed. The following report documents the qualification.

\section{Qualification of Mitutoyo Crysta Apex 920H Coordinate Measuring Machine for} Clad Vent Set Cup Diameter and Radius Inspections - G. B. Ulrich (Material Science and Technology Division), B. D. Walls and W. E. Wright (Quality Systems and Services Division)

A CMM or an optical comparator is required for diameter measurements of CVS cups. A CMM or an Olympus STM toolmaker's microscope is required for cup radius measurements. A new CMM was purchased and set up in 2007 by the ORNL Quality Measurement Services Group to replace the existing CMM. The existing CMM (serial \# 2-4420-1183), manufactured in 1983, was a Cordax 1820 DCC (Sheffield Measurement, a division of Hexagon Metrology, Inc. Fond du Lac, WI) with a Renishaw (Gloucestershire, UK) PH9/Mk2 probe head, TP2 probe, and a two mm diameter ruby stylus. The new CMM (serial \# 0001212) is a Mitutoyo (Aurora, IL) Crysta Apex 920H CMM with a Renishaw PH10MQ probe head, TP200 Touch Trigger probe, and a two $\mathrm{mm}$ diameter ruby stylus. Comparison measurements were made to qualify the new CMM for CVS cup dimensional inspections per procedure GPHS-C-3624/25, Rev. V (now Rev. 23).

During early comparison work an error source for the new CMM was discovered and corrected. The inspection speed used for the early CVS qualification work had been decreased from $8 \mathrm{~mm} / \mathrm{s}$ to $4 \mathrm{~mm} / \mathrm{s}$ to reduce the potential for moving the part during measurement. Calibration of the probe stylus to the calibration sphere had been performed at the recommended $8 \mathrm{~mm} / \mathrm{s}$. This tended to yield diameters approximately 0.005 to $0.006 \mathrm{~mm}$ small. The measurement speed for inspecting components must be 
equal to the probe stylus calibration speed to ensure proper results. The component fixturing method was modified to enable the inspection speed to be increased to $8 \mathrm{~mm} / \mathrm{s}$. Both the default calibration speed and the default component measurement speed have been set at $8 \mathrm{~mm} / \mathrm{s}$.

\subsubsection{Evaluation of a Cylindrical Standard}

Following the aforementioned error source correction, a Pratt and Whitney 1.125" $(28.575 \mathrm{~mm})$ diameter cylindrical standard was characterized at two latitudes (similarly to those used for the CVS cups) by measuring ten diameters using a Mahr (Jena, Germany) Universal Length Measuring Machine (ULM) model Opal 300. Once these ULM measurements were completed, each CMM was used to measure the diameters of the Pratt \& Whitney cylindrical standard similarly to how CVS cups are measured, i.e. four diameters every $45^{\circ}$ at both the $0.4 \mathrm{~mm}$ and $6 \mathrm{~mm}$ latitudes near the open end. This was repeated ten times on three different days. Table 12 shows the averages, standard deviations, maximums, minimums, and ranges of the diameter measurements at the two latitudes by machine. Note: The CMM average maximums and average minimums are averages of the maximums and minimums of the four diameters measured from each of the 30 runs (ten times on three different days). The maximums and minimums are individual (not average) diameters, thus they are worst-case values from 120 measurements. The ranges are the differences between these maximum and minimum individual values.

Table 12. New Versus Old CMM Diameter Measurements (mm)

\begin{tabular}{|c|c|c|c|c|c|c|c|c|c|c|}
\hline Machine & \multicolumn{5}{|c|}{ 0.4 mm Latitude (Equivalent to Cup Dimension 3) } & \multicolumn{5}{|c|}{$6 \mathrm{~mm}$ Latitude (Equivalent to Cup Dimension 4) } \\
\hline & $\begin{array}{l}\text { Average } \\
\mathrm{max} / \mathrm{min}\end{array}$ & $\begin{array}{l}\text { Std. } \\
\text { Dev. }\end{array}$ & Max. & Min. & Range & $\begin{array}{l}\text { Average } \\
\mathrm{max} / \mathrm{min}\end{array}$ & $\begin{array}{l}\text { Std. } \\
\text { Dev. }\end{array}$ & Max. & Min. & Range \\
\hline ULM & 28.5756 & 0.0004 & 28.5759 & 28.5749 & 0.0010 & 28.5758 & 0.0003 & 28.5765 & 28.5756 & 0.0009 \\
\hline $\begin{array}{l}\text { New } \\
\text { CMM }\end{array}$ & $\begin{array}{l}28.5785 \\
28.5767\end{array}$ & $\begin{array}{l}0.0005 \\
0.0005\end{array}$ & 28.5799 & 28.5757 & 0.0042 & $\begin{array}{l}28.5786 \\
28.5762\end{array}$ & $\begin{array}{l}0.0009 \\
0.0008\end{array}$ & 28.5801 & 28.5749 & 0.0052 \\
\hline $\begin{array}{l}\text { Existing } \\
\text { CMM }\end{array}$ & $\begin{array}{l}28.5789 \\
28.5704\end{array}$ & $\begin{array}{l}0.0054 \\
0.0042\end{array}$ & 28.5940 & 28.5650 & 0.0290 & $\begin{array}{l}28.5792 \\
28.5705\end{array}$ & $\begin{array}{l}0.0055 \\
0.0047\end{array}$ & 28.5980 & 28.5630 & 0.0350 \\
\hline
\end{tabular}


The new CMM average maximum and average minimum values are all closer than the existing CMM values to the ULM values indicating greater accuracy for the new CMM. The new CMM values are significantly less variable than the existing CMM values as evidenced by standard deviations, individual maximums, individual minimums, and ranges all closer than the existing CMM values to the corresponding ULM values. The new CMM standard deviations and ranges tend to be a factor of six to ten times smaller than the existing CMM values. The data that make up the summary values in Table 12 are graphed individually (four sets of 30 measurements at both the dimension 3 and 4 latitudes) and in Figures 5 and 6. These figures, using the same scales, clearly show the reduction in variability with the new CMM.

New CMM - Cylindrical Standard

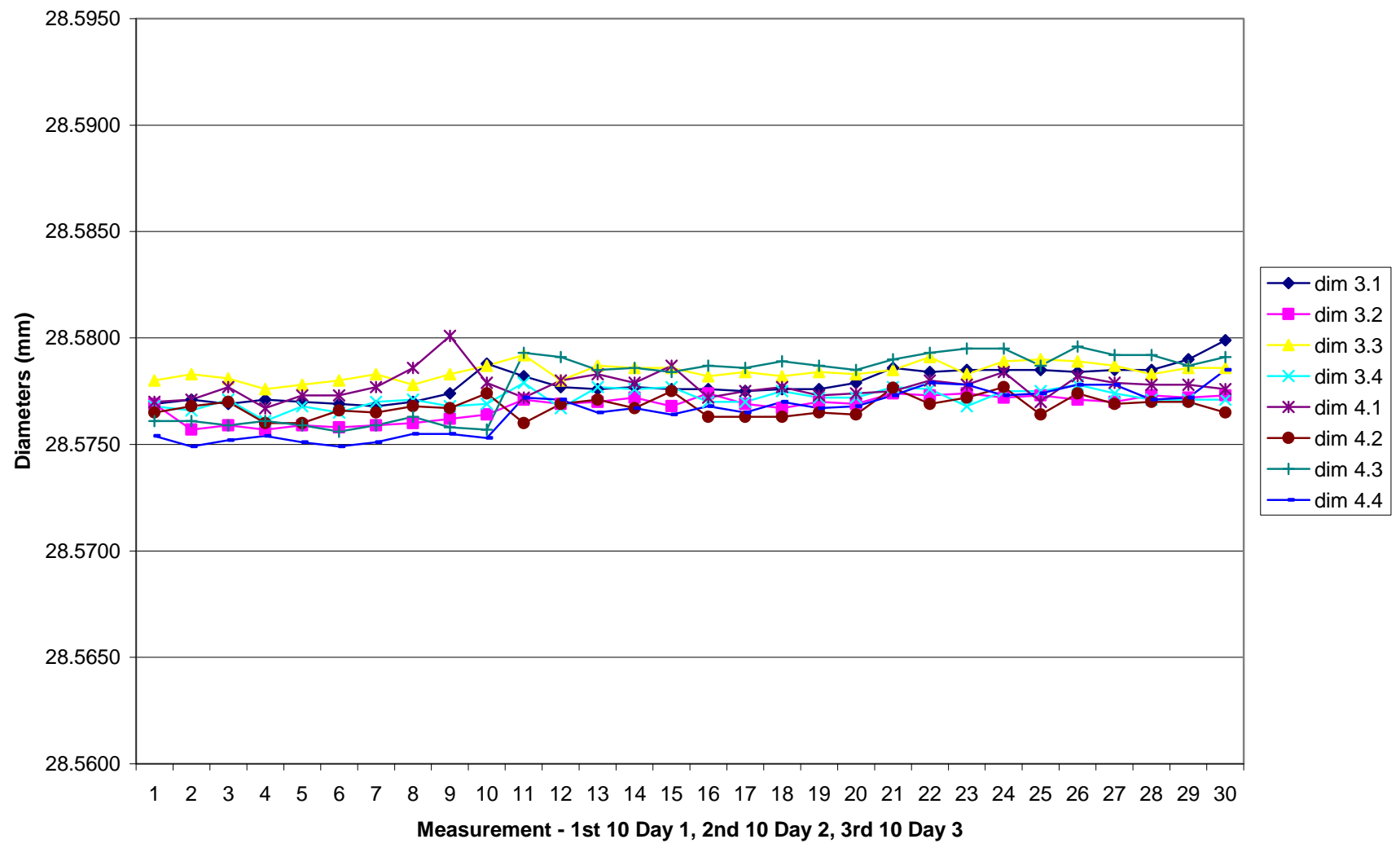

Figure 5. Graph of cylindrical standard diameter measurements made using new CMM. 


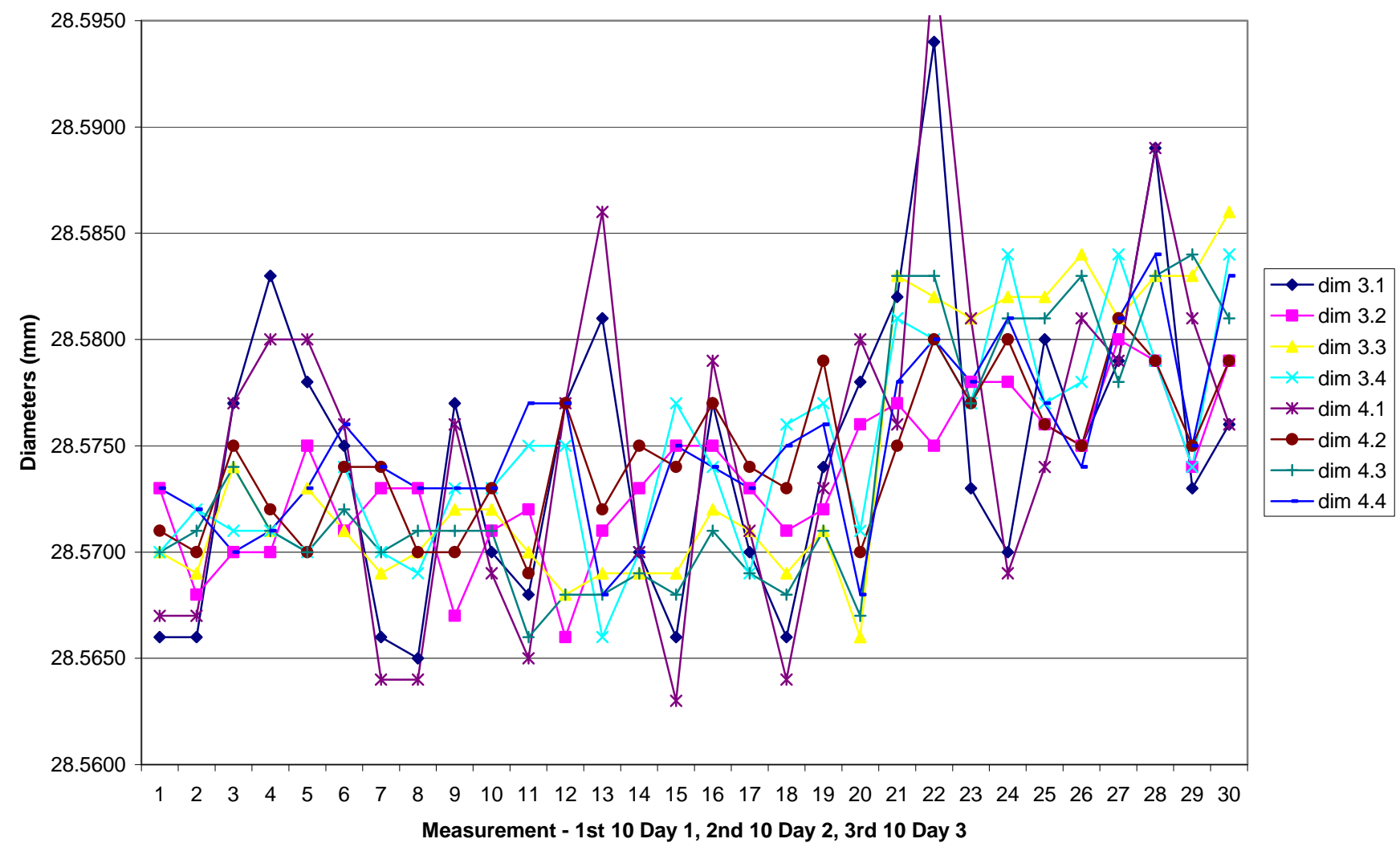

Figure 6. Graph of cylindrical standard diameter measurements made using old CMM.

\subsubsection{Evaluation of CVS Reinspection Surveillance Cups for Diameters and Radii}

Comparison inspection runs between the new and existing CMM were completed using two CVS Reinspection Surveillance cups, 3624-TC25 and 3624-5047. The cups were measured every $45^{\circ}$ at the two standard $(0.4 \mathrm{~mm}$ and $6 \mathrm{~mm})$ latitudes for diameters as well as every $45^{\circ}$ for the radius positions. The inspections were repeated ten times on three different days. The diameter results are summarized in Tables 13 and 14 for cups 3624-TC25 and 3624-5047, respectively. These results show that the new CMM yields smaller standard deviations and ranges than the existing CMM, thus the new CMM has better repeatability (less variation) than the existing CMM for diameter measurements. The bias values indicate that the new CMM measurements are averaging from 0.002 to $0.011 \mathrm{~mm}$ larger than those for the existing CMM. 
Table 13. Cup 3624-TC25 Diameters - New Versus Existing CMM (mm)

\begin{tabular}{|c|c|c|c|c|c|c|c|c|c|c|c|c|}
\hline $\begin{array}{l}\mathrm{CMM} / \\
\text { Statistic }\end{array}$ & \multicolumn{6}{|c|}{0.4 mm Latitude (Cup Dimension 3) Position Number } & \multicolumn{6}{|c|}{6 mm Latitude (Cup Dimension 4) Position Number } \\
\hline $\mathrm{CMM}$ & 1 & 2 & 3 & 4 & Max & Min & 1 & 2 & 3 & 4 & Max & Min \\
\hline Average & 29.763 & 29.811 & 29.847 & 29.813 & 29.847 & 29.763 & 29.753 & 29.780 & 29.810 & 29.775 & 29.810 & 29.753 \\
\hline Std Dev & 0.002 & 0.005 & 0.002 & 0.003 & 0.002 & 0.002 & 0.001 & 0.002 & 0.001 & 0.001 & 0.001 & 0.001 \\
\hline $\operatorname{Max}$ & 29.765 & 29.816 & 29.852 & 29.822 & 29.852 & 29.765 & 29.756 & 29.784 & 29.812 & 29.777 & 29.812 & 29.756 \\
\hline Min & 29.759 & 29.800 & 29.845 & 29.809 & 29.845 & 29.759 & 29.751 & 29.778 & 29.807 & 29.774 & 29.807 & 29.751 \\
\hline Range & 0.006 & 0.017 & 0.007 & 0.013 & 0.007 & 0.006 & 0.004 & 0.006 & 0.005 & 0.004 & 0.005 & 0.004 \\
\hline $\begin{array}{l}\text { Existing } \\
\text { CMM }\end{array}$ & 1 & 2 & 3 & 4 & Max & Min & 1 & 2 & 3 & 4 & Max & Min \\
\hline Average & 29.759 & 29.800 & 29.840 & 29.811 & 29.840 & 29.759 & 29.750 & 29.771 & 29.803 & 29.772 & 29.803 & 29.750 \\
\hline Std Dev & 0.008 & 0.010 & 0.002 & 0.005 & 0.002 & 0.008 & 0.008 & 0.005 & 0.003 & 0.003 & 0.003 & 0.008 \\
\hline Max & 29.777 & 29.817 & 29.846 & 29.822 & 29.846 & 29.777 & 29.768 & 29.780 & 29.810 & 29.778 & 29.810 & 29.768 \\
\hline Min & 29.749 & 29.784 & 29.835 & 29.802 & 29.835 & 29.749 & 29.737 & 29.763 & 29.798 & 29.767 & 29.798 & 29.737 \\
\hline Range & 0.028 & 0.033 & 0.011 & 0.020 & 0.011 & 0.028 & 0.031 & 0.017 & 0.012 & 0.011 & 0.012 & 0.031 \\
\hline $\begin{array}{c}\text { New } \\
\text { CMM } \\
\text { Bias }\end{array}$ & 0.004 & 0.011 & 0.007 & 0.002 & 0.007 & 0.004 & 0.003 & 0.009 & 0.007 & 0.003 & 0.007 & 0.003 \\
\hline
\end{tabular}

Table 14. Cup 3624-5047 Diameters - New vs. Existing CMM (mm)

\begin{tabular}{|c|c|c|c|c|c|c|c|c|c|c|c|c|}
\hline $\begin{array}{l}\mathrm{CMM} / \\
\text { Statistic }\end{array}$ & \multicolumn{6}{|c|}{ 0.4 mm Latitude (Cup Dimension 3) Position Number } & \multicolumn{6}{|c|}{6 mm Latitude (Cup Dimension 4) Position Number } \\
\hline CMM & 1 & 2 & 3 & 4 & Max & Min & 1 & 2 & 3 & 4 & Max & Min \\
\hline Average & 29.813 & 29.817 & 29.793 & 29.775 & 29.817 & 29.775 & 29.774 & 29.776 & 29.763 & 29.756 & 29.776 & 29.756 \\
\hline Std Dev & 0.003 & 0.005 & 0.004 & 0.005 & 0.005 & 0.005 & 0.004 & 0.003 & 0.002 & 0.003 & 0.003 & 0.003 \\
\hline Max & 29.818 & 29.825 & 29.797 & 29.779 & 29.825 & 29.779 & 29.779 & 29.779 & 29.766 & 29.760 & 29.779 & 29.760 \\
\hline Min & 29.808 & 29.811 & 29.788 & 29.763 & 29.811 & 29.763 & 29.767 & 29.770 & 29.759 & 29.752 & 29.770 & 29.752 \\
\hline Range & 0.010 & 0.014 & 0.009 & 0.017 & 0.014 & 0.017 & 0.011 & 0.009 & 0.007 & 0.007 & 0.009 & 0.007 \\
\hline $\begin{array}{l}\text { Existing } \\
\text { CMM }\end{array}$ & 1 & 2 & 3 & 4 & Max & Min & 1 & 2 & 3 & 4 & Max & Min \\
\hline Average & 29.808 & 29.805 & 29.786 & 29.769 & 29.812 & 29.769 & 29.772 & 29.769 & 29.760 & 29.754 & 29.774 & 29.754 \\
\hline Std Dev & 0.010 & 0.008 & 0.004 & 0.008 & 0.008 & 0.008 & 0.008 & 0.005 & 0.004 & 0.006 & 0.007 & 0.005 \\
\hline Max & 29.830 & 29.822 & 29.793 & 29.785 & 29.830 & 29.784 & 29.792 & 29.780 & 29.764 & 29.768 & 29.792 & 29.763 \\
\hline Min & 29.790 & 29.792 & 29.781 & 29.753 & 29.796 & 29.753 & 29.755 & 29.759 & 29.753 & 29.742 & 29.761 & 29.742 \\
\hline Range & 0.040 & 0.030 & 0.012 & 0.032 & 0.034 & 0.031 & 0.037 & 0.021 & 0.011 & 0.026 & 0.031 & 0.021 \\
\hline $\begin{array}{l}\text { New } \\
\text { CMM } \\
\text { Bias }\end{array}$ & 0.005 & 0.012 & 0.007 & 0.006 & 0.006 & 0.006 & 0.003 & 0.007 & 0.003 & 0.002 & 0.001 & 0.003 \\
\hline
\end{tabular}

The radii results are summarized in Tables 15 and 16 for cups 3624-TC25 and 36245047, respectively. These results show that the new CMM yields smaller standard deviations and ranges than the existing CMM, thus the new CMM has better repeatability (less variation) than the existing CMM for radii measurements as well. There is no consistent bias between the new and existing CMM average radius values. 
Table 15. Cup 3624-TC25 Radius - New Versus Existing CMM (mm)

\begin{tabular}{|c|c|c|c|c|c|c|c|c|c|c|}
\hline $\begin{array}{l}\mathrm{CMM} / \\
\text { Statistic }\end{array}$ & \multicolumn{10}{|c|}{ Cup Radius Dimension 5 Position Number } \\
\hline $\begin{array}{l}\text { New } \\
\text { CMM }\end{array}$ & 1 & 2 & 3 & 4 & 5 & 6 & 7 & 8 & $\operatorname{Max}$ & Min \\
\hline Average & 5.790 & 5.810 & 5.813 & 5.808 & 5.794 & 5.809 & 5.811 & 5.811 & 5.815 & 5.789 \\
\hline Std Dev & 0.002 & 0.002 & 0.005 & 0.002 & 0.004 & 0.004 & 0.003 & 0.002 & 0.003 & 0.002 \\
\hline Max & 5.794 & 5.818 & 5.820 & 5.815 & 5.799 & 5.817 & 5.818 & 5.814 & 5.820 & 5.794 \\
\hline Min & 5.786 & 5.807 & 5.806 & 5.805 & 5.789 & 5.803 & 5.806 & 5.807 & 5.811 & 5.786 \\
\hline Range & 0.008 & 0.010 & 0.014 & 0.010 & 0.009 & 0.014 & 0.012 & 0.007 & 0.009 & 0.008 \\
\hline $\begin{array}{l}\text { Existing } \\
\text { CMM }\end{array}$ & 1 & 2 & 3 & 4 & 5 & 6 & 7 & 8 & Max & Min \\
\hline Average & 5.776 & 5.808 & 5.806 & 5.810 & 5.790 & 5.810 & 5.806 & 5.810 & 5.817 & 5.774 \\
\hline Std Dev & 0.008 & 0.008 & 0.005 & 0.007 & 0.013 & 0.006 & 0.003 & 0.009 & 0.006 & 0.007 \\
\hline Max & 5.790 & 5.821 & 5.815 & 5.826 & 5.817 & 5.827 & 5.814 & 5.825 & 5.827 & 5.787 \\
\hline Min & 5.757 & 5.788 & 5.794 & 5.798 & 5.767 & 5.800 & 5.800 & 5.790 & 5.809 & 5.757 \\
\hline Range & 0.033 & 0.033 & 0.021 & 0.028 & 0.050 & 0.027 & 0.014 & 0.035 & 0.018 & 0.030 \\
\hline $\begin{array}{l}\text { New } \\
\text { CMM } \\
\text { Bias }\end{array}$ & 0.014 & 0.003 & 0.006 & -0.001 & 0.005 & -0.002 & 0.005 & 0.000 & -0.002 & 0.015 \\
\hline
\end{tabular}

Table 16. Cup 3624-5047 Radius - New Versus Existing CMM (mm)

\begin{tabular}{|c|c|c|c|c|c|c|c|c|c|c|}
\hline $\begin{array}{l}\mathrm{CMM} / \\
\text { Statistic }\end{array}$ & \multicolumn{10}{|c|}{ Cup Radius Dimension 5 Position Number } \\
\hline New & & & & & & & & & & \\
\hline CMM & 1 & 2 & 3 & 4 & 5 & 6 & 7 & 8 & Max & Min \\
\hline Average & 5.779 & 5.773 & 5.781 & 5.774 & 5.772 & 5.758 & 5.777 & 5.780 & 5.785 & 5.758 \\
\hline Std Dev & 0.003 & 0.002 & 0.002 & 0.003 & 0.003 & 0.002 & 0.010 & 0.005 & 0.004 & 0.002 \\
\hline Max & 5.788 & 5.777 & 5.784 & 5.778 & 5.778 & 5.761 & 5.790 & 5.789 & 5.790 & 5.761 \\
\hline Min & 5.774 & 5.771 & 5.777 & 5.769 & 5.768 & 5.755 & 5.766 & 5.776 & 5.781 & 5.755 \\
\hline Range & 0.014 & 0.006 & 0.007 & 0.008 & 0.010 & 0.006 & 0.024 & 0.013 & 0.010 & 0.006 \\
\hline Existing & & & & & & & & & & \\
\hline CMM & 1 & 2 & 3 & 4 & 5 & 6 & 7 & 8 & Max & Min \\
\hline Average & 5.761 & 5.776 & 5.778 & 5.774 & 5.772 & 5.759 & 5.775 & 5.778 & 5.786 & 5.754 \\
\hline Std Dev & 0.009 & 0.009 & 0.005 & 0.008 & 0.012 & 0.008 & 0.007 & 0.009 & 0.004 & 0.007 \\
\hline Max & 5.777 & 5.793 & 5.783 & 5.788 & 5.793 & 5.773 & 5.789 & 5.792 & 5.793 & 5.767 \\
\hline Min & 5.742 & 5.756 & 5.768 & 5.753 & 5.749 & 5.738 & 5.765 & 5.759 & 5.780 & 5.738 \\
\hline Range & 0.035 & 0.037 & 0.015 & 0.035 & 0.044 & 0.035 & 0.024 & 0.033 & 0.013 & 0.029 \\
\hline $\begin{array}{c}\text { New } \\
\text { CMM } \\
\text { Bias }\end{array}$ & 0.018 & -0.003 & 0.003 & 0.000 & -0.001 & -0.001 & 0.002 & 0.002 & -0.001 & 0.003 \\
\hline
\end{tabular}




\subsubsection{Summary}

This new versus existing CMM comparison study showed that the new Mitutoyo CMM is more accurate and less variable than the existing Cordax CMM for the pertinent CVS diameter and radius inspection measurements. The new CMM is considered qualified for CVS dimensional inspections per procedure GPHS-C-3624/25.

\subsubsection{Decontamination Cover Tooling}

A study was begun in FY 2008 to evaluate the potential for improving the DC blank flattening operation before forming. Flatter DC edges can aid the EB weld operation. The back-up DC blanking tooling fabricated by Gemcity Engineering and Manufacturing (Dayton, OH) in FY 2007 was used with non-prime DCs. The intent was to measure material thicknesses, part heights and part minimum and maximum diameters in the following conditions: blanked, flattened, formed, and deburred.

Material thicknesses were measured using a micrometer. Heights were measured using a height gauge and indicator. The diameters were measured using a micrometer, an Olympus STM comparator/toolmaker's microscope (STM), and a Mitutoyo QVAce 200 vision measuring machine (VMM). Die/punch diameter combinations of $0.4575 / 0.4572$ inches $(11.621 / 11.613 \mathrm{~mm})$ and $0.4568 / 0.4563$ inches $(11.603 / 11.590 \mathrm{~mm})$ were only partially evaluated because of mixed results for the diameters from the different inspection techniques. The micrometer tended to yield approximately $0.04 \mathrm{~mm}(0.0016$ inches) larger maximum diameters than either the STM or VMM. However, the VMM tended to yield approximately $0.02 \mathrm{~mm}(0.0008$ inches $)$ smaller minimum diameters than either the micrometer or STM.

This study was halted until the proper instrument for measuring diameters could be determined. It is hoped that in FY 2009 the VMM can be optimized for this measurement. The micrometer measurements are very tedious while the STM measurements are almost as tedious. The VMM is a very fast and repeatable measuring instrument. If the correct inspection parameters can be found for the VMM it will be very beneficial for evaluating the decontamination diameters in each processing condition with different blanking dies/punches and flattening parameters.

\subsubsection{Cup Forming Evaluations}

Build-up of dried and hardened Fiske (Fiske Brothers Refining Co. Newark, NJ) 604 lubricant on the second-forming die occasionally occurs. This can result in local depressions or grooves in the outer contour of the cup wall and concomitant bulges on the inner contour. These impressions are not preferred. In FY 2007, seven forming lubricants were screened as possible replacements for the current Fiske 604 lubricant. The Bostik Never-Seez (Bostik Findley, Inc. Middleton, MA) Regular Grade lubricant was selected for further evaluation in FY 2008.

Twenty five non-prime cups were first-formed in five parameter sets of five cups each to evaluate the Bostik Never-Seez Regular Grade lubricant versus the current Fiske 604 
lubricant along with punch and die heating to the current $250^{\circ} \mathrm{C}$ versus no heating or partial heating (die only or punch only). Visual examination indicated that all first-form assemblies looked similar to each other and to standard first-form assemblies. Although the first-form assemblies were in a fairly rough condition for precise dimensional inspection, some statements could be made from analysis of the dimensional inspection results for diameters, heights, and thicknesses prior to second-forming.

1) No differences were found between lubricating the blank holder with Bostik Never-Seez Regular Grade vs. Fiske 604.

2) The smallest punch-to-die clearance (0.1040") produced the tallest cup heights with the thinnest cup open end thicknesses.

3) The largest punch-to-die clearances (0.1084" and 0.1063") produced the thickest cup open end thicknesses.

4) The dies with the larger diameter (warm dies) produced the largest diameter firstform cup assemblies.

5) The die with the smaller diameter (cold die) in combination with the larger diameter punch (warm) produced the smallest diameter first-form cup assemblies.

None of this information was surprising. It indicated that, within the parameter limits investigated, dimensional inspection in the first-form assembly condition probably is of limited value. The cups were then second-formed, trimmed, chemically stripped, deburred, cleaned, and dimensionally inspected.

\subsubsection{Cup Sizing Evaluations}

The current cup production sizing operation is performed at room temperature after the recrystallization operation. The outer surface of a cup is lubricated prior to placing it in a closed steel die. Hydrostatic pressure is applied through a polyurethane punch nose on the inside of the cup to size the cup to the proper final diameter, radius, and roundness dimensions. Cup sizing evaluations were done to determine if the wrought (as-formed) cups possessed enough ductility to achieve proper dimensions before recrystallization. If sizing could be done before recrystallization, then concerns regarding cups with hardened lubricant impressions receiving undesirable localized critical strain (cold work from sizing) after full recrystallization could be allayed. Cold work imparted from sizing before recrystallization would be eliminated during recrystallization along with the potential for abnormal grain growth from critical strain at a subsequent elevated temperature.

Four non-recrystallized cups (TC172, 178, 183, and 187) were sized with a 12,000 pound load (12 kips) using a 50 kip MTS Systems Corporation (Eden Prairie, MN) load frame. The load histories are shown in Figure 7. Note: Production sizing is done with approximately 12 kips using a Wabash (Wabash, IN) model 30-12SM hydraulic press. Dimensional inspection of these cups after sizing showed inadequate dimensional 
control. Cup TC172 was re-sized with a 20 kip load while cup TC168 was sized for the first time with a 25 kip load. Subsequent dimensional inspections still showed inadequate dimensional control. Also the $25 \mathrm{kip}$ load overloaded the polyurethane punch. It was decided to continue the sizing load evaluations in FY 2009 using recrystallized cups and new sizing punches.

The purpose of the FY 2009 sizing load evaluations using recrystallized cups will be to determine the practical minimum and maximum sizing load limits. Note: The 23 FY 2008 maintenance production cups were dimensionally inspected prior to production sizing and as finished cups to gather comparison data for the aforementioned 25 nonprime cups formed to evaluate forming lubricants, punch and die pre-heats, and sizing loads.

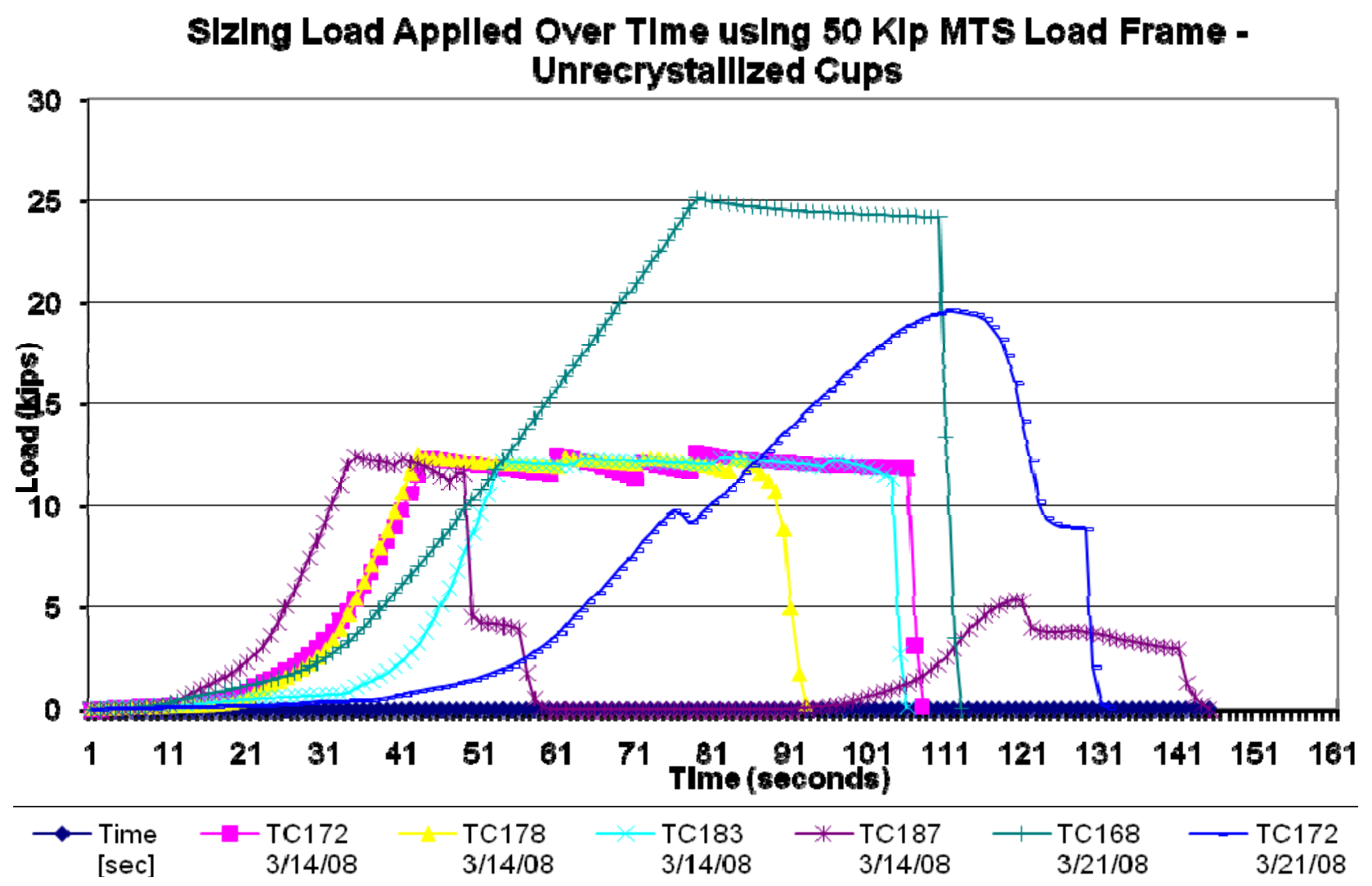

Figure 7. Sizing load history for non-recrystallized cups.

\subsubsection{Frit Vent Tooling Evaluation}

During FY 2007 graphite sintering tooling was made from POCO Graphite (Decatur, TX) grade DFP-1 and Graphtek LLC (Buffalo Grove, IL) grade GM-10 in an effort to address the problem of iridium powder sticking to the graphite tooling instead of the frit vent backing disc during sintering. The intent was to find a material, machined to the required surface finish of $16 \mu$ in $V_{\mathrm{rms}}$, that would perform better (lower incidence of iridium 
powder sticking to the graphite pins and/or bushings during sintering) than the currentlyspecified UCAR (Clarksburg, WV) ATJ graphite. Dimensional and visual (10X to 20X) inspections of the new sintering tooling components showed the tooling surfaces to be rougher than desired.

Nevertheless, initially in FY 2008 three $1500^{\circ} \mathrm{C}$ sintering runs were made to evaluate the influence of pin tooling graphite materials on the incidence of powder sticking. The production iridium powder lots, 92-0035-Jar 6, 91-0087-Jar 4C and 21-012800-Jar A, shown in Figures 8, 9, and 10, respectively, were used. The incidence of powder sticking was high for all three graphite materials with powder lots 92-0035-Jar 6 and 21-012800Jar A. There was no sticking with any of the graphite materials for powder lot 91-0087Jar 4C. Although all three powders have different morphologies, it was not clear why powder lot 91-0087-Jar 4C performed better than the other two with regard to sticking to the tooling. It was decided to repeat these sintering runs with the other trained operator.

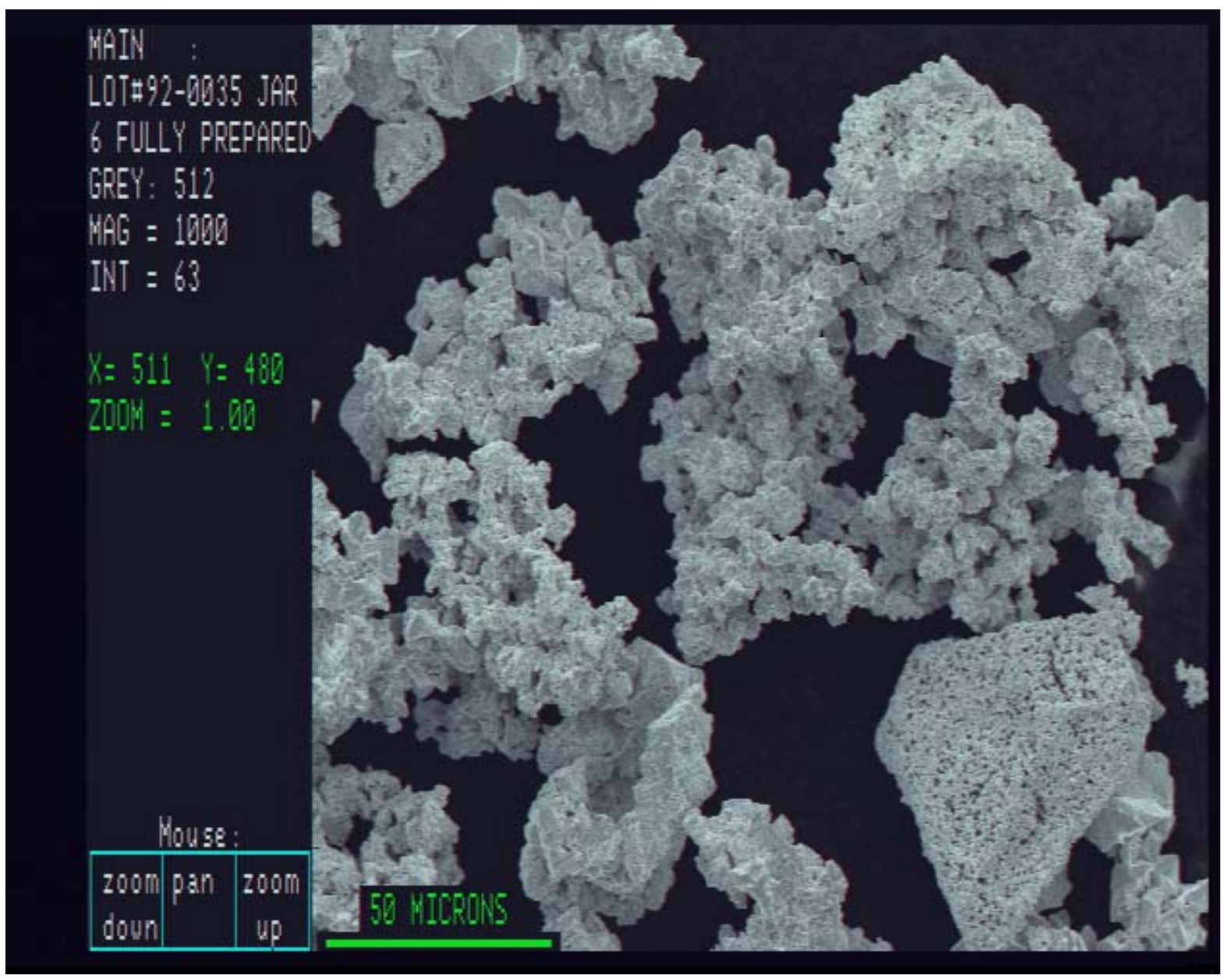

Figure 8. Production frit vent powder, lot 92-0035-jar 6, at 1000X magnification. 


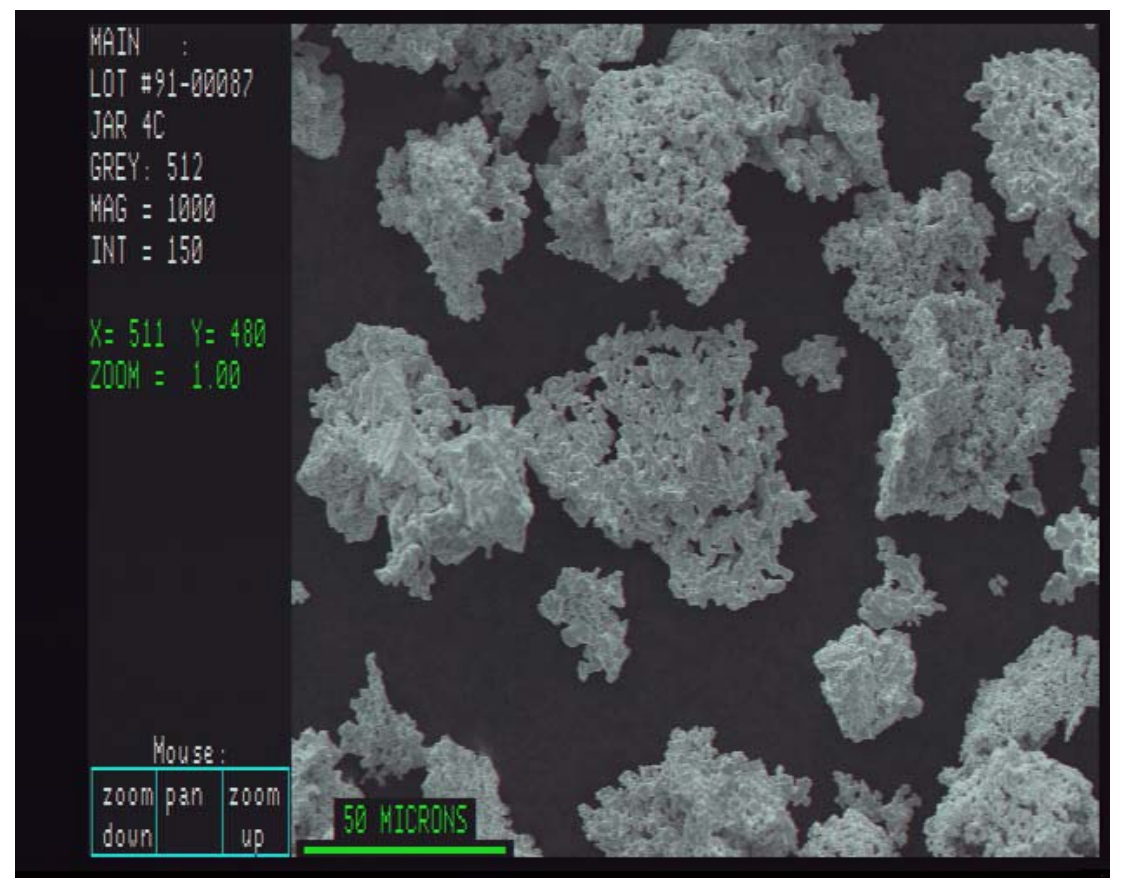

Figure 9. Production frit vent powder, lot 91-0087-jar 4C, at 1000X magnification.

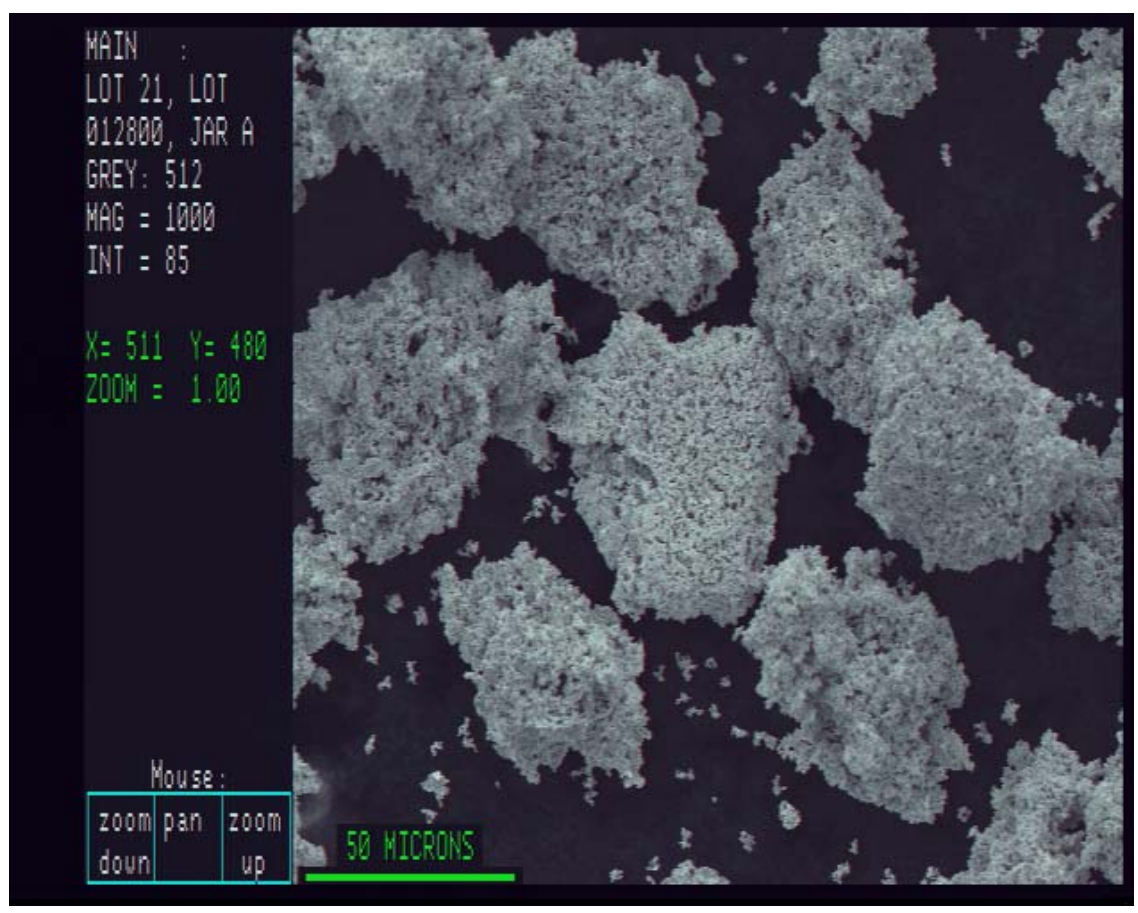

Figure 10. Production frit vent powder, lot 21-012800-jar A, at 1000X magnification. 
The results of the three additional $1500^{\circ} \mathrm{C}$ sintering runs made by the other trained operator showed no sticking with any of the graphite materials for powder lot 91-0087Jar 4C, just as before with the first operator. There was no sticking for powder lots 920035-Jar 6 and 21-012800-Jar A with the ATJ graphite tooling. The incidence of powder sticking was minor for the DFP-1 graphite material with powder lots 92-0035-Jar 6 and 21-012800-Jar A. There was no sticking for graphite material GM-10 with powder lot 92-0035- Jar 6 and only minor sticking with powder lot 21-012800-Jar A. It was noted that all six sintering runs were made using the same 18 backing discs. The powder from any previous run was removed and the backing discs were re-used. It was decided to have the second operator make two final evaluation runs.

One of the last two sinter runs, using powder lot 92-0035-Jar 6, was made with 12 new backing discs and 6 re-used backing discs to discern whether re-using backing discs had an effect on powder sticking to the graphite tooling. Sticking around the edge occurred for the DFP-1 graphite with the re-used backing discs as well as for the GM-10 graphite with new backing discs. No sticking occurred for the ATJ graphite with new backing discs. The final run was made with the same powder and the same backing discs as the previous run except that the "new" backing discs were flipped over to the unused side and the loaded fixtures were vacuum pumped overnight prior to the $1500^{\circ} \mathrm{C}$ sinter run. Powder sticking occurred with the DFP-1 and GM-10 graphite tooling, but not the ATJ tooling. The DFP-1 and GM-10 graphite tooling materials were not evaluated further in FY 2008. Note: A total of 144 sintered parts were evaluated for this work.

In FY 2009 SEM photos may be taken of all three tooling materials, ATJ, DFP-1, and GM-10, at various magnifications to discern an explanation for the powder sticking. Also an alternate graphite machine shop may be used in an effort to produce pins and bushings with better surface finishes.

\subsubsection{Equipment Maintenance and Housekeeping}

The cooling water dechlorination system (Culligan Hi-Flow 55 Automatic Carbon Filter) for Vacuum Furnaces A and B and the laser welder was repaired in early FY 2008. Six cartridges and seats, two caps, and the pilot valve were replaced. Prior to the repair, when the furnaces and laser cooling water valves were off, the dechlorinated water was dumping to the drain instead of being valved off.

Prior to FY 2008 cup forming, maintenance was completed on the Dake Press. The hydraulic oil and gaskets were changed, the motor was greased, sound insulation was replaced, and the stroke control unit bolts were tightened. Also the $1^{\text {st }}$ - and $2^{\text {nd }}$-form punches and dies were successfully inspected for key dimensional measurements prior to maintenance production forming.

Instrument calibrations were completed for both High Temperature Vacuum Furnaces A and $\mathrm{B}$.

A $167 \mathrm{KVA}$ transformer supplying 480V power to the CVS equipment failed in midNovember 2007. All three transformers were quickly replaced. Unfortunately, the phase 
failure caused control relays CR-51 and CR-51A on High Temperature Vacuum Furnace B to fail. Replacements (Heavy Duty Open, 25A 4 PDT Contacts, 480 VAC @32 mA, Coil $60 \mathrm{~Hz}$, with screw terminals, Potter \& Brumfield PM17AY- 480) were ordered with a long lead time. The replacements were received and installed three months later with problems continuing.

One of the three $167 \mathrm{KVA}$ transformers supplying $480 \mathrm{~V}$ power to the CVS equipment was replaced again. Seven hours after control power was applied, relays CR-51, CR51A, and CR-51B failed. A fast-track order was placed for six additional relays. Control relays CR-51, 51A, and 51B and their lead wires were replaced within two weeks of ordering. Power was applied to the control cabinet and it was monitored using a Ranger Rustrak HA-5059 Harmonic Analyzer for approximately one week to detect any anomalous conditions. The furnace was run successfully and the analyzer was removed. One day after the furnace was operated successfully for a second run control relay CR-51 failed for the third time with power on the control cabinet, but no power on the furnace. After CR-51 was replaced again, the Ranger Rustrak HA-5059 Harmonic Analyzer was re-installed. Furnace $\mathrm{B}$ was run successfully eight times without any electrical anomalies. The power was monitored for another month. No abnormal conditions were detected or encountered.

A representative from Struthers-Dunn, LLC, the control relay manufacturer, visited to discuss the problems that were encountered. All six failed relays plus one of the recent purchases were examined by Struthers-Dunn laboratory personnel. No assignable causes, other than current overload, were identified for these failures. Three very-recentlymanufactured relays were given in exchange for the failed ones plus the older unused one.

Significant clean-up and de-cluttering efforts were performed in rooms 119, 122, and 123 in building 2525 (not owned by MS\&T Division) where some RPS Program operations are conducted. Large quantities of excess scrap metal were sent for recycle. Excess equipment and storage cabinets were radiologically surveyed and then removed for salvage. These efforts should significantly improve the housekeeping status in these rooms.

\subsubsection{Electron Beam Welder Re-Qualification Support After Control System Upgrade}

Twenty six Cassini-era cups (11 vent and 15 shield cups) remaining from past Oak Ridge Y-12 Plant production were dimensionally inspected to verify their dimensional status for EB welder re-qualification work. The 11 vent cups were prepared further for this work by EDM vent holes and cleaning. Also 14 vent cup assemblies remaining from past Y-12 production were released for this re-qualification effort.

A total of 75 non-prime weld shields were fabricated and cleaned for the EB welder requalification efforts including two pulser evaluations and welding operator training/qualification. Fifty non-prime DCs were fabricated, leak tested, and cleaned for the EB welder re-qualification work as well. 
Five weld qualification vent cup assemblies (VCA) with just the frit vent-to-cup weld complete were flow tested. This was followed by completion of the DC-to-cup welds and leak testing. These VCA along with six shield cup assemblies (SCA) were processed through the air burn-off, vacuum outgas, weld inspection, and dimensional inspection operations. Two each VCA and SCA were EDMed for metallographic evaluation.

The position \#5 pocket shaft (Ten Head Weld Positioner drawing T2E-140445) never had a required central through-hole for facilitating post-weld cup assembly removal. The through-hole was successfully EDMed. The pocket shaft was cleaned and re-installed in the Ten Head Weld Positioner.

\subsection{IRIDIUM POWDER AND INVENTORY MANAGEMENT}

The purpose of this work is to manage an iridium inventory for all heat source contractors with emphasis on the significant quantities of iridium located at LANL, INL, and ORNL and to maintain a no-change iridium inventory through an annual write-off of inventory and processing losses.

\subsubsection{Iridium Demand and Supply Schedule}

The demand and supply schedule, prepared for contingent planning purposes, presents a strategy to assess the availability of iridium for all improving and producing activities by projecting future demands. An adequate inventory must be maintained for the NASA and defense mission needs. Table 17 indicates that enough iridium will be available for these missions.

The first part of Table 17 shows the estimated production demand factors for prime blanks and foil. The schedule of produced blanks and foil represents the quantity and timing for delivery or storage at ORNL. The ingots from new material represent the quantity produced from new iridium powder to make either blanks or foil. These ingots must be produced on a timely basis to meet the lead-time requirement to produce and deliver or store the blanks and foil.

The production of blanks and foil produces recyclable iridium material that can be placed back into the production process at ORNL. A greater economic benefit is realized by using recycled material, since the need to purchase powder from an outside vendor is reduced.

Refinable iridium scrap is also generated from the production of blanks and foil. This scrap is sent to a commercial refinery when a sufficient accumulation occurs at ORNL, funding is available for the refining, and it makes economic sense based on a comparison of refining versus new material costs.

Process losses of iridium occur during the working of the material at ORNL, LANL, and INL. Losses also occur during the refining process. These inventory losses are writtenoff annually. 
The information contained within Table 17 can be summarized as follows. There will be an adequate supply of iridium powder to produce the hardware for NASA space exploration and defense missions and $94 \mathrm{~kg}$ will remain at the beginning of FY 2012.

\section{Table 17. Demand and Supply Schedule Shows Factors and Provides Strategy to Ensure an Adequate Supply of Iridium Powder for NASA and Defense Missions}

\begin{tabular}{lcccc}
\hline & \multicolumn{4}{c}{ U. S. Government Fiscal Years } \\
\cline { 2 - 5 } \multicolumn{1}{c}{ Factors and strategy } & FY 2008 & FY 2009 & FY 2010 & FY 2011 \\
\hline & Production-demand factors & \\
Produced blanks ${ }^{1}$ & 30 & 30 & 30 & 30 \\
Ingots from new material & 0 & 0 & 0 & 1 \\
Ingots from recyclable material & 0 & 0 & 0 & 0 \\
Produced foil (m ${ }^{2}$ ) & 0 & 0 & 0 & 0 \\
& Refining and process losses (kg) & \\
Refining loss & 0 & 0 & 0 & 0 \\
Processing losses & 3.5 & 3.0 & 3.0 & 3.0 \\
& Supply strategy (kg) & & \\
Beginning balance of powder & 120 & 117 & 115 & 113 \\
Receipt of refined powder & 0 & 0 & 0 & 0 \\
Receipt of purchased powder & 0 & 0 & 0 & 0 \\
\hline
\end{tabular}

${ }^{1}$ Estimate of maximum number of blanks

${ }^{2} \mathrm{FY} 2012$ beginning balance of powder is estimated to be $94 \mathrm{~kg}$.

\subsubsection{Annual Write-Off}

The annual FY 2008 write-off of iridium inventory was completed in July. A total of 3.5 $\mathrm{kg}$ of iridium was written off as a normal operating loss. The write-off appropriately reduced the non-fund iridium inventory. This $3.5 \mathrm{~kg}$ loss was considered a normal operating loss compared to the history of iridium losses during the past several years.

\subsubsection{Iridium Accountability Reviews}

The reviews at ORNL and LANL were conducted in June and July, respectively. The purpose of these reviews was to evaluate the accountability, physical inventory, and security of iridium at each location. It was concluded that the accountability, physical 
inventory, and security for the iridium was in place and operating in a proper manner at both locations. No recommendations were necessary.

\subsubsection{Shipment of Iridium}

The shipment of ten (10) iridium alloy CVSs to LANL departed ORNL on September 29 and arrived at LANL on September 30. The security seals on the shipping container were intact upon arriving at LANL. U. S. DOE Transfer Voucher No. 901-OR4-NS4-001 dated October 17 was issued to properly account for this shipment.

\subsection{WELDING}

\subsubsection{Equipment Upgrades}

An upgraded control system for the production EB welder was installed under the supervision of a field engineer from the equipment manufacturer (PTR Precision Technologies). Note: The new control system was purchased with FY 2007 capital funds. Included in the upgrade was integration of the ten head rotary positioner to Computer Measuring Control (CNC). Previously, control of the positioner was performed by a separate speed controller. Radiation generation equipment testing was successfully performed on the upgraded equipment which included radiation field measurements and safety equipment verification. Equipment operation training and $\mathrm{CNC}$ programming of the GE Fanuc controller was conducted by the equipment manufacturer representative. A total of six personnel were trained on equipment operation by either the PTR representative or the ORNL subject matter expert. Acceptance testing of the new control system was completed in accordance with the equipment purchase specification. A revised standard operating guideline for equipment operation (GPHS-OP-003, Rev. 4) was approved and issued in June 2008. Figure 11 shows the system at the completion of machine acceptance. 


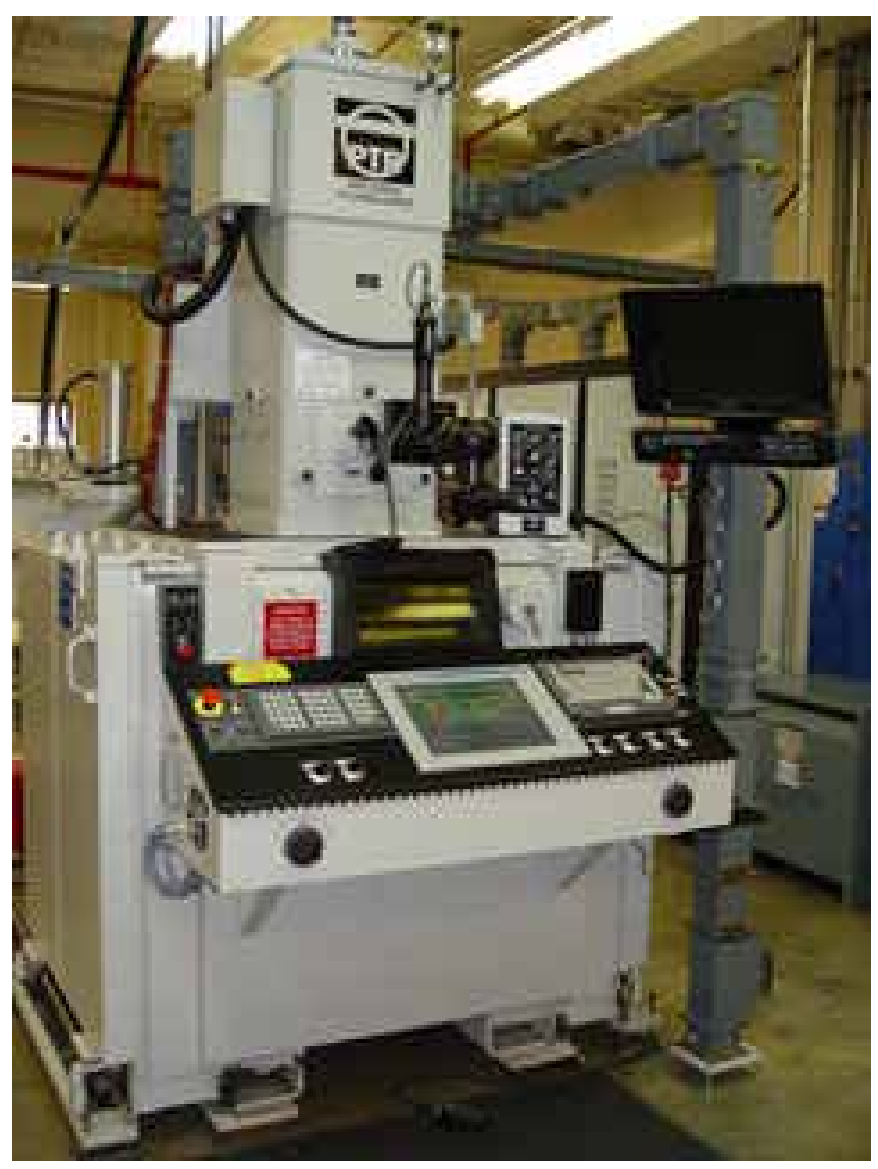

Figure 11. Production electron beam welder after upgrade.

\subsubsection{Equipment Requalification}

After installation and acceptance testing of the production EB welder control system, trial welding was successfully conducted. From the initial welding trials, it was found that improvements could be made in the weld schedules to provide for additional weld consistency for the weld shield butt weld and the stainless steel waster sheet. A weld development program was performed on these two weldments. Other weldments (frit to vent cup, DC to vent cup, weld shield to shield cup) required only minor adjustments and the writing of new $\mathrm{CNC}$ programs.

One area of improvement identified was to evaluate ways of stabilizing the alignment of frit vent assemblies (FVAs) and DCs with the vent cup during welding. Past observations indicated the components may move radially out from the center of the vent cup as they are being aligned for welding. When this occurs the chamber must be vented and the parts are realigned. To remedy this condition a set of stainless steel tack tools that could be integrated with the existing welding equipment were machined that would allow tack welding of the FVAs and DCs while preventing the radial movement. This technique proved successful and production tooling was manufactured from tungsten. Tungsten was selected so that if the tools were occasionally hit by the EB they would not 
be damaged nor cause deleterious material to be deposited onto the weldments resulting in a nonconformance.

Draft changes to three welding procedures (GPHS-K-001, GPHS-K-9753, and GPHS-K9754) were evaluated prior to equipment and operator qualification. These three procedures cover four of the five welds performed for CVS production. Two operators and the equipment were successfully qualified in September 2008 per the Training Guidelines for RPS Program, GPHS-PGD-1, Rev. 1. Figures 12 through 15 are weld section micrographs taken at the completion of qualification welding with the exception of Figure 13 which is a weld shield butt weld at the completion of weld development.

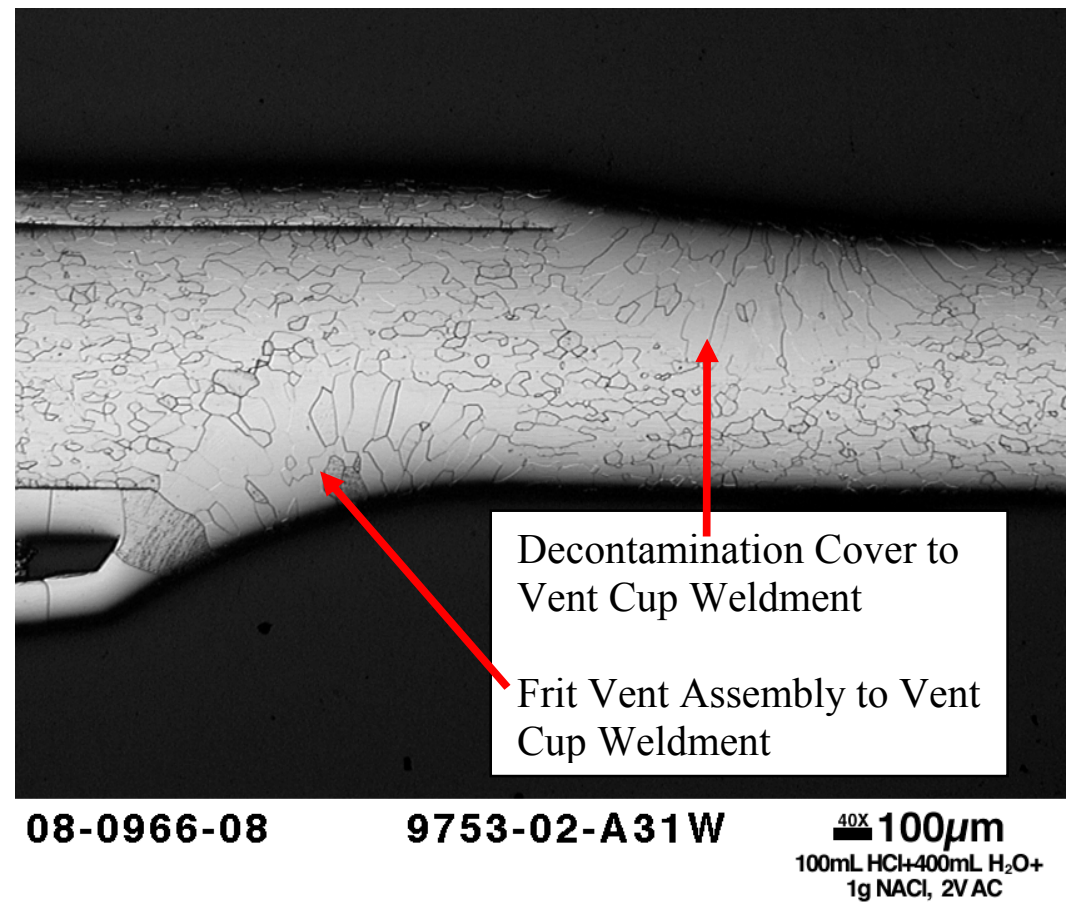

Figure 12. FVA and DC to Vent Cup Weldments 


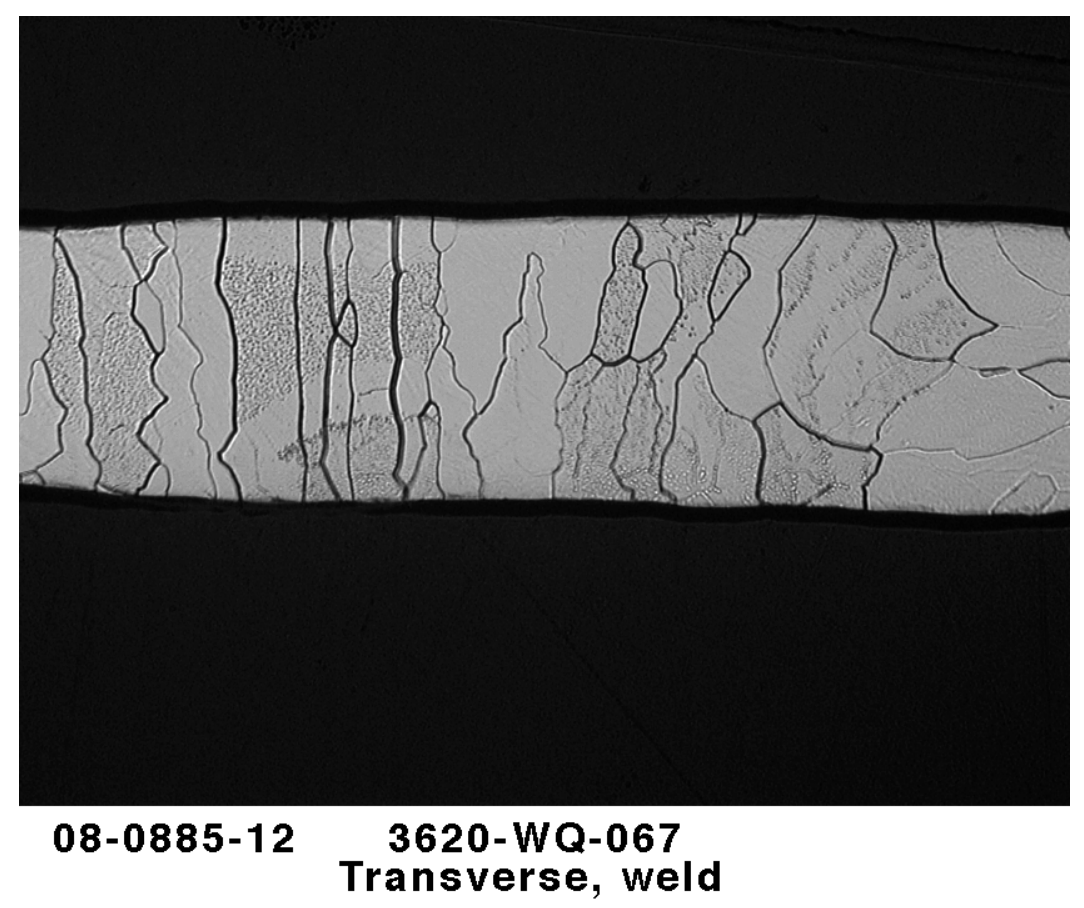

Figure 13. Weld shield butt weld.

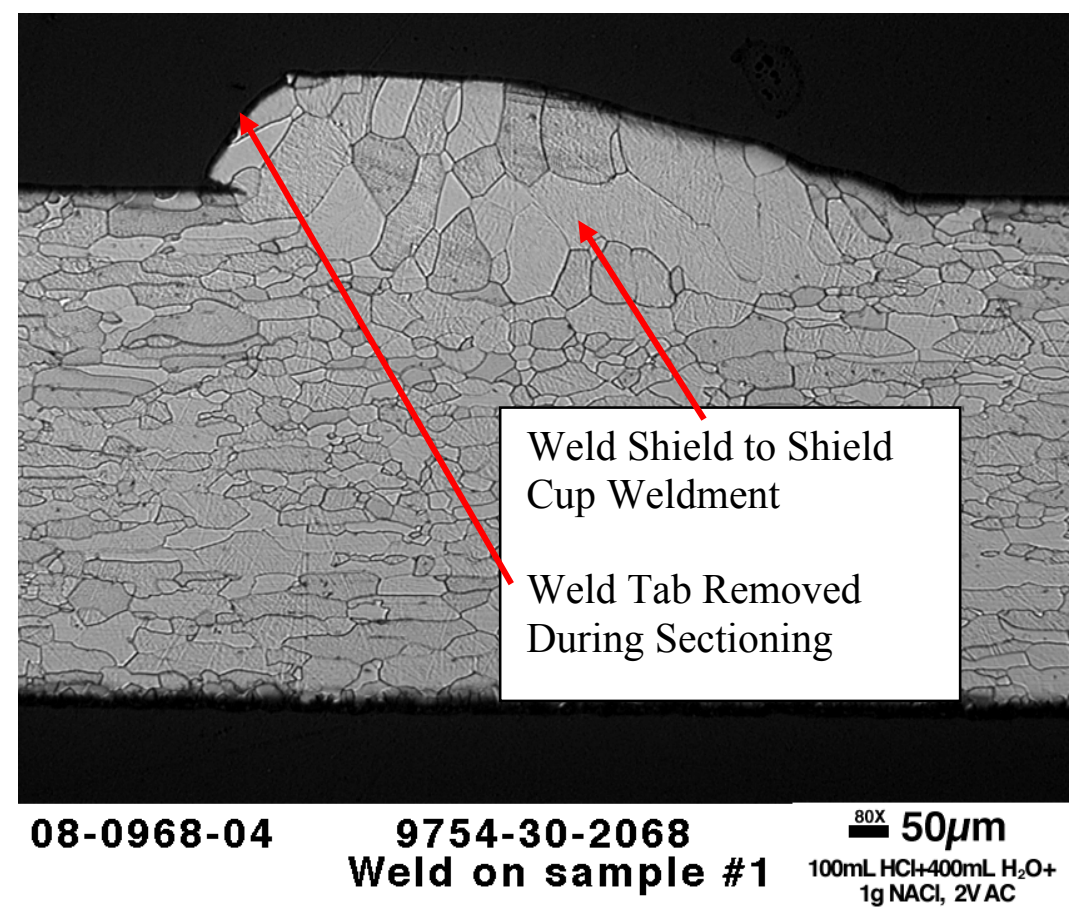

Figure 14. Weld shield to shield cup weldment. 


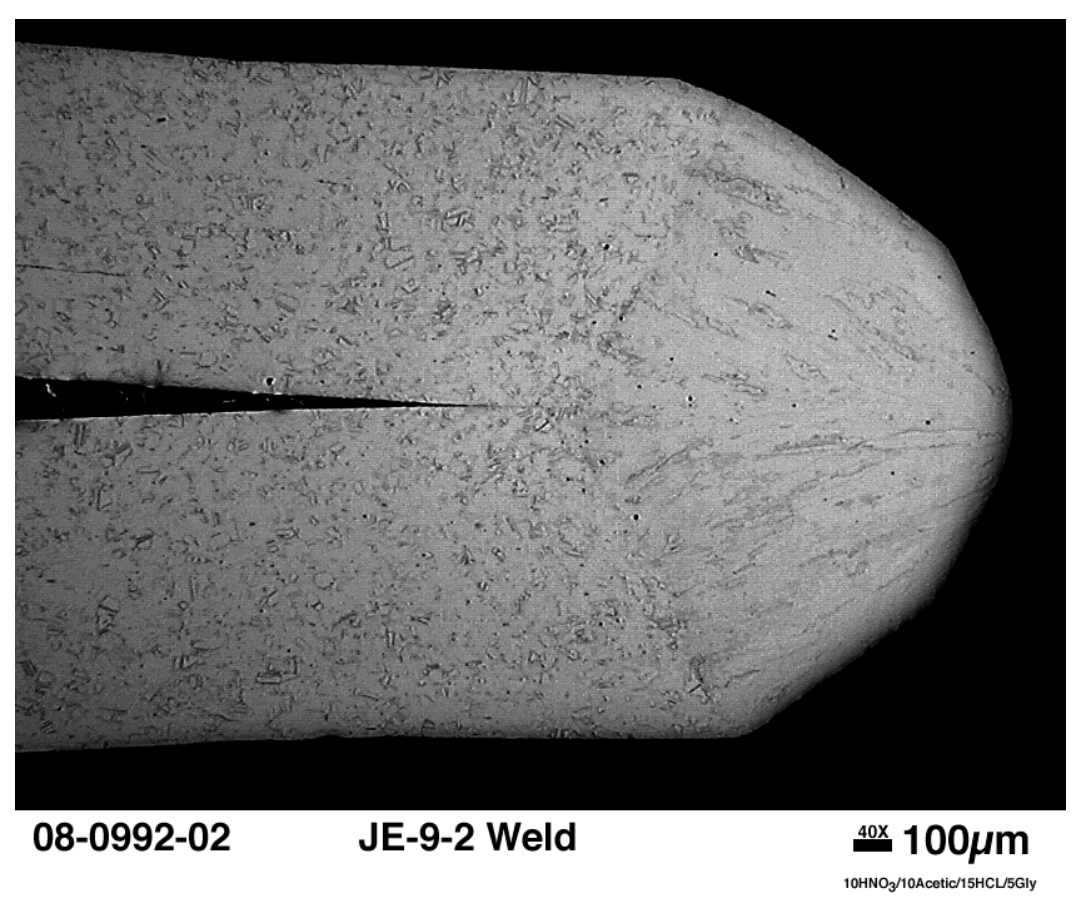

Figure 15. Stainless steel waster sheet weldment.

Final qualifications of the third operator and final evaluation and qualification of the remaining weld procedure GPHS-K-3620 is planned for FY2009.

\subsubsection{Russian Fuel Procurement}

Support was provided to DOE NE-34 to support onsite surveillances at the Mayak Production Association. This effort is to ensure processing and packaging of the material meets the contract requirements with TENEX and the USA/9516/B(U)F-85 CoCA transportation package.

A planned trip for the spring of 2008 was delayed and was cancelled in May 2008 due to the refusal of the Russian FSB to allow the delegation onsite access in Ozyorsk, Russia. This visit was later rescheduled and completed in October 2008.

\subsubsection{Radioactive Material Transport}

Support was provided to INL concerning past uses, manufacturing methods, design intent of the USA/9516/B(U)F-85 and USA/9904/B(U)F-85 transportation packages. Support was also provided to Energy Solutions for review of SARP and SARP Addendum revisions. 


\section{BASE TECHNOLOGY TASKS}

\subsection{ALLOY CHARACTERIZATION}

The objective of this task is to characterize the mechanical and metallurgical properties of metallic materials that are of interest to the RPS Program. Summarized below are the results of our activities during FY 2008.

\subsubsection{Effects of Temperature, Grain Size, and Strain Rate on the Ductility and Strength of DOP-26 Iridium}

In support of previous NASA missions, ORNL measured tensile impact ductilities of "new process" DOP-26 iridium at temperatures in the range $800-1100^{\circ} \mathrm{C}$. Since then, RTGs with lower operating temperatures than in previous designs have been contemplated for certain missions. Therefore, we were asked to extend the impactductility database of DOP-26 iridium from $800^{\circ} \mathrm{C}$ to $500^{\circ} \mathrm{C}$. To this end, during FY 2008, tensile impact tests were performed at grain sizes of 30 and $35 \mu \mathrm{m}$, and temperatures of $550,650,750$, and $850^{\circ} \mathrm{C}$. Together with the data obtained in the last three years, these results show a clear trend of increasing ductility with increasing test temperature for grain sizes of 23-35 $\mu \mathrm{m}$. In addition, ductility decreases with increasing grain size, with the magnitude of the decrease increasing as the temperature increases. The above tests provide information on only ductility and fracture behavior, and not the detailed stressstrain behavior of DOP-26 iridium, which is needed for the safety analyses performed by Sandia National Laboratory. Therefore, about two years ago we were asked to initiate a study to obtain tensile stress-strain curves for DOP-26 iridium as a function of temperature and strain rate. During FY 2008, additional tests were carried out at $750^{\circ} \mathrm{C}$ and a strain rate of $1 \times 10^{-3} \mathrm{~s}^{-1}$, and at $400^{\circ} \mathrm{C}$ and strain rates of $1 \times 10^{-3}, 10$, and $50 \mathrm{~s}^{-1}$ to fill in the gaps in the data obtained last year.

\subsubsection{Grain-Boundary Chemistries of DOP-26 Iridium Alloyed with Copper}

Approximately three years ago, research was initiated at ORNL to investigate the effects of trace amounts of $\mathrm{Cu}$ on the physical metallurgy and mechanical behavior of DOP-26 iridium. This element was chosen because, at various times during processing, the DOP26 alloy comes into contact with copper (e.g., the hearth in the arc-melting furnace is made of copper). Therefore, it is of interest to determine whether accidental contamination with $\mathrm{Cu}$ can have any deleterious effects on the properties of DOP-26 iridium. An embrittling effect was observed when $\mathrm{Cu}$ was present at levels exceeding about $24 \mathrm{wppm}$, resulting in lower ductilities and greater amounts of intergranular fracture compared to DOP-26 iridium containing lower amounts of copper. Grain size differences appeared not to be responsible for the observed $\mathrm{Cu}$ effect because, for a given heat treatment, all the $\mathrm{Cu}$-containing alloys had similar grain sizes as DOP-26 iridium containing no added copper. Since $\mathrm{Cu}$ was found to promote intergranular fracture, a possible mechanism for the observed embrittlement is that $\mathrm{Cu}$ segregates to the grain boundaries in DOP-26 iridium and lowers grain-boundary cohesion. This study was undertaken to test that hypothesis by analyzing grain boundary chemistries in a scanning Auger microprobe. The grain-boundary chemistries of four DOP-26 iridium alloys 
containing 7-42 wppm $\mathrm{Cu}$ were analyzed by Auger spectroscopy. The four alloys were analyzed after three different heat treatments: $1 \mathrm{~h}$ at $1375^{\circ} \mathrm{C}, 1 \mathrm{~h}$ at $1500^{\circ} \mathrm{C}$, and $1 \mathrm{~h}$ at $1670^{\circ} \mathrm{C}$. Auger analysis showed that $\mathrm{Cu}$ did not segregate to the grain boundaries in any of the specimens investigated, consistent with its relatively high solid solubility in iridium. Therefore, the embrittlement observed in alloys containing more than about 24 wppm $\mathrm{Cu}$ is not due to $\mathrm{Cu}$ segregation to the grain boundaries. Additional studies are needed to understand the mechanism of the $\mathrm{Cu}$-induced embrittlement.

\subsubsection{Effects of Environment and Temperature on the Tensile Properties of Ta-base Alloys}

Starting in FY 2004, a study was undertaken at ORNL to compare the effects of oxygen on the mechanical properties of Ta-10W and T-111 (Ta-8W-2Hf). Among other things, we showed that, at conventional (i.e., quasi-static, $\sim 10^{-3} \mathrm{~s}^{-1}$ ) strain rates, Ta-10W is severely embrittled by absorbed oxygen, similar to the behavior of T-111. Oxygeninduced embrittlement of Ta-10W was shown to occur also at impact strain rates $\left(\sim 10^{3} \mathrm{~s}^{-1}\right)$. However, the embrittlement was found to be more severe at room temperature than at elevated temperatures, in contrast to quasi-static strain rates where the embrittlement is more severe at elevated temperatures. Since this difference may be related to the kinetics of oxygen transport to crack tips, additional experiments were initiated to better understand the mechanism of oxygen-induced embrittlement. Preliminary results of that investigation were reported last year. During FY 2008 we continued that investigation and studied the effects of test environment and temperature on the tensile properties of $\mathrm{Ta}-10 \mathrm{~W}$ and $\mathrm{T}-111$ at quasi-static strain rates and temperatures to $1000^{\circ} \mathrm{C}$. At temperatures above $400^{\circ} \mathrm{C}$, severe embrittlement was observed in both alloys in oxygen-containing environments, with $\mathrm{T}-111$ being significantly more susceptible for a given grain size. Associated with this embrittlement was a tendency for the fracture mode to change from transgranular to intergranular with increasing oxygen partial pressure and test temperature. Ultimate tensile strengths generally followed the trends in ductility in the vicinity of the ductility minimum, but yield strengths depended only on test temperature and not test environment.

\subsubsection{Diffusion of Silicon into DOP-26 Iridium}

Following the discovery at LANL of elevated Si levels in some batches of plutonia fuel, ORNL was asked to evaluate what effects Si might have on the DOP-26 iridium fuel clad. Therefore, studies were initiated to investigate how, and at what levels, silicon added to DOP-26 iridium affects its physical metallurgy and mechanical properties. Those studies showed that Si has deleterious effects on grain growth, grain-boundary chemistry, tensile impact ductility, and weldability of DOP-26 iridium. At levels higher than 500 wppm, silicon severely embrittled DOP-26 iridium. The mechanism of this embrittlement was shown to be related to its segregation to the grain boundaries where it displaced beneficial thorium, increased grain size, and formed a low melting eutectic. At lower levels (50 wppm silicon), although the embrittlement was not severe, the ductility of the Si-doped alloy was nevertheless lower than that of DOP-26 iridium containing no intentionally added silicon. In addition, Si had other undesirable effects. For example, at

a level of $50 \mathrm{wppm}$, there was clear evidence of segregation to the grain boundaries and 
increased grain growth at high temperature $\left(1800^{\circ} \mathrm{C}\right)$. Silicon also lowered the weldability relative to that of production heats of DOP-26 iridium. It was considered prudent, therefore, that studies be conducted on DOP-26 containing lower levels of silicon $(<50 \mathrm{wppm})$ to obtain sufficient data to support lowering the allowable $\mathrm{Si}$ in the DOP-26 specification from its current level of $50 \mathrm{wppm}$. After several unsuccessful attempts to make "old-process" DOP-26 with controlled amounts of Si in the range 15-25 wppm, during FY 2008 we investigated alternative approaches of introducing Si into DOP-26 iridium. Our experiments showed that Si can be made to diffuse from a surface deposited layer into DOP-26 iridium at $1300^{\circ} \mathrm{C}$. However, during the diffusion anneal, $\mathrm{Si}$ appeared to react with the Th present on the grain boundaries to form Th-silicide. This reaction makes the diffusion couple approach difficult to interpret and less useful in determining allowable Si concentrations in DOP-26 iridium. Therefore, future efforts should focus on how to successfully arc melt DOP-26 iridium containing 15-25 wppm silicon.

\subsection{ORNL CHARACTERIZATION OF MIN-K TE-1400}

\subsubsection{Introduction}

ORNL was requested to characterize the thermomechanical properties of Thermal Ceramics Min-K 1400TE material, hereafter referred to as Min-K, in support of its MultiMission Radioisotope Thermoelectric Generator (MMRTG) Program. In particular, ORNL was tasked with the determination of the high temperature compressive strength and stress relaxation behavior of Min- $\mathrm{K}$ up to $900^{\circ} \mathrm{C}$ in helium along with the formulation of a general model for the mechanical behavior exhibited by Min-K. Testing was to consist of general high temperature compressive mechanical testing, isothermal stress relaxation testing, and stress relaxation testing of samples exposed to a thermal gradient.

Previous reports were written for the first three years of the project and can be referenced, "ORNL Characterization of Min-K TE-1400 FY'05", "ORNL Characterization of Min-K TE-1400 FY'06", and "ORNL Characterization of Min-K TE-1400 FY'07", describing the initial compression testing performed at room temperature and under various loading rates to determine the required sample sizes and geometries for compressive test specimens and the initial isothermal and gradient stress relaxation testing along with modeling efforts. Additional gradient stress relaxation testing was performed in year two and test equipment was redesigned to facilitate longer-term testing to further characterize the elevated temperature mechanical behavior of Min-K TE-1400. Additionally, modeling efforts were refined to predict the long-term mechanical behavior of the Min-K material when subjected to a temperature gradient condition. Work was continued in year three to further characterize the elevated temperature mechanical behavior of Min-K TE1400. Gradient stress relaxation testing was continued to obtain longer-term data of up to one-year duration. Additionally, modeling efforts were continued to predict the long-term mechanical behavior of the Min-K material when subjected to a temperature gradient condition. 
This year, the gradient stress relaxation testing was continued to obtain long-term data out to two-year duration. Previous modeling efforts were also continued to predict the long-term mechanical behavior of the Min-K material when subjected to temperature gradient conditions.

\subsubsection{Experimental Procedures}

Gradient stress relaxation testing was continued on 6-inches diameter by 3 -inches long cylindrical samples. Temperature gradients consisted of $700 / 100^{\circ} \mathrm{C}$ with initial loads of 200 psi. A modified test procedure was used based on the original gradient stress relaxation test procedure and testing was performed using a set-up similar to that previously described. This set-up consists of an electromechanical testing machine (Instron Model 1380) equipped with load and displacement digital controllers, a $35 \mathrm{kN}$ load cell, a heated Inconel platen above and below the sample, and a single zone furnace. An aluminum environmental chamber with helium flow was used for controlling the environment. Loading was performed in strain control utilizing a twelve-step loading scheme with loading every half hour at a rate of $5.56 \%$ strain/hour. Loading was followed by stress relaxation in strain control with testing scheduled to be carried out for up to two-years (17,520 hours).

\subsubsection{Results}

Following year three, two tests (\#13 and \#15) remained active and were continued through year four to obtain data in excess of 17,520 hours.

Transient strain event (TSE) testing was previously performed on Test \#13 during year two. At the conclusion of the TSE testing the strain was returned back to the original strain level of $11.493 \%$. This resulted in a change of stress from approximately 110 psi to 118 psi. Following this, the test was put back in hold under fixed displacement and was continued during year three at the end of which, the test had been running in excess of one year (over 10,050 hours) and was at a current level of 105 psi. The test was continued during year four to obtain data in excess of two years. Results are shown in Figure 16. Total duration of this test was 18,135 hours and the final stress level was 92 psi. Due to a stuck crosshead, this test was simply terminated instead of being unloaded and cooled. 


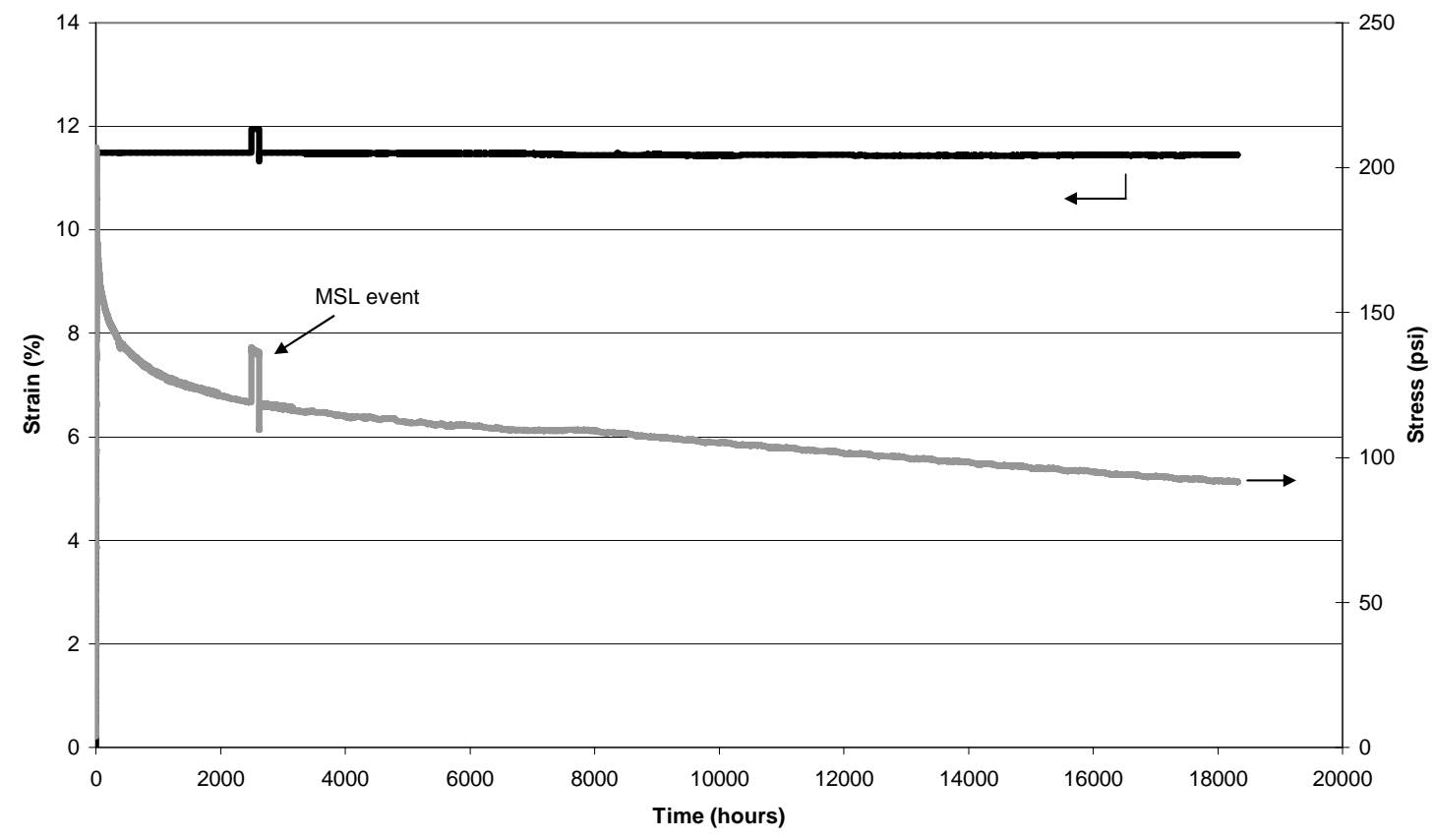

Figure 16. Results from $700 / 100^{\circ} \mathrm{C}$ gradient stress relaxation test (test \#13).

Test \#15 was run unaltered since its start. At the end of year three, this test had been running in excess of one year with over 9,735 hours of exposure and a current level of 126 psi. The test was continued during year four to obtain data in excess of two years. Results are shown in Figure 17. Total duration of this test was 17,935 hours and the final stress level was 120 psi. Following completion of the test, TSE testing was performed on this sample. Phase I of the testing was successfully completed, raising the strain from $6.11 \%$ to $6.57 \%$ at a rate of $1.07 \%$ per hour and the stress from 120 to $146 \mathrm{psi}$. The test was then allowed to sit for approximately four days under fixed displacement. After sitting, the sample had relaxed to a stress of 145 psi. Following this hold, Phase II was initiated by decreasing the strain from $6.57 \%$ to $5.95 \%$ at a rate of $1.52 \%$ per hour. This resulted in a loss of stress from approximately 145 psi to roughly $111 \mathrm{psi}$. The sample was then held again under fixed displacement for thirty minutes. Phase III consisted of switching to load control and holding the existing stress level for one hour. During this time, no measurable change in the strain level was seen. Following the hold, the system was switched back to displacement control and Phase IV was started. For this phase, the strain was returned from $5.95 \%$ back to the original strain level of $6.11 \%$. This resulted in a change of stress from approximately 111 psi to 120 psi. Following Phase IV, the test was put back in hold under fixed displacement and allowed to sit over night (18 hours). At the conclusion of testing the sample was at a stress level of 120 psi. Following TSE testing, the sample was cooled to room temperature. Results for this test are shown in Figure 18. 


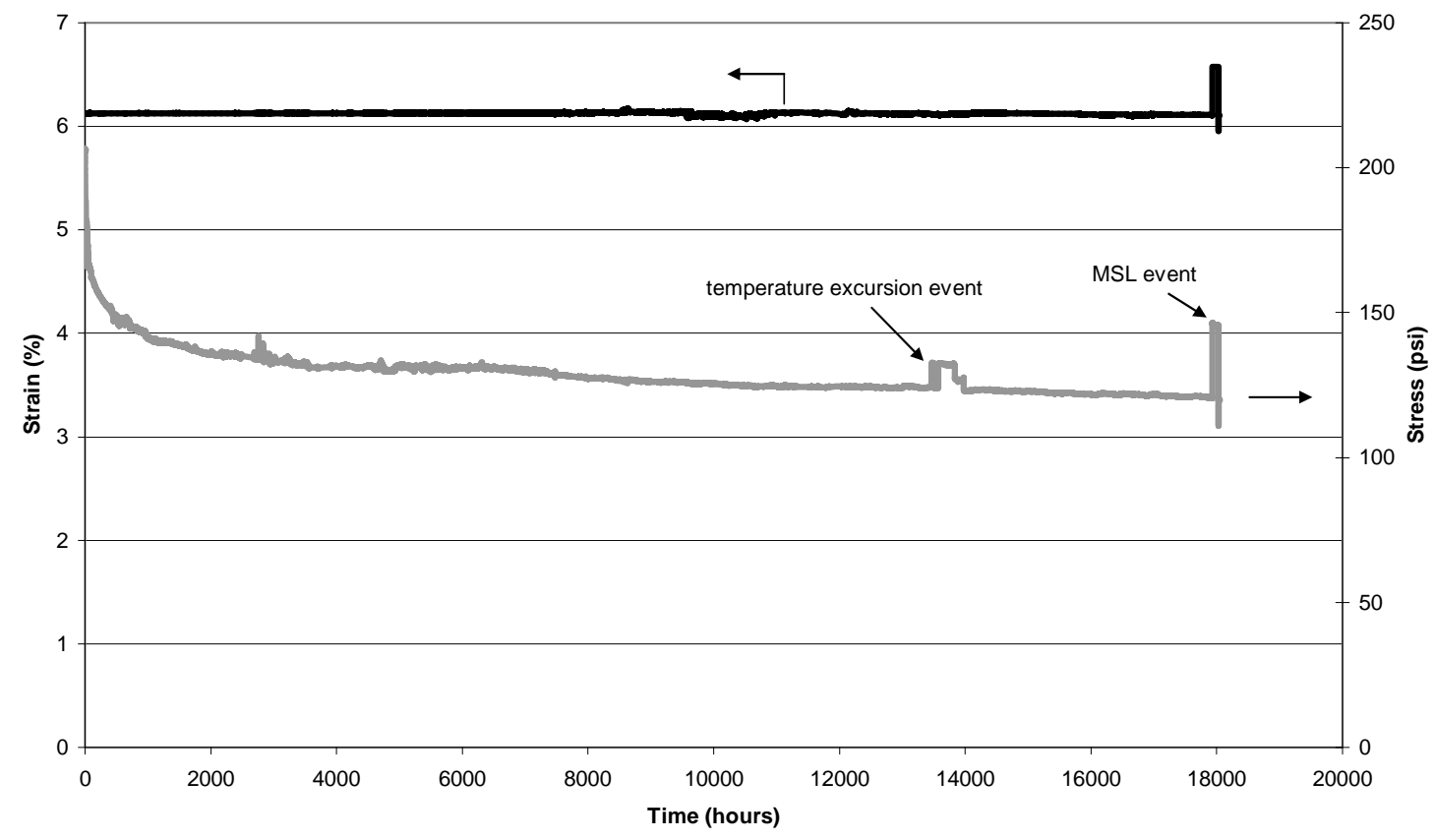

Figure 17. Results from $700 / 100^{\circ} \mathrm{C}$ gradient stress relaxation test (test \#15).

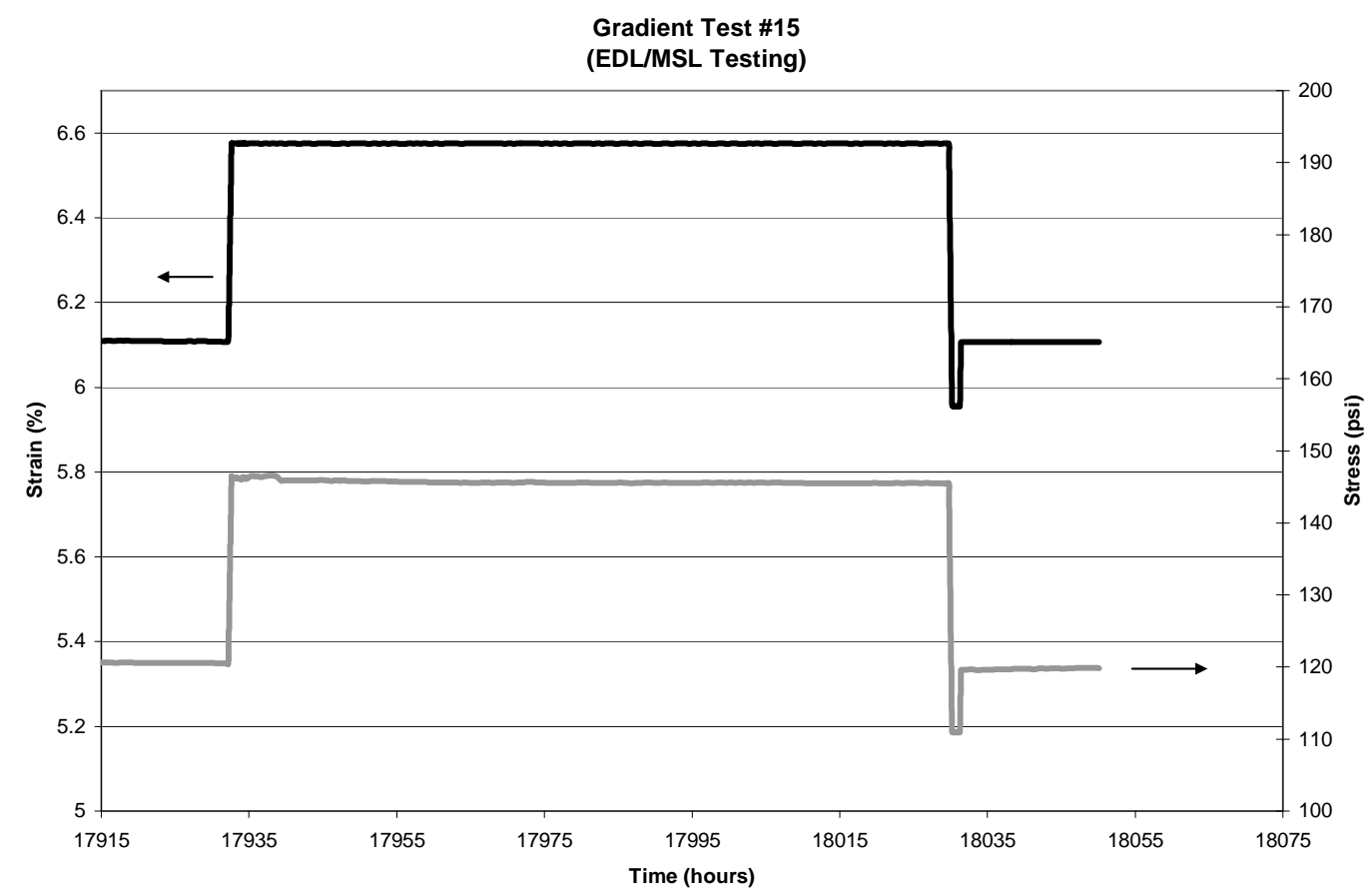

Figure 18. Results from $700 / 100^{\circ} \mathrm{C}$ gradient stress relaxation test (test $\# 15$ ). 
Consistent with the year three efforts, modeling was pursued independently by Rocketdyne and ORNL. ORNL continued the use of a simple log function $(y=a-b$ * $\log (\mathrm{x}))$ to fit the long-term gradient stress relaxation data obtained through year four as shown in Figure 19 for Test \#13 and Test \#15. In both cases, an R value of greater than 0.97 was obtained using this function.

a)
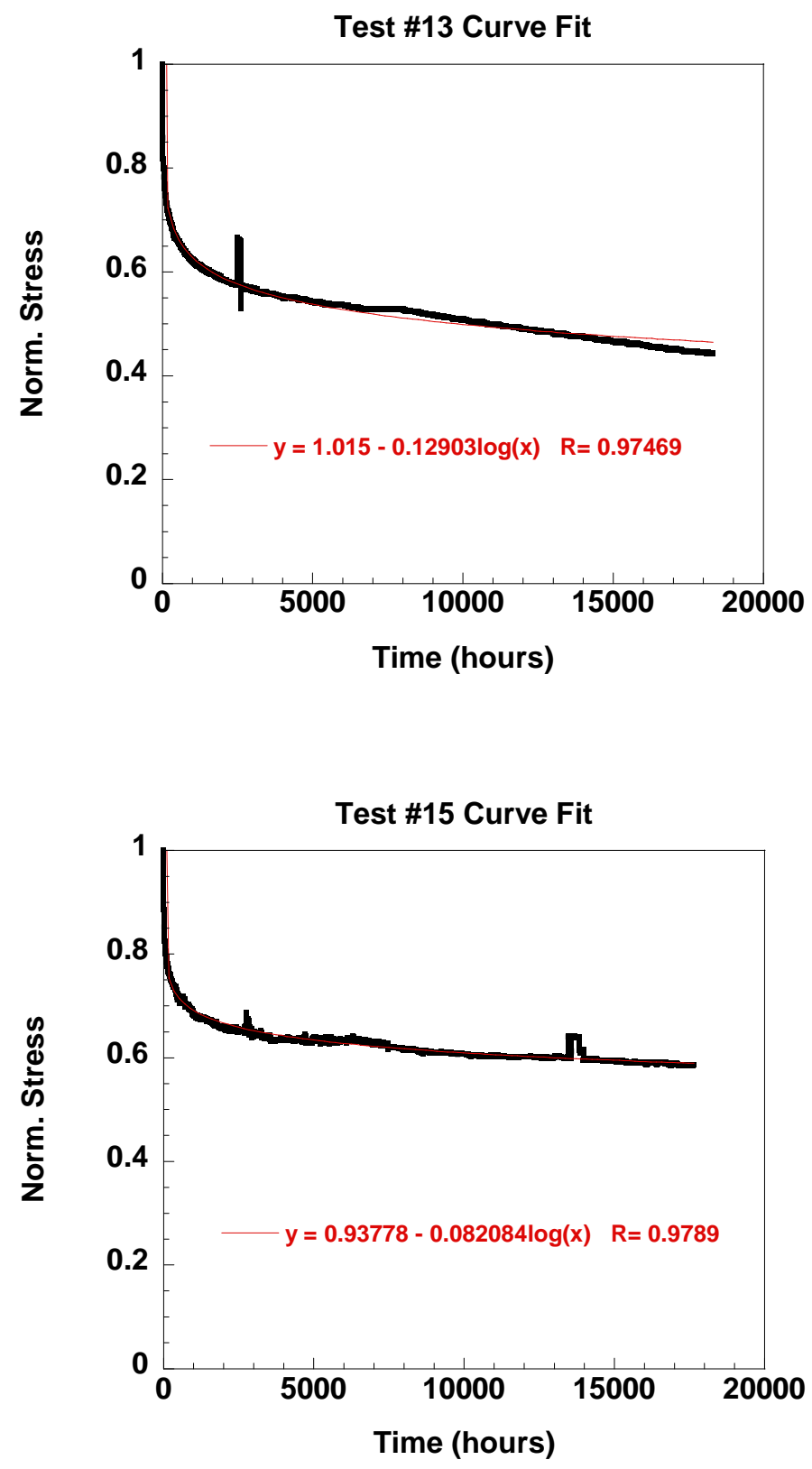

b)

Figure 19. Log function curve fits of long-term gradient stress relaxation data $(\mathrm{a}-$ test $\# 13, \mathrm{~b}-$ test \#15).

Also, an investigation of the effect of fitting various time scales of data for predicting long term behavior was repeated. Fits were made using the same simple log function as 
above using data from 1,000, 2,500, 5,000, 7,500, 10,000, 12,500, 15,000, and 17,500 hours. Predictions out to 17,500 and 50,000 hours for Test \#13 and Test \#15 are shown in Figure 20 and Figure 21, respectively.

Test \#13 Curve Fits

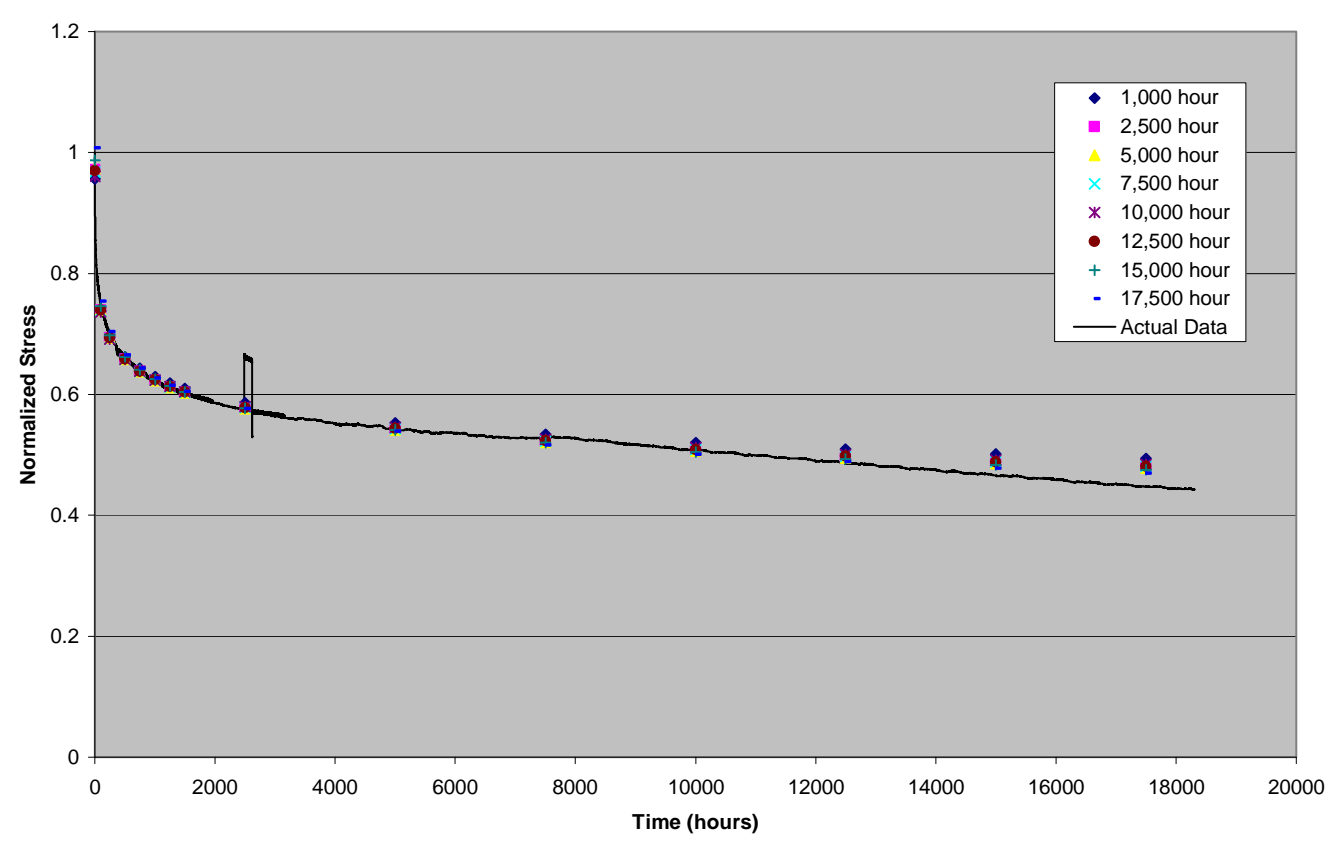

Test \#13 Curve Fits

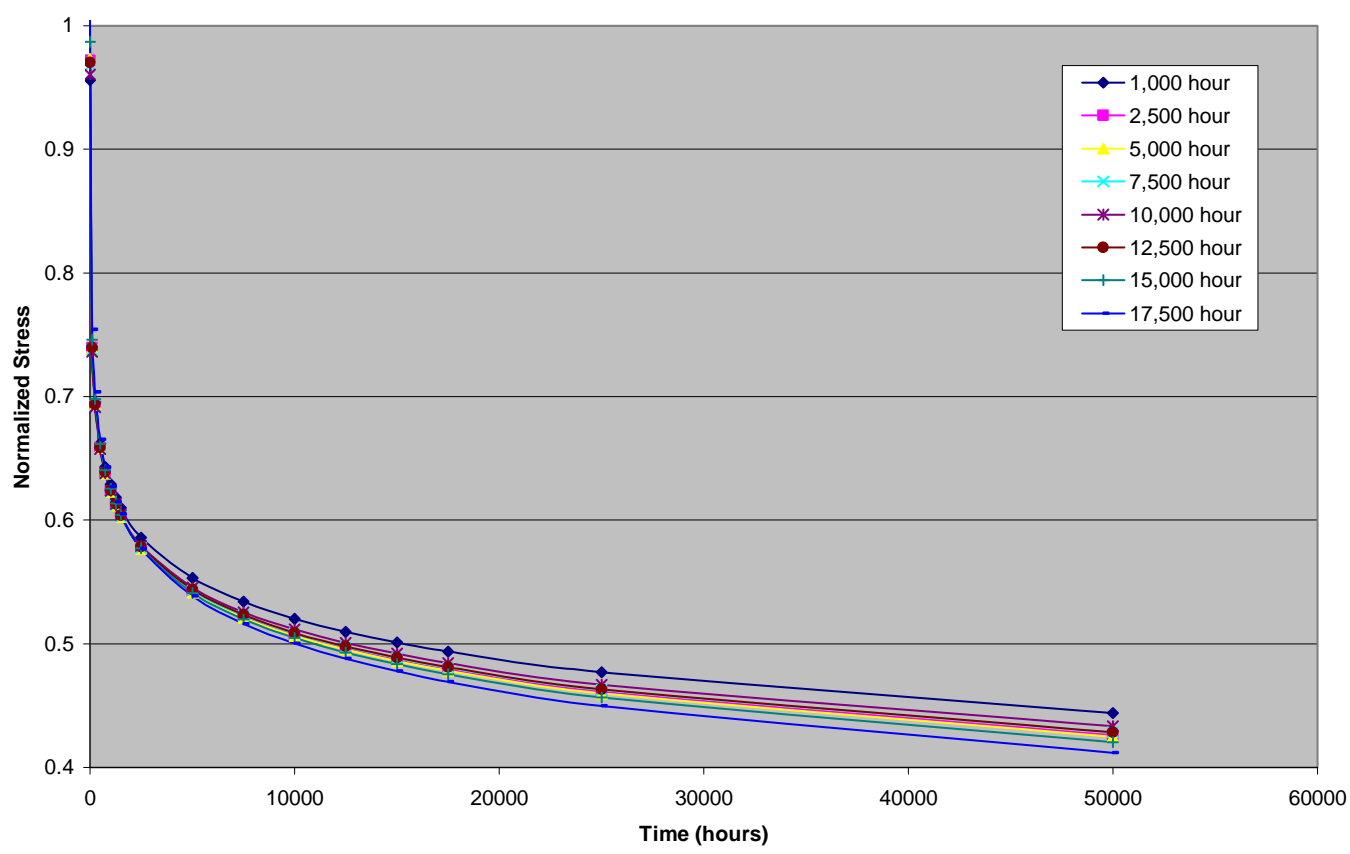

Figure 20. Gradient test \#13 log fit predictions (year four). 
Test \#15 Curve Fits

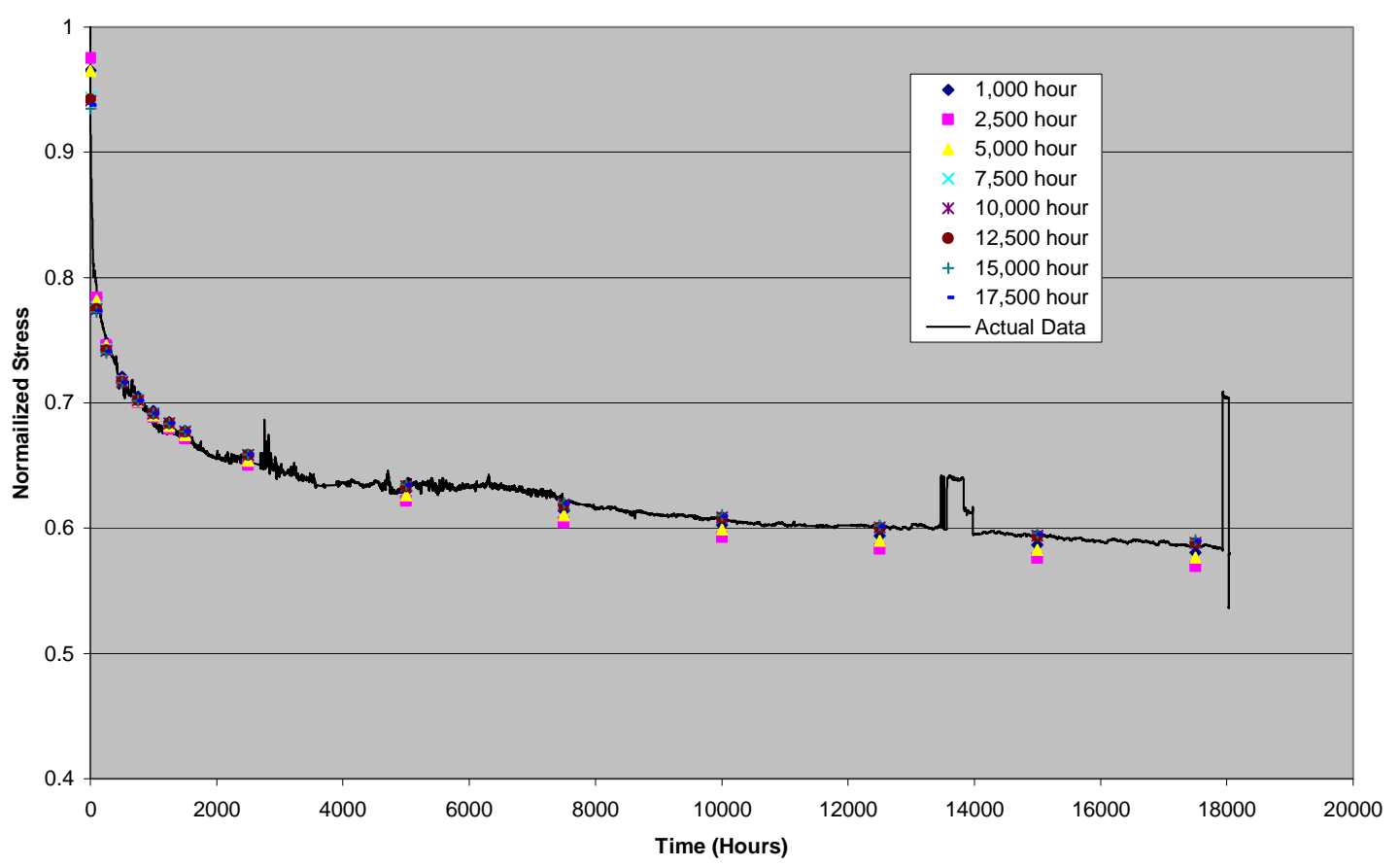

Test \#15 Curve Fits

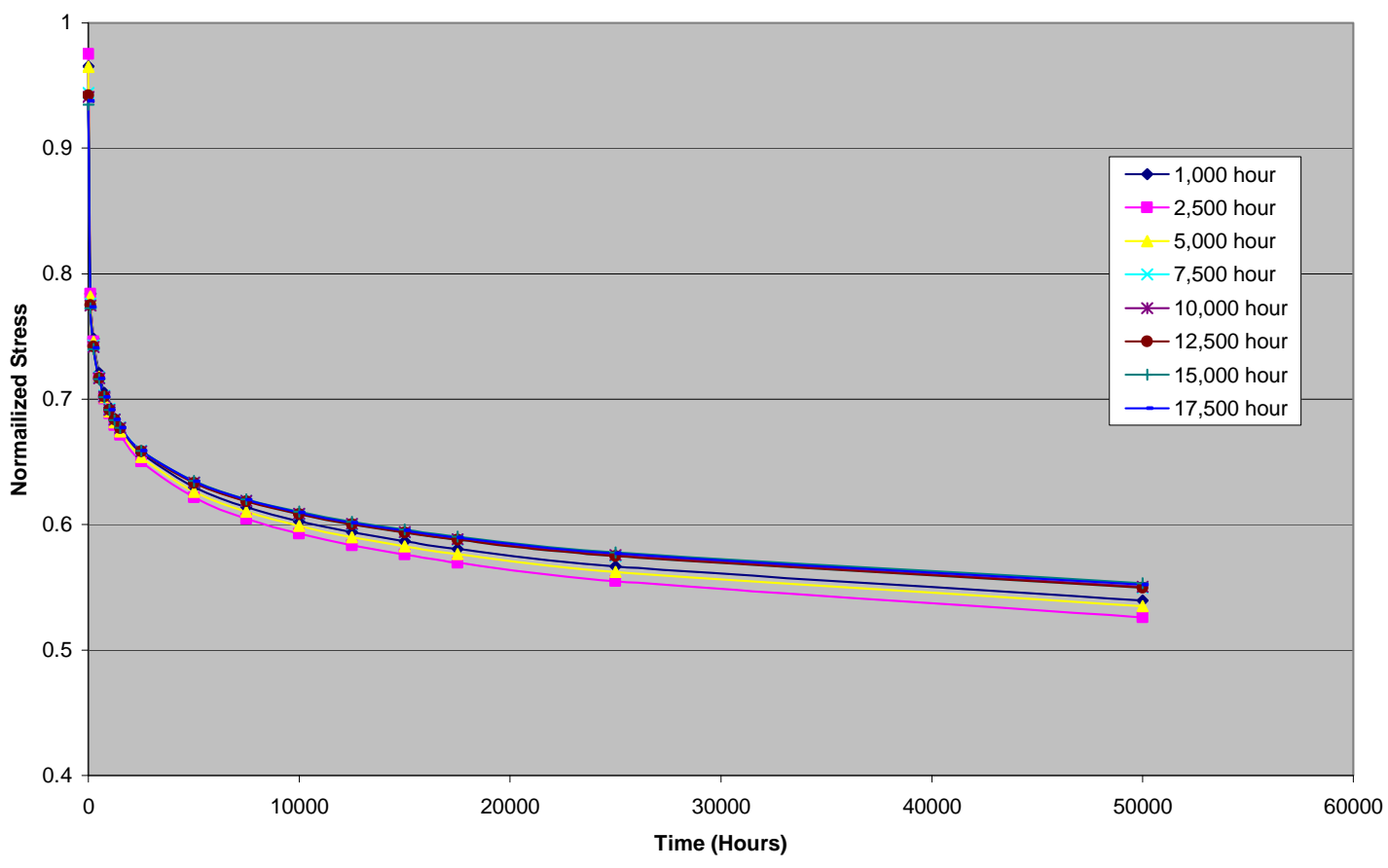

Figure 21. Gradient test \#15 log fit predictions (year four). 
From the previous analysis performed last year based on $\approx 10,000$ hours of data, it appeared that data between 5,000 and 7,500 hours was sufficient to predict behavior out to 10,000 hours. Data of less than 5,000 hours tended to under predict the stress relaxation. Data of greater than 7,500 hours accurately predicted the stress relaxation, but did not provide any improvement in the prediction. Therefore it was concluded that it may not be necessary to extend testing to this duration, even for predictions out to 50,000 hours. Further analysis incorporating the new data out to 17,500 hours found that at 10,000 hours the predictions of the 7,500 and 12,500 hour fits were the best. For Test $\# 13$, no increase in accuracy was seen for the 15,000 hour fit and a decrease in accuracy was seen for the 17,500 hour fit. For Test \#15, fits of data less than 7,500 hours tended to under predict and fits of data greater than 12,500 hours tended to over predict the stress.

The same kind of analysis as above was also performed this year at 17,500 hours. For Test \#13, all predictions over estimated the remaining stress in the sample with the 15,000 and 17,500 hour predictions being the closest (errors of 4.69 and $6.25 \%$, respectively), followed by the 5,000 and 2,500 hour predictions (errors of 6.70 and $6.92 \%$, respectively). The predictions for Test \#15 were found to be much better. Predictions made with 5,000 hours of data or less under predicted the remaining stress and predictions made with 7,500 hours of data or more over predicted the remaining stress. The 12,500 hour prediction was the closest with an error of $0.52 \%$, closely followed by the predictions with 7,000 and 10,000 hours of data (errors of 0.54 and $0.62 \%$, respectively). 


\section{APPENDIX A IRIDIUM BLANK AND FOIL TASK}

\section{Nonconformance Reports}

NCR-IrBF-2166 was written for the impurities analysis results by glow discharge mass spectroscopy (GDMS) of the samples from four jars of iridium powder $(14.8 \mathrm{~kg})$ showed ruthenium content above the specified limit of $50 \mu \mathrm{g} / \mathrm{g}$. The nonconformance report was approved for four jars of iridium powder with a recommended disposition for use as-is, with the justification that blending with other powders will produce a batch of $82 \mathrm{~kg}$ with an average $\mathrm{Ru}$ content of $17 \mu \mathrm{g} / \mathrm{g}$. This value is below the specification limit of $50 \mu \mathrm{g} / \mathrm{g}$ for blank and foil and is a typical composition of production blanks. The powder was released for use in M-batch.

\section{Deviation Requests}

The following deviation requests were approved in FY 2008:

DR-Ir-216 updated the equipment lists for rolling and heat treating of foil in three procedures. The $4 \mathrm{Hi} / 2 \mathrm{Hi}$ mill was added to the list of equipment for use in foil rolling.

DR-Ir-217 updated the equipment lists for rolling and heat treating of sheet materials and heat treating of blanks in three procedures. The $4 \mathrm{Hi} / 2 \mathrm{Hi}$ mill was added to the list of equipment for use in flattening of sheets and the Thermal Technologies furnace replaced the CANEL furnace for vacuum heat treating.

DR-Ir-218 revised the procedure for rolling of foil and the procedure for sampling and cleaning of foil. Methods for assuring control of foil thickness were revised and sample sizes for oxygen and carbon analyses were clarified.

DR-Ir-219 revised the procedure for preparation of iridium powder compacts for blank and foil production. The process was made more efficient and the sample size for carbon analysis was increased.

DR-Ir-220 revised the procedure for dye penetrant inspection of blanks. The description of steps included greater detail with no technical changes in the method.

DR-Ir-221 revised the procedure for metallographic examination of blanks and foil. References to American Society for Testing and Materials (ASTM) standard methods were updated.

DR-Ir-222 revised the specification for blanks. Regions of the blank subject to inspection and examination were made consistent for the various nondestructive examination methods. References to ASTM standard methods were updated.

DR-Ir-223 revised the specification for foil. References to ASTM standard methods were expanded and updated. 
DR-Ir-224 revised the specification for powder for frit vents. Changes were editorial.

DR-Ir-225 revised the procedure for EB melting and button arc melting to permit use of the new beam deflection system for EB melting and the two new furnaces for arc melting.

DR-Ir-227 revised the procedure for rework of blanks by sanding to improve efficiency and decrease the need for repeated reworking operations.

DR-Ir-228 revised the visual examination of blanks to be consistent with the revised blank specification and to simplify subsequent reworking operations when they are needed.

DR-Ir-229 introduced an alternative procedure for carbon analysis, applicable to powder, blanks, foil, and cups. 


\section{APPENDIX B CLAD VENT SET TASK}

\section{Nonconformance Reports}

Two nonconformance reports, NCR-CVS-071 and -072, were submitted and accepted in FY 2008. NCR-CVS-071 was for shield cups 3625-05-5364, -5365, -5366, and -5367. They were first-formed (in numerical order) without lubricating the blankholder as called for in Step 2.4.3 of Procedure GPHS-XF-3624/25, Rev. S. There were no forming difficulties with the first two cups, 3625-05-5364 and -5365. Cup 3625-05-5366 split during first-forming on the outer stainless steel waster sheet. This first-form cup was given a standard weld repair rework and then second-formed without incident. Cup 3625-05-5367 split extensively during the first-form operation because of excessive blankholder friction caused by the progressively-abraded blankholder surface from lack of lubrication during forming of the first three cups. This cup could not be weld repaired. The split ring of material at the top of the cup was removed and the cup was secondformed. This cup was designated for use as a Destructive-test (D-test) cup because of the possibility of surface contamination resulting from the damaged stainless steel waster sheet. The first three cups were processed subsequently for Use As-Is.

NCR-CVS-072, for shield cups 3625-05-5364 through 5373 (Note: cup 5367 was already designated as the D-test cup.), addressed the issue of vent notches being ground perpendicular instead of parallel to the sheet rolling/blank grinding direction. This was in violation of Step 9.2b of Procedure GPHS-XF-3624/25, Rev. S. Vent cup notches are to be ground perpendicular to the sheet rolling/blank grinding direction for vent cups versus parallel for shield cups. These shield cups were downgraded to Engineering Use because of insufficient information to judge whether or not the material property/behavior differences between the perpendicular and parallel rolling/grinding directions are significant.

Initially, an attempt was made to argue that recently-measured elevated temperature tensile property differences in the longitudinal (parallel) and transverse (perpendicular) directions were not significant with corroboration from formed cup wall thickness measurements in the closure weld zone. Anisotropy in the blanks is exhibited in the formed iridium cups as "earing", i.e. high and low areas at the cup open end that correspond to thin and thick walls, respectively, which are due to material strength/ductility variations in different orientations.

Twenty five non-prime cups, TC167 through TC191, were measured with a Mitutoyo (Aurora, IL) Crysta Apex 920H Coordinate Measuring Machine (CMM) every 10 degrees at a latitude $13.83 \mathrm{~mm}$ from the outside bottom of the cup (equivalent to the middle of the finished cup weld zone). The $0^{\circ} / 360^{\circ}$ and $180^{\circ}$ positions are parallel to the rolling direction. The results, shown graphically in Figure 4, indicate that cup thin areas are located every $90^{\circ}$ (at the $0^{\circ}, 90^{\circ}, 180^{\circ}$, and $270^{\circ}$ positions) while the thick areas are shifted $45^{\circ}$ from the thin areas, but they too are located $90^{\circ}$ from each other (at $45^{\circ}, 135^{\circ}$, $225^{\circ}$, and $315^{\circ}$ positions). Note: the scatter in the data is most likely related to difficulty visually aligning the vent notches with the grinding direction and the grinding direction 
with the rolling direction. Thus, the largest wall thickness differences occur every $45^{\circ}$, but wall thicknesses $90^{\circ}$ apart are similar.

\section{Cup Wall Thickness vs. Radial Position (0/180 Degrees are Parallel to Rolling/Grinding Direction)}

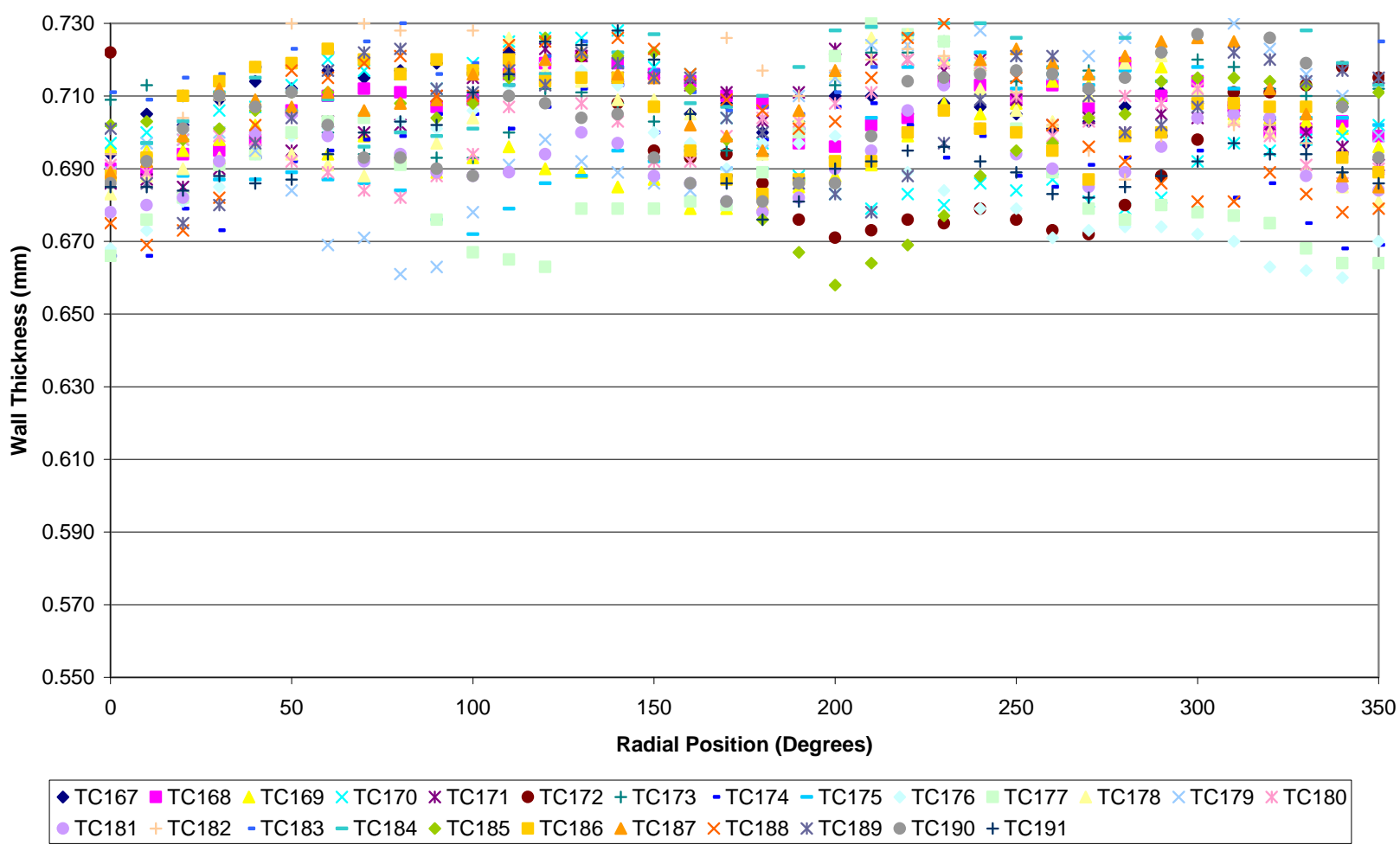

Figure 4. Cup wall thickness in the closure weld zone versus radial position.

The ORNL Material Review Board concluded that insufficient information currently exists to judge definitively that material properties/behavior in both the perpendicular and parallel rolling/grinding directions, especially under high temperature impact conditions, are similar. If that could have been shown, then aligning cup vent notches at $0^{\circ}$ (parallel/longitudinal) and $90^{\circ}$ (perpendicular/transverse) to the rolling/grinding direction would be acceptable. The cups in question would be acceptable for Prime Use and the cup fabrication procedure could be simplified to grind vent notches in the same orientation for all cups. Thus with insufficient information at this time, the cups were downgraded to Engineering Use and more data will be required to consider this type of procedure change.

\section{Deviation Requests}

Thirteen deviation requests, DR-CVS-065 through 075 plus DR-Ir-221 and 229, were processed in FY 2008. DR-CVS-065 and -066 addressed revisions of the respective Dye Penetrant Inspection Procedures, GPHS-Y-3619A, Rev. 9 and GPHS-Y-010, Rev. 9. These were prepared based on the results from the CVS Quality Assurance Programs 
Surveillance (now entitled Instructions, Procedures, and Drawings) and the DOE Assessment of the ORNL NDE Operations at Building 5500 in early FY 2008. DR-CVS067, -068, -069, and -070 concerned revisions to procedures GPHS-Y-002, Rev. 19, GPHS-Y-002A, Rev. 8, GPHS-G-9753, Rev. 25, and GPHS-G-9754, Rev. 12, respectively. These revisions involved corrections/updates to tooling/equipment/ materials lists and elimination of references to witness specimens because the witness specimen surveillance was removed from the GPHS-QA-002 Surveillance Plan in early FY 2008.

The deviation request DR-Ir-221 addressed changes to the Metallography Methods for Iridium Alloy Products Procedure, MET-MetL-QA-2, Rev. 9 primarily involving updates to ASTM references. This deviation request was made in conjunction with DR-Ir-222 for Iridium Alloy Blank Specification GPHS-M-185, Rev. 5 (including Blank Drawing M2C920101A003, Rev. 3), DR-Ir-223 for Iridium Alloy Foil Specification GPHS-M186, Rev. 6, and DR-CVS-071 for Deep Drawn Iridium Alloy Cups Specification GPHSM-188, Rev. 8 (including Iridium Alloy Cup Drawing M2D920101A005, Rev. 4). All of these documents were changed for updates to ASTM references and/or formats as well as various corrections/clarifications. Note: DR-Ir-224 addressed changes to Iridium Powder for Frit Vents Specification GPHS-M-187, Rev. 5. The changes to this specification were primarily format updates and wording revisions to reflect that frit vent powder is supplied internally within ORNL, not to or from an external entity.

All remaining specifications and drawings, listed below, were editorially revised for updated formats.

Specifications

GPHS-M-189, Rev. 6: Tungsten Carbide Powder

GPHS-M-190, Rev. 9: Iridium Frit Vents

GPHS-M-191, Rev. 8: Iridium Cup Subassembly

GPHS-M-192, Rev. 5: Marking Parts or Assemblies

GPHS-M-193, Rev. 5: Iridium Weld Shields

GPHS-M-194, Rev. 4: Iridium Decontamination Covers

Product Drawings

M2C920101A001, Rev. A (Decontamination Cover)

M2D920101A004, Rev. B (Frit Vent)

M2D920101A006, Rev. A (Post Impact Shell/Vent)

M2D920101A007, Rev. A (Post Impact Shell/Shield)

M2D920101A008, Rev. D (Post Impact Containment Shell)

M2D920101A009, Rev. A (Weld Shield - Integral)

M2C920101A010, Rev. A (Frit Vent Cover Disc)

M2C920101A011, Rev. A (Frit Vent Backing Disc)

M2D800748A002, Rev. C (Type II Weld Shield) 
Deviation requests DR-CVS-072, 073, and 074 dealt with modifications for Procedures Weld Shield to Shield Cup Welding GPHS-K-9754, Rev. 5, Iridium Alloy Blank Assembly Weld GPHS-K-001, Rev. 13 and Frit Vent and Decontamination Cover (DC) to Vent Cup Welding GPHS-K-9753, Rev. 12, respectively. The modifications ranged from editorial/format updates to technical changes related to the control system upgrade for the EB Welder S/N 698 which was completed in FY 2008.

Deviation request DR-CVS-075 addressed the changes to the Assembly, Inspection, and Packing Procedure GPHS-G-9808, Rev. 23. Beside the editorial/format revisions, many of the changes involved making this procedure consistent with changes made to other procedures over the last few years. A statement was added to this deviation request that similar changes to other procedures will be handled as editorial changes that will not require a formal deviation request. This was followed by editorial/format revisions for all 9 remaining CVS dimensional inspection procedures (listed below).

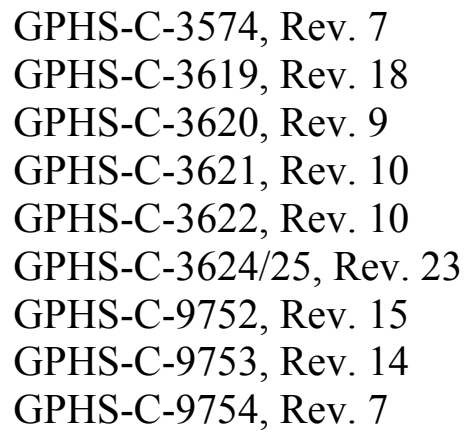

The final deviation request for FY 2008 was DR-Ir-229 for the new Carbon Analysis of Iridium and Iridium Alloys by Combustion Guideline MST-MatP-SOG-110, Rev. 0. This guideline allows the LECO Corporation to serve as an analytical back-up source for carbon in iridium testing. Extensive analytical testing was conducted at Y-12 and LECO using powder, foil, blank, and cup samples over two time periods referred to as "Week 1" and "Week 2". Statistical analyses of the results showed that LECO is qualified for this particular analysis. Similar work is planned for oxygen in iridium testing in FY 2009. 


\section{INTERNAL DISTRIBUTION}

1. E. P. George

2. J. G. Hemrick

3. J. M. Holladay

4. J. S. Ivey

5. J. F. King
6. R. G. Miller

7. E. K. Ohriner

8. G. R. Romanoski

9. G. B. Ulrich

10. ORNL Laboratory Records - OSTI

\section{EXTERNAL DISTRIBUTION}

11-17. U. S. DEPARTMENT OF ENERGY, NE-34/Germantown Building, 1000 Independence Avenue S. W., Washington, District of Columbia 20585-1290
W. A. Bohne
J. Dowicki
D. Cairns-Gallimore
L. L. Rutger
A. K. Caponiti
R. L. Wiley
W. P. Carroll

18. DEPARTMENT OF ENERGY, Oak Ridge Office, Building 4500N, Oak Ridge, TN 37831

S. R. Martin, Jr., Mail Stop 6269

19. IDAHO NATIONAL LABORATORY, P. O. Box 1625, Idaho Falls, ID 83415

K. L. Lively

20. LOS ALAMOS NATIONAL LABORATORY, P. O. Box 1663, NMT-9, MS E502, Los Alamos, NM 87545

C. E. Van Pelt

21-22. ORBITAL SCIENCES CORPORATION, INC., 20030 Century Blvd., Suite 102, Germantown, MD 20874
R. T. Carpenter
E. A. Skrabek

23. URS Washington Division, P. O. Box 5388, Aiken, SC 29804-5388

M. O. Smith 